\title{
Cooperative Research in C1 Chemistry
}

Annual report on research conducted from May 1, 2000 to April 30, 2001

DOE Cooperative Agreement No. DE-FC26-99FT40540

Prepared by the Consortium for Fossil Fuel Liquefaction Science

Gerald P. Huffman, Director

CFFLS / University of Kentucky

533 S. Limestone Street, Room 111

Lexington, KY 40506

Phone: (859) 257-4027

FAX: (859) 257-7215

E-mail: cffls@pop.uky.edu

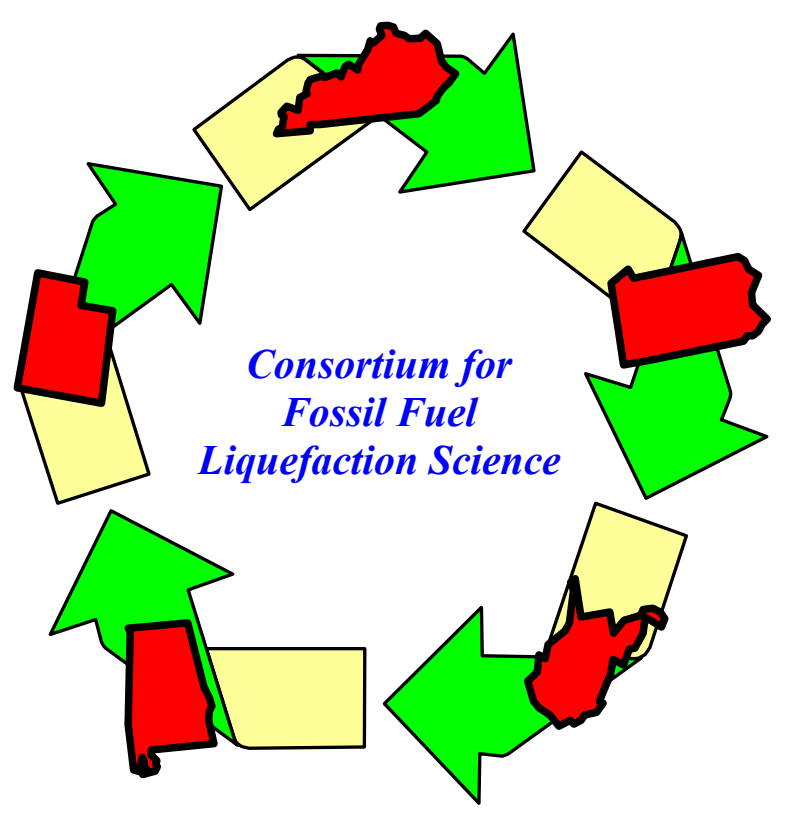

University of Kentucky West Virginia University University of Pittsburgh

University of Utah

Auburn University 
This report was prepared as an account of work sponsored by an agency of the United States Government. Neither the United States Government nor any agency thereof, nor any of their employees, makes any warranty, express or implied, or assumes any legal liability or responsibility for the accuracy, completeness, or usefulness of any information, apparatus, product, or process disclosed, or represents that its use would not infringe privately owned rights. Reference herein to any specific commercial product, process, or service by trade name, trademark, manufacturer, or otherwise does not necessarily constitute or imply its endorsement, recommendation, or favoring by the United States Government or any agency thereof. The views and opinions of authors expressed herein do not necessarily state or reflect those of the United States Government or any agency thereof. 


\section{Table of Contents}

\begin{tabular}{|l|c|}
\hline Topic & Page \\
\hline Executive Summary/Abstract & 4 \\
\hline Fuels and Chemicals Via Fischer-Tropsch & 9 \\
\hline $\begin{array}{l}\text { Hydrogenation of F-T Products and Polyolefins to Environmentally Clean High } \\
\text { Cetane Diesel Fuels, Jet Fuels and Lube-based Oils }\end{array}$ & 13 \\
\hline $\begin{array}{l}\text { Supercritical Fluids as an Alternative Reaction Medium for Fischer-Tropsch } \\
\text { Synthesis }\end{array}$ & 20 \\
\hline $\begin{array}{l}\text { New and Improved Catalysts/Processes for Production of Ethylene, Propylene } \\
\text { and other Light Olefins via C-1 Chemistry }\end{array}$ & 25 \\
\hline $\begin{array}{l}\text { Synthesis and Testing of Diethyl Carbonate as a Possible Diesel Fuel Additive } \\
\text { Higher Alcohol Synthesis from Methanol or Syngas }\end{array}$ & 32 \\
\hline $\begin{array}{l}\text { Production of Hydrogen and Carbon Nanotubes by Catalytic Decomposition of } \\
\text { Methane }\end{array}$ & 42 \\
\hline $\begin{array}{l}\text { Investigation of the Molecular Structure of Nanoscale, Binary Fe/M/Al } 2 \mathrm{O}_{3} \\
\text { catalysts by XAFS and Mössbauer Spectroscopy }\end{array}$ & 48 \\
\hline Dry Reforming of Methane with Tungsten Carbide Catalyst & 52 \\
\hline Analytical Characterization of Catalyst Structure and Product Distribution & 59 \\
\hline $\begin{array}{l}\text { Capabilities at the Diesel Engine Test Facility for Measuring Gas-Phase and } \\
\text { Particulate Emissions }\end{array}$ & 64 \\
\hline
\end{tabular}




\section{Executive Summary}

Prepared by Gerald P. Huffman, Director CFFLS, University of Kentucky, 111 Whalen Building, 533 S. Limestone St., Lexington, KY 40506

Phone: (859) 257-4027; FAX: (859) 257-7215; E-mail: cffls@pop.uky.edu

\section{Background}

Faculty and students from five universities (Kentucky, West Virginia, Utah, Pittsburgh and Auburn) are collaborating on a basic research program to develop novel C1 chemistry processes for the production of clean, high quality transportation fuel. An Industrial Advisory Board (IAB) with members from Chevron, Eastman Chemical, Energy International, Teir Associates, and the Department of Defense has been formed to provide practical guidance to the program. The program has two principal objectives.

1. Develop technology for conversion of $\mathrm{C} 1$ source materials (natural gas, synthesis gas, carbon dioxide and monoxide, and methanol) into clean, high efficiency transportation fuel.

2. Develop novel processes for producing hydrogen from natural gas and other hydrocarbons.

Some of the principal accomplishments of the program in its first two years are summarized below.

$\star$ The addition of acetylenic compounds in Fischer-Tropsch synthesis is found to produce significant amounts of oxygenated products in FT diesel fuels. Such oxygenated products should decrease particulate matter (PM) emissions.

* Nanoscale, binary, Fe-based catalysts supported on alumina have been shown to have significant activity for the decomposition of methane into pure hydrogen and potentially valuable multi-walled carbon nanotubes.

* Catalytic synthesis processes have been developed for synthesis of diethyl carbonate, higher ethers, and higher alcohols from $\mathrm{C} 1$ source materials. Testing of the effect of adding these oxygenates to diesel fuel on PM emissions has begun using a wellequipped small diesel engine test facility.

* Supercritical fluid (SCF) FT synthesis has been conducted under SCF hexane using both $\mathrm{Fe}$ and $\mathrm{Co}$ catalysts. There is a marked effect on the hydrocarbon product distribution, with a shift to higher carbon number products.

These and other results are summarized briefly below.

\section{Effect of Probe Molecules on Oxygenated Products in Fischer-Tropsch Synthesis}

(Full report - pages 4-8)

It is reported that particulate matter (PM) emission reductions of $4-10 \%$ can be achieved for every $1 \%$ of oxygen blended into diesel fuel. In this project, the production of oxygenated diesel fuels by modifying Fischer-Tropsch (F-T) catalysts and reaction conditions is being investigated. The addition of acetylenic molecules, specifically 1- 
and 2-hexyne into the F-T synthesis with iron and cobalt catalysts to produce oxygenated products is reported here.

1-Hexyne is readily incorporated into the F-T reaction to produce heptanol, heptanal and $\mathrm{C} 8+$ straight chain alcohols. In the case of 2-hexyne addition, a large amount of branched $\mathrm{C} 7+$ oxygenates are produced. At lower temperatures, these hexynes initiate chain-growth in the FT reaction and produce mainly $\mathrm{C}^{+}$products. The mode of incorporation of acetylenic molecules into F-T reactions is under investigation.

\section{Production of Hydrogen and Carbon Nanotubes by Catalytic Decomposition of Methane (Full report - pages 13-19)}

Traditionally, hydrogen has been produced by reforming or partial oxidation of methane to produce synthesis gas, followed by the water-gas shift reaction to convert $\mathrm{CO}$ to $\mathrm{CO}_{2}$ and produce more hydrogen, followed in turn by a purification or separation procedure. This research is investigating the direct catalytic decomposition of undiluted methane into pure hydrogen and carbon using nanoscale, binary, Fe-M catalysts $(\mathrm{M}=\mathrm{Pd}, \mathrm{Mo}$, and $\mathrm{Ni})$ supported on alumina $\left[(4.5 \% \mathrm{Fe}-0.5 \% \mathrm{M}) / \mathrm{Al}_{2} \mathrm{O}_{3}\right]$. All of the supported $\mathrm{Fe}-\mathrm{M}$ catalysts reduced methane decomposition temperature by $400-500{ }^{\circ} \mathrm{C}$ relative to noncatalytic thermal decomposition and exhibited significantly higher activity than Fe or any of the secondary metals ( $\mathrm{Pd}, \mathrm{Mo}$, and $\mathrm{Ni}$ ) supported on alumina alone. At reaction temperatures of approximately $700-800{ }^{\circ} \mathrm{C}$ and space velocities of 0.1 per hour, the product stream was comprised of over 85 volume $\%$ of hydrogen, with the balance being unconverted methane. No C2 or higher hydrocarbons were observed in the product gas.

High resolution SEM and TEM characterization established that almost all carbon produced at $700-800{ }^{\circ} \mathrm{C}$ is in the form of potentially useful multi-walled nanotubes. At somewhat higher temperatures $\left(>850^{\circ} \mathrm{C}\right)$, hydrogen production is decreased and carbon is deposited on the catalysts in the form of amorphous carbon, carbon flakes, and carbon fibers.

\section{Supercritical Fluids as a Reaction Medium for Fischer-Tropsch Synthesis}

(Full report - pages 20-24)

Supercritical Fluids (SCFs) offer several advantages over traditional solvents as reaction media for catalytic reactions. Advantages of SCF-phase Fischer-Tropsch synthesis (SCFFT) include high diffusivity and improved heat transfer (relative to a liquid) and high solubility (relative to a gas). In this investigation, FT synthesis has been conducted under SCF hexane conditions in a continuous, high-pressure reactor employing traditional $\mathrm{Fe}$ and $\mathrm{Co}$ catalysts (e.g., $15 \% \mathrm{Co}-0.5 \% \mathrm{Pd} / \mathrm{Al}_{2} \mathrm{O}_{3}$ ). Steady state operation was quickly achieved under SCF conditions and the product distributions obtained were constant over extended periods of operation (over 40 hours). The SCF-FT process has a marked effect on the hydrocarbon product distribution with a shift to higher carbon number products due to enhanced heat and mass transfer from the catalyst surface. Relatively flat product distributions with similar mass percentages of the $\mathrm{C} 11-\mathrm{C} 17$ products were obtained. In addition, an obvious difference is observed for the 1-olefin content obtained in the SCFFT synthesis, which is always higher than that from gas or liquid phase FT synthesis. This phenomenon suggests that the SCF-FT reaction rate is not diffusion controlled, 
whereas the secondary olefin hydrogenation and isomerization reactions are diffusion limited. The SCF-FT process results in higher diffusivity and more rapid removal of high molecular weight 1-olefins from the catalyst surface thereby suppressing secondary hydrogenation and isomerization reactions.

\section{Catalytic synthesis and testing of oxygenated compounds for use as fuel additives}

(Full report - pages 25-41)

Effective catalysts have been developed for the synthesis of several oxygenated compounds that may be useful as fuel additives. These include higher alcohols, higher ethers, and organic carbonates.

* Carbon-supported molybdenum-based catalysts, promoted with $\mathrm{Ni}$ and $\mathrm{K}$, were found to be good catalysts for synthesis of higher alcohols from syngas. Reactivity studies were carried out at $250-350{ }^{\circ} \mathrm{C}$. The liquid product contained appreciable quantities of $\mathrm{C}_{1-5}$ alcohols in an aqueous phase with no hydrocarbon phase.

$\star \mathrm{A} \mathrm{C}_{7}$ ether, 2,3 dimethyl-2-methoxybutane (DM2MB), was synthesized from dimethyl butene and methanol. Several other higher ethers were synthesized from this olefin and butanol, propanol and ethanol, as well as binary mixtures of these alcohols. Reactions were performed using the commercial catalyst, Amberlyst-15, and several laboratory-prepared catalysts $\left(\mathrm{Zr}\left(\mathrm{SO}_{4}\right)_{2}\right.$ on sulfuric acid-treated $\left.\mathrm{SiO}_{2}\right)$.

$\star$ Synthesis of diethyl carbonate (DEC) from ethanol, $\mathrm{CO}$, and $\mathrm{O}_{2}$, was accomplished using a $\mathrm{Cu} / \mathrm{Pd} /$ activated carbon catalyst pretreated with potassium hydroxide, $\mathrm{KOH}$. $\mathrm{X}$-ray diffraction characterization of the catalysts has established that the most active state of the catalyst is paratacamite, $\mathrm{Cu}_{2} \mathrm{Cl}(\mathrm{OH})_{3}$.

\section{Diesel engine test facility (Full report - pages 64-66)}

A small diesel engine test facility utilizing a two-cylinder Kubota model Z482B has been established. The facility includes a TSI Scanning Mobility Particle Sizer (SMPS) that measures particle size distributions from $7 \mathrm{~nm}$ to $300 \mathrm{~nm}$, and a Lasair 310 optical particle counter (OPC) that measures particle counts in seven size ranges from $0.3 \mu \mathrm{m}$ to $10 \mu \mathrm{m}$. The laboratory also has a high volume particulate matter (PM) sampler for collecting large quantities of PM with diameter less than $10 \mu \mathrm{m}$. For gas-phase emissions, the laboratory has the capabilities to measure $\mathrm{CO}, \mathrm{CO}_{2}, \mathrm{NO}_{\mathrm{x}}, \mathrm{CO}_{2}$ and total hydrocarbons. In addition, the laboratory can measure real-time $\mathrm{PAH}$ and elemental carbon on particles. Initial tests conducted using the DEC additive to a conventional diesel fuel exhibited a significant reduction in PM emissions.

\section{Hydrocracking and isomerization of alkane chains representative of FT products} (Full report - pages 13-19)

Laboratory work was then carried out successfully in a small continuous trickle-bed reactor using a $\mathrm{Pt} / \mathrm{ZrO}_{2} / \mathrm{WO}_{3}$ catalyst. A $90 \mathrm{wt} \%$ iso- $\mathrm{C}_{16}$ selectivity and a $71 \mathrm{wt} \%$ iso- $\mathrm{C}_{16}$ yield were achieved at $79 \mathrm{wt} \%$ conversion of hexadecane. The objective in the last halfyear has been to extend research to the conversion of paraffins longer than hexadecane, such as those produced in the F-T process, to a variety of clean transportation fuels. This was carried out using the stable and selective $\mathrm{Pt} / \mathrm{ZrO}_{2} / \mathrm{WO}_{3}$ catalyst to hydroisomerize and hydrocrack pure compounds, namely $n-C_{16}, n-C_{20}, n-C_{24} n-C_{28}$ and their mixtures, representative of alkane chains found in F-T products. 
The lube-base oil yield is highest at $79 \%$ conversion and consists of only branched isomers, mostly iso- $\mathrm{C}_{28}$. The yield of lube-base oil decreases gradually with increasing conversion as the yield of diesel fuel and gasoline increases. The major product is diesel fuel at $99 \%$ conversion, only a $20 \%$ change in conversion. If the reaction is carried to $100 \%$ conversion, the major product becomes highly branched gasoline. Switching between these three fuels occurs at high conversion values. It appears possible to obtain the desired fuel range by adjusting the conversion at a selected temperature but maintaining relatively high conversion.

\section{Analytical research}

Significant progress was made in several areas of analytical research. These results are summarized below.

X-ray diffraction and ESR characterization of C1 catalysts (pages 59-63): $\mathrm{CuCl}_{2} / \mathrm{PdCl}_{2} /$ activated carbon catalysts are being used for the synthesis of diethyl carbonate (Eyring et al) and $\mathrm{Pt} / \mathrm{WO}_{\mathrm{x}} / \mathrm{ZrO}_{2}$ catalysts are being used for the synthesis of high octane-index gasoline components (Wender et al). In our work, we have employed electron spin resonance (ESR) and x-ray diffraction (XRD) to determine the nature of the active species in these reactions, by comparing the catalytic activity with the observed species in XRD and ESR. For $\mathrm{Pt} / \mathrm{WO}_{\mathrm{x}} / \mathrm{ZrO}_{2}$, we observe ESR signals, which suggest electron transfer between $\mathrm{W}^{5+}$ and $\mathrm{Zr}^{3+}$ states. For the synthesis of diethyl carbonate, evidence points to paratacamite being the active species. Details of these results will be presented.

Molecular Structure of Binary Methane Decomposition Catalysts (pages 48-51): Nanoscale, binary Fe-M catalysts supported on alumina $(\mathrm{M}=\mathrm{Mo}, \mathrm{Pd}, \mathrm{Ni})$ exhibit high activity for the catalytic decomposition of methane into hydrogen and carbon nanotubes. In order to better understand the catalytic reaction mechanisms, the molecular structure of the catalysts is being investigated by x-ray absorption fine structure (XAFS) spectroscopy and Mössbauer spectroscopy. Additionally, a high temperature in situ XAFS cell has been constructed to permit investigation of catalyst structure at temperature under reaction conditions. Several conclusions of this work are presented. First, in order for the catalyst to be active, it must be at least partially in the metallic state. This has been confirmed by both in situ XAFS measurements at $700{ }^{\circ} \mathrm{C}$ and by ex situ Mossbauer and XAFS measurements at room temperature on previously reduced and reacted catalysts. Second, the spectroscopy data indicates the $\mathrm{Mo}, \mathrm{Pd}$, and $\mathrm{Ni}$ are all incorporated into an alloy phase with the Fe. In the case of the Mo, a specific intermetallic compound, $\mathrm{Fe}_{2} \mathrm{Mo}$ was identified

NMR characterization of particulates from diesel engine tests: The Utah team has focused on two major objectives: 1) synthesis of diethyl carbonate as a fuel additive and 2) obtaining fuel additive performance data in a diesel engine. Synthetic methods have been developed and tested in a batch reactor and a flow reactor. Diethyl carbonate is the primary product in the synthesis scheme but the product distribution seems to vary between the batch and flow reactor processes. ${ }^{13} \mathrm{C}$ labeled starting materials 
$\left({ }^{13} \mathrm{CH}_{3} \mathrm{DH}_{2} \mathrm{OH}, \mathrm{CH}_{3}{ }^{13} \mathrm{CH}_{2} \mathrm{OH}\right.$, and $\left.{ }^{13} \mathrm{CO}\right)$ were used to identify reaction products adsorbed on the catalyst surface and suggest possible reaction pathways for isotope incorporation in the two different processes. NMR and ESR data were obtained on particulate samples collected from diesel engine tests (at idle and under load) of a standard fuel with and without diethyl carbonate additive. 


\section{Fuels and Chemicals Via Fischer-Tropsch}

\section{Wender, J.W. Tierney and G. D. Holder, University of Pittsburgh}

Diesel engines are more efficient than gasoline engines, but they emit 10-20 times more particulate matter than do gasoline engines. It is known that addition of oxygenates to diesel from petroleum lowers particulate matter emissions (PMEs). Just adding oxygenated compounds to diesel fuel has problems involving availability, toxicity, cost, solubility and biodegradability. Our aim is to increase the amount of oxygenates in diesel fuel from Fischer-Tropsch (F-T) products, thus decreasing PMEs in the fuel.

We are pursuing three methods of increasing oxygenates in F-T products: (a) incorporate certain small molecules into the F-T reaction to increase the oxygen content of the product, (b) modify F-T catalysts and reaction parameters to obtain more oxygenates and (c) hydroformylate olefinic F-T products to aldehydes and alcohols.

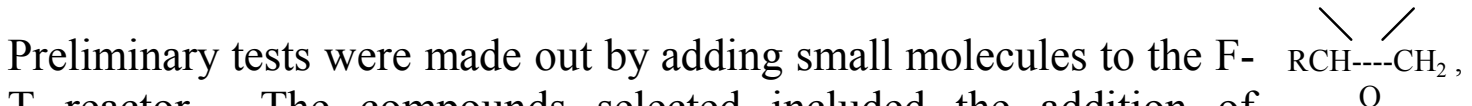
$\mathrm{T}$ reactor. The compounds selected included the addition of epoxides vinyl ethers $\left(\mathrm{ROCH}=\mathrm{CH}_{2}\right)$, and acetylenic compounds $(\mathrm{RC} \equiv \mathrm{CH})$. The addition of the latter produced intriguing results and the remainder of our F-T work has since been focused on the effect of adding hexynes, compounds containing a triple bond ( $\mathrm{CO}$ also has a triple bond) in a chain of six carbon atoms $\left(\mathrm{CH}_{3}\left(\mathrm{CH}_{2}\right)_{3} \mathrm{C} \equiv \mathrm{CH}\right.$ and $\left.\mathrm{CH}_{3}\left(\mathrm{CH}_{2}\right)_{3} \mathrm{C} \equiv \mathrm{CCH}_{3}\right)$.

An outline of the continuous F-T unit, with excellent analytical facilities, is shown in Figure 1. An iron catalyst ( $\mathrm{Fe} \mathrm{100,} \mathrm{Si} \mathrm{5.1,} \mathrm{Cu} \mathrm{2.0,} \mathrm{K} \mathrm{5.0)} \mathrm{was} \mathrm{used} \mathrm{at}$ temperatures from 170 to $260^{\circ} \mathrm{C}, 300 \mathrm{psi}$ and a $\mathrm{CO} / \mathrm{H}_{2}$ of $3 / 2$. Analysis was by $\mathrm{GC}$ online and GCMS offline. Olefins were the main product on this iron catalyst. Surprisingly, 1-hexyne addition to the reactor showed that the hexyne had reacted to produce significant amounts of heptanal and 1-heptanol with a trace of 1octanol (Figure 2). The distribution of F-T products with and without addition of 1-hexyne is shown in Figure 3. It is obvious from this Figure that acetylenic compounds initiate carbon chain in the F-T reaction.

Addition of 2-hexyne to the F-T reaction gave a more complex mixture of products, including a 2-methyl-branched $\mathrm{C}_{7}$ aldehyde and a similarly branched alcohol (Figure 4).

Further work will be carried out with iron catalysts that do not contain copper, to avoid formation of acetylides. Possible mechanisms of oxygenate formation with 
addition of acetylenic compounds to the F-T reaction catalyzed by iron and by cobalt will be explored. The addition of acetylene itself, a cheap, readily available compound, will be investigated.

It is interesting to postulate a mechanism for the reaction of a triple-bonded molecule such as occurs with 1- and 2-hexyne with an F-T catalyst. If 1-hexene is added to an iron-catalyzed F-T catalyst, it is converted to n-hexane. It is known that olefins combine exothermically with metal surfaces. A possible structure follows in which the dashed lines (Figure 5) infer partial bonding while half of the double bond is weakened but probably not fully broken.

If we apply this to an acetylenic bond, one pair of electrons would bond with the F-T catalyst in a similar way. This, however, leaves a pair of electrons still available for further reaction and may undergo the equivalent of a hydroformylation (oxo) reaction with synthesis gas as shown in Figure 5. This could account for the formation of $\mathrm{C}_{7}$ alcohols from the hexynes.

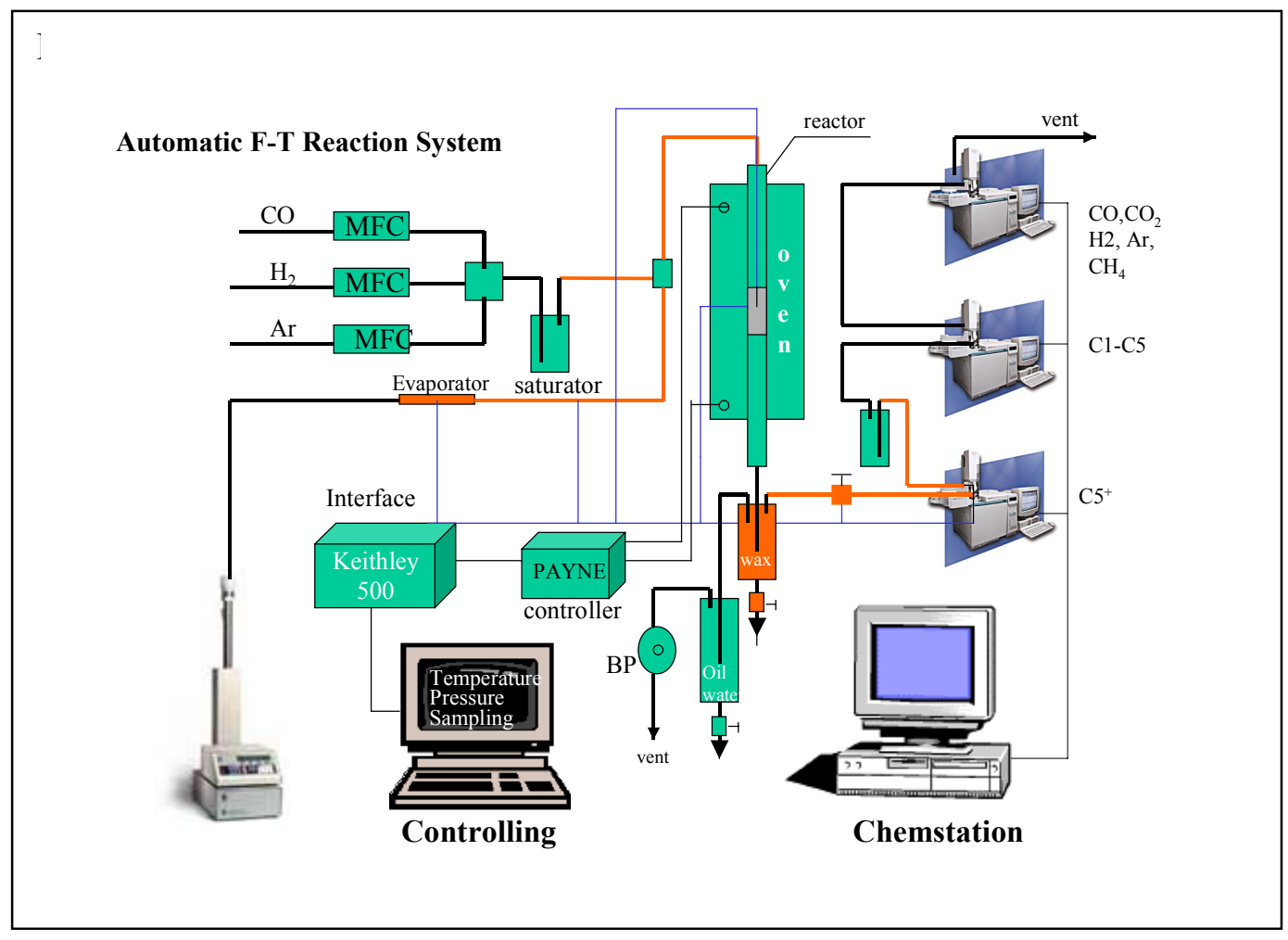

Figure 1. Sketch of Fischer-Tropsch Reactor System. 


\section{GC-MS of FT products with 1-hexyne addition}

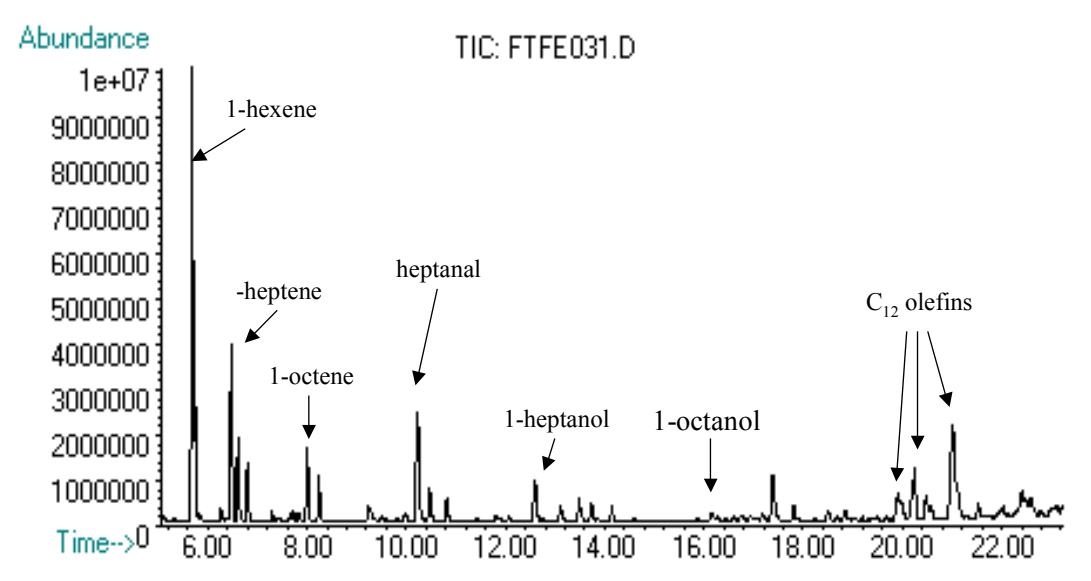

Figure 2. Addition of 1-hexyne produces significant amounts of heptanal and 1heptanol.

\section{Distribution of F-T products with/without 1-hexyne}

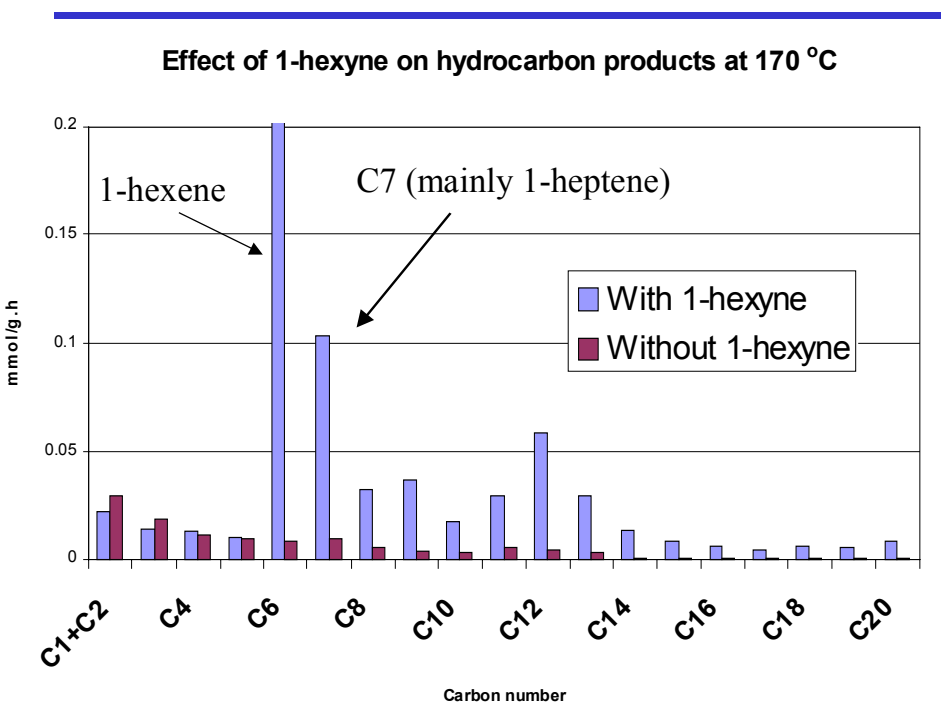

Figure 3. Participation of hexyne in Fischer-Tropsch reaction is indicated by change in product distribution when adding 1-hexyne. 


\section{GC-MS analysis of F-T products with 2-hexyne}

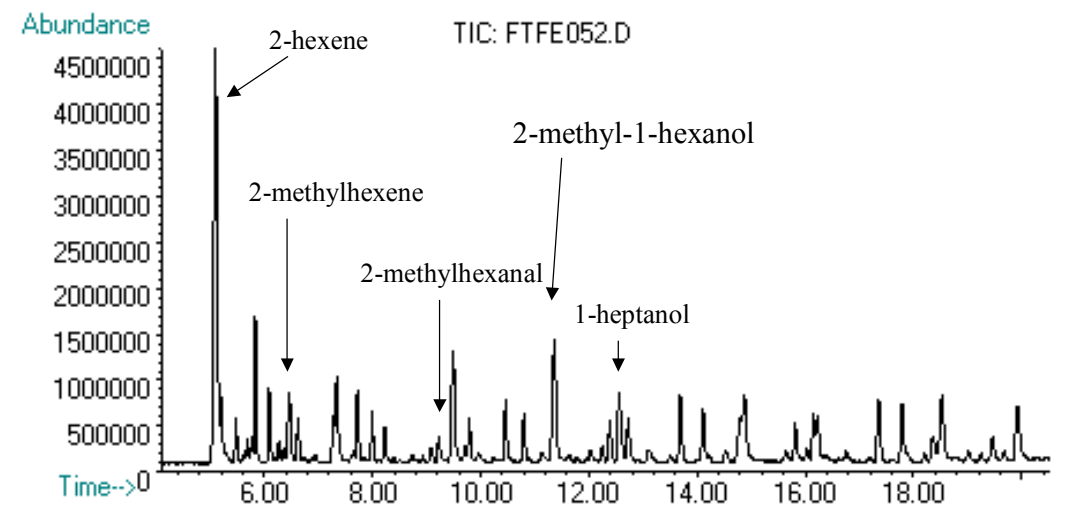

Figure 4. Addition of 2-hexyne gives a more complex mixture of products.

Possible mechanisms of oxygenates formation with 1-hexyne addition

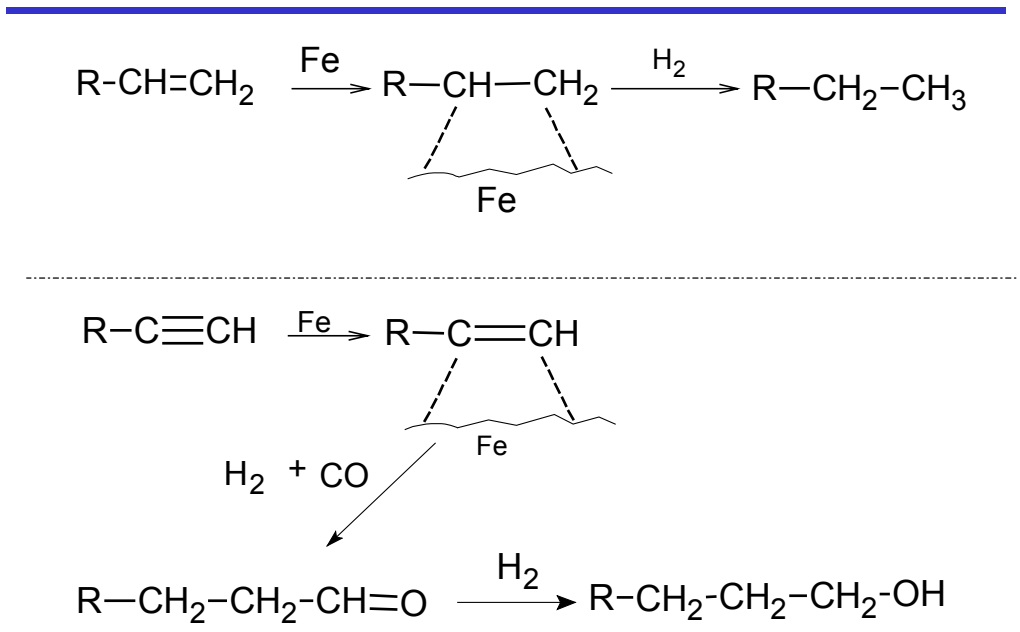

Figure 5. Possible mechanisms for reaction of 1-hexene and 1-hexyne in the Fischer-Tropsch reaction. 


\title{
Hydrogenation of F-T Products and Polyolefins to Environmentally Clean High Cetane Diesel Fuels, Jet Fuels and Lube-based Oils.
}

\author{
I. Wender, J.W. Tierney and G.D. Holder, University of Pittsburgh
}

Previous research in this laboratory investigated the activity of a platinum-promoted zirconia catalyst, $\mathrm{Pt} / \mathrm{ZrO}_{2} / \mathrm{SO}_{4}$, for the isomerization of n-heptane and n-hexadecane. These catalytic systems, however, lost activity due to the loss of sulfur from the catalyst. We then found that the substitution of tungsten trioxide $\left(\mathrm{WO}_{3}\right)$ for $\mathrm{SO}_{4}$ resulted in a more stable and selective catalyst for the hydroisomerization of n-hexadecane.

Laboratory work was then carried out successfully in a small continuous trickle-bed reactor using a $\mathrm{Pt} / \mathrm{ZrO}_{2} / \mathrm{WO}_{3}$ catalyst. A $90 \mathrm{wt} \%$ iso- $\mathrm{C}_{16}$ selectivity and a $71 \mathrm{wt} \%$ iso- $\mathrm{C}_{16}$ yield were achieved at $79 \mathrm{wt} \%$ conversion of hexadecane. The objective in the last halfyear has been to extend research to the conversion of paraffins longer than hexadecane, such as those produced in the F-T process, to a variety of clean transportation fuels. This was carried out using the stable and selective $\mathrm{Pt} / \mathrm{ZrO}_{2} / \mathrm{WO}_{3}$ catalyst to hydroisomerize and hydrocrack pure compounds, namely $\mathrm{n}-\mathrm{C}_{16}, \mathrm{n}-\mathrm{C}_{20}, \mathrm{n}-\mathrm{C}_{24}, \mathrm{n}-\mathrm{C}_{28}$ and their mixtures, representative of alkane chains found in F-T products.

Catalytic activity tests were carried out in a $27 \mathrm{ml}$ micro autoclave system. In a typical reaction, $0.25 \mathrm{~g}$ of the catalyst was activated at $450^{\circ} \mathrm{C}$ for 40 minutes in air and then charged into a microreactor that was predried overnight. After loading the catalyst, the reactant (typically $3 \mathrm{~g}$ ) was charged. The reactor was cooled to room temperature and hydrogen added to $500 \mathrm{psi}$ (cold) in all reactions. The reactor was shaken horizontally at $200 \mathrm{rpm}$. A computer was used to record the reaction pressure, temperature and time during the reaction. The reaction was terminated by cooling to room temperature.

Since the catalyst and reactants were chosen, the remaining reaction variables are reaction time, reaction temperature, hydrogen pressure, and hydrocarbon/catalyst ratios. Only the effects of reaction time and reaction temperature on product distributions were studied. The effect of hydrogen pressure was not studied because it is known that conversion decreases with increasing hydrogen pressure for platinum-promoted tungstate-modified zirconia catalysts.

A typical GC chromatogram for the reaction of $\mathrm{n}-\mathrm{C}_{28}$ and the product fuel ranges are shown in Figure 1. Selectivity was calculated by dividing the total weight in the desired product range by the conversion of the reactant. Yield is defined as the ratio of the selected product range to the amount of reactant in the feed.

Figure 2 shows yield-product distribution graphs at three different conversions for octacosane $\left(\mathrm{C}_{28}\right)$ at $220^{\circ} \mathrm{C}$. It illustrates the yields to fuel ranges with increasing conversion. Figure 2 -a is at $79 \%$ conversion, Figure 2 -b at $92 \%$ conversion and Figure 2 -c at $99 \%$ conversion. The lube-base oil yield is highest at $79 \%$ conversion and consists of only branched isomers, mostly iso- $\mathrm{C}_{28}$. The yield of lube-base oil decreases gradually with increasing conversion as the yield of diesel fuel and gasoline increases. The major 
product is diesel fuel at $99 \%$ conversion, only a $20 \%$ change in conversion. If the reaction is carried to $100 \%$ conversion, the major product becomes highly branched gasoline. Switching between these three fuels occurs at high conversion values. It appears possible to obtain the desired fuel range by adjusting the conversion at a selected temperature but maintaining relatively high conversion.

The fuel ranges contain more than $75 \%$ of branched isomers at all conversions. A highly branched isomer ratio results in a high octane number for gasoline and a low pour point for diesel and lube-base oil. The isomerization percentage increases slightly for gasoline and diesel fuel with increasing conversion, but this effect is negligible compared to the temperature effect.

Product distribution changes with increasing temperature (Figure 3). Temperatures are $220^{\circ} \mathrm{C}, 240^{\circ} \mathrm{C}$ and $250^{\circ} \mathrm{C}$ in Figure 3-a, b and c. All data are for 20 minute reactions with $\mathrm{n}-\mathrm{C}_{28}$. At $220^{\circ} \mathrm{C}, 79 \%$ conversion is reached while $100 \%$ conversion was attained at both $240^{\circ} \mathrm{C}$ and $250^{\circ} \mathrm{C}$. The reaction at $240^{\circ} \mathrm{C}$ reached $100 \%$ conversion before 20 minutes and cracking increased. This effect can be seen in the product distribution for reaction at $250^{\circ} \mathrm{C} ; 80 \%$ of the product is in the gasoline range with none in the lube-base range. The lube-base and most of the diesel fuel have already been cracked into gasoline. Low temperatures favor isomerization to branched alkanes.

Overall, temperature has a more significant effect on product distribution than time. The ability to vary time and temperature independently allows flexibility in the product. Moderate temperatures give rise to middle range products while lower temperatures favor heavier but branched products.

For this catalyst, hydroisomerization takes place first and then multibranched isomers begin to crack. Both catalyst properties and reaction conditions have an effect on the hydroisomerization and hydrocracking balance and product distribution. By adjusting reaction time and temperature it is possible to obtain high conversion to diesel fuel, gasoline or lube-base oil. Selectivity to branched isomers is high at high conversions with this catalyst.

\section{Reactions with Zeolites}

It is well known that zeolites, through their network of micropores, can show interesting properties by a molecular sieving effect and shape selectivity in adsorption and catalysis. Work has been started in this laboratory to study the use of various zeolites to control the nature of the products in the hydroisomerization and hydrocracking of hydrocarbons varying in chain length for $\mathrm{C}_{20}$ to $\mathrm{C}_{32}$.

Three zeolite types, as powders, were obtained from Zeolyst International: two Y type zeolites with $\mathrm{Si} / \mathrm{Al}$ ratios of 5:1 and 30:1, a mordenite (MOR) with a $\mathrm{Si} / \mathrm{Al}$ ratio of 20 and a Beta type Zeolite with a $\mathrm{Si} / \mathrm{Al}$ ratio of 25 . Surface areas of these zeolites ranged from $925 \mathrm{~m}^{2} / \mathrm{gm}$ for the $\mathrm{Y}$ type to $500 \mathrm{~m}^{2} / \mathrm{gm}$ for mordenite. Since it is possible that the pores of these zeolites may be too small or too large, an amorphous silica-alumina sample was 
obtained from Sasol; its $\mathrm{Si} / \mathrm{Al}$ ratio was 40,

The aforementioned $\mathrm{Pt} / \mathrm{ZrO}_{2} / \mathrm{SO}_{4}$ and $\mathrm{Pt} / \mathrm{ZrO}_{2} / \mathrm{WO}_{3}$ catalysts can be used to convert longchains, depending on conditions, to high cetane gasoline, diesel fuel and lube-base oils. Our aim with the zeolites is to obtain high yields of fractions in the diesel range with the remainder of the products as high octane gasoline. The first approach is to use the $\mathrm{Pt} / \mathrm{ZrO}_{2} / \mathrm{SO}_{4}$ and $\mathrm{Pt} / \mathrm{ZrO}_{2} / \mathrm{WO}_{3}$ catalysts in the presence of zeolites to direct product distribution to the desired products.

Several papers presented at the recent North American Catalyst Conference in Toronto in June, 2001 did indeed investigate the use of sulfated zirconia catalysts. One study used the zirconia-based catalysts supported on mesoporous silica, but this study was confined to the isomerization of n-butane. Another paper (Fang Li et al.) found that $\mathrm{Pt} / \mathrm{H}$-Beta modified by $\mathrm{WO}_{\mathrm{x}} \mathrm{ZrO}_{2}$ exhibited higher isomerization of $\mathrm{n}$-heptane than $\mathrm{Pt} / \mathrm{H}-\mathrm{Beta}$. Our work will deal with the hydroisomerization of F-T type waxy hydrocarbons to obtain diesel fractions.

Based on our early research, $\mathrm{Pt} / \mathrm{ZrO}_{2} / \mathrm{WO}_{3}$ has been shown to be a very good catalyst for the hydroisomerization of long-chain ( to $\mathrm{C}_{32}$ ) normal alkanes. The use of hybrid Ptpromoted and amorphous-silica alumina shape selective supports is a possible way of combining the zirconia catalysts with zeolites having proper surface acidity and surface areas, to direct product distributions. The pore structure of the silica-alumina supports can be used to direct reaction selectivity.

Preliminary work was carried out on a Pt-Y zeolite (Pt-LZY82). At $230^{\circ} \mathrm{C}$, conversions and selectivities to the various fuel ranges are shown in Figure 4. When the Y zeolite was modified by the addition of $\mathrm{Ca}^{++}$and reacted at $260^{\circ} \mathrm{C}$, the amount of the diesel fraction increased. This could be attributed to the lowering of acidity of the zeolite by addition of the $\mathrm{Ca}^{++}$. 


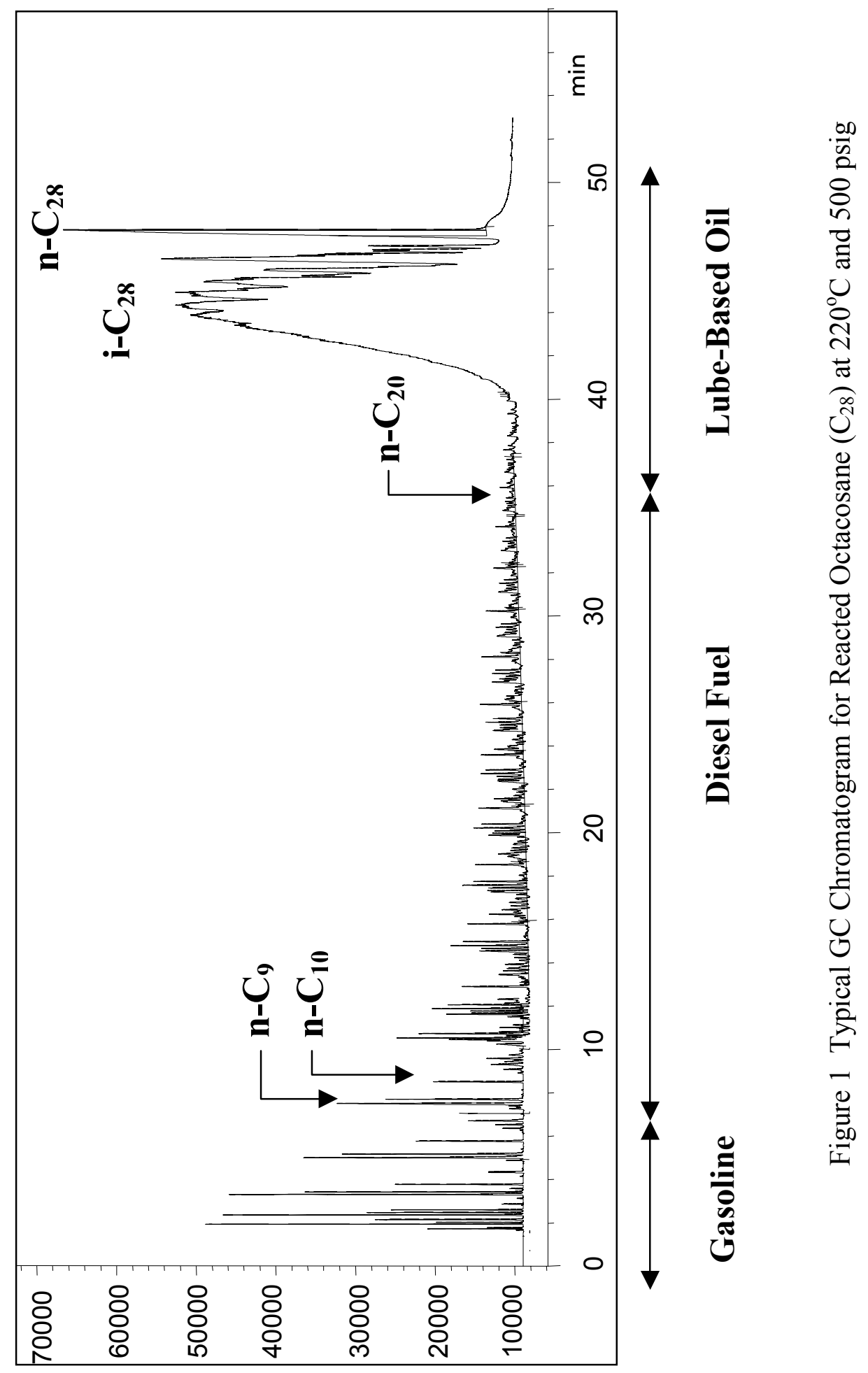


a-)

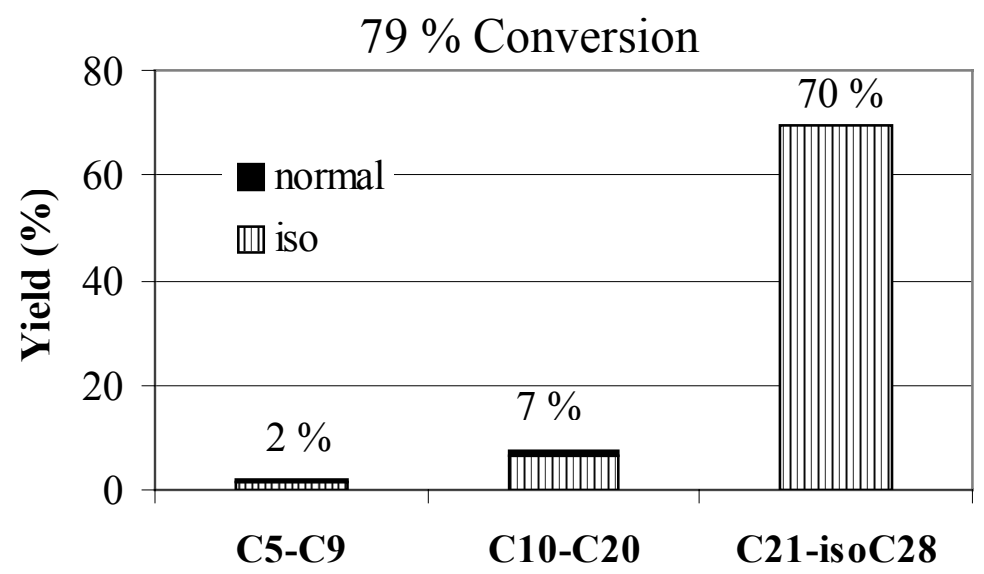

b-)

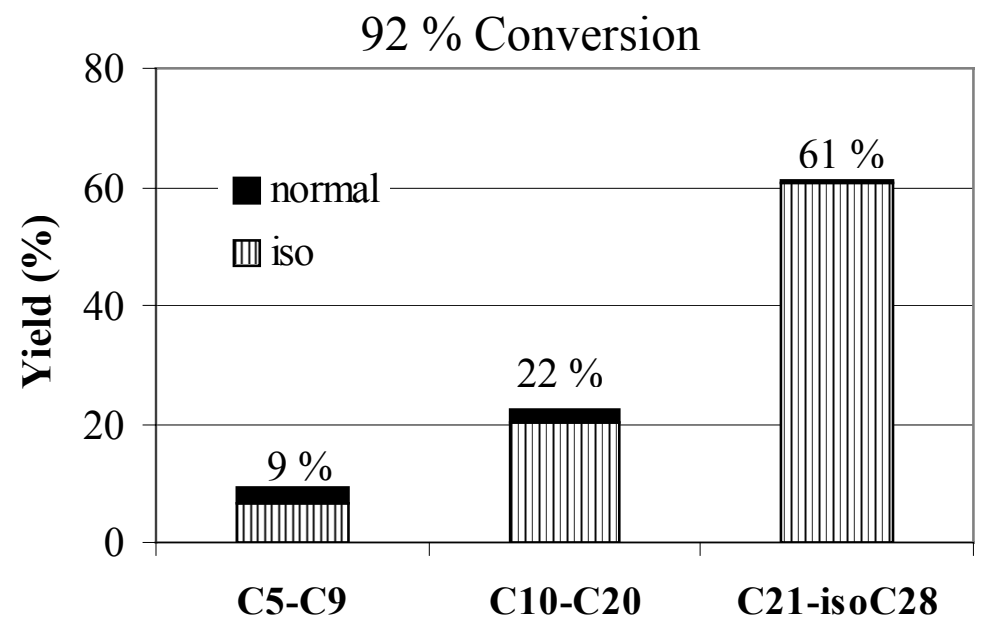

c-)

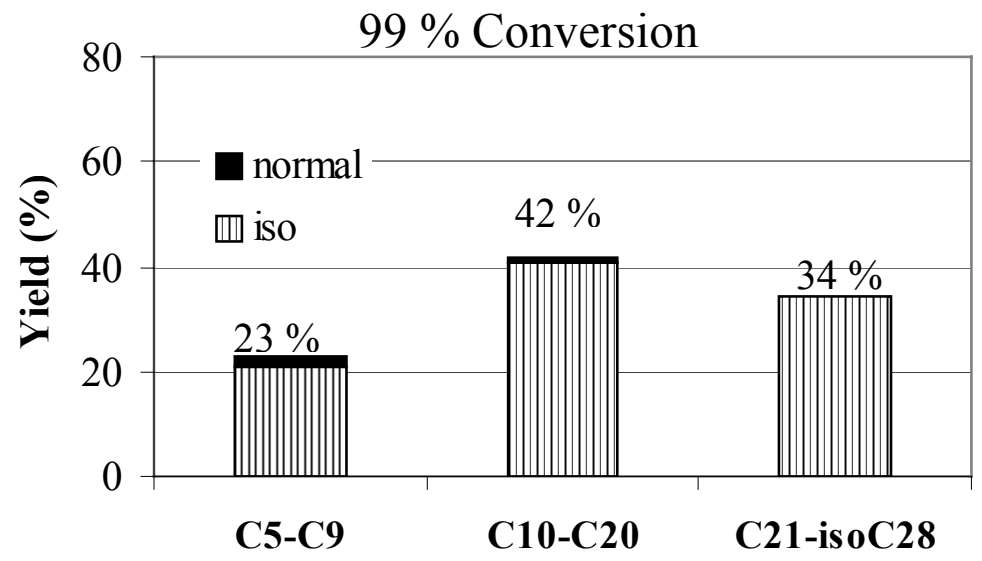

Figure 2 Effect of Conversion on Product Distribution for Reacted $\mathrm{C}_{28}$ at $220^{\circ} \mathrm{C}$ and 500psig 
a-)

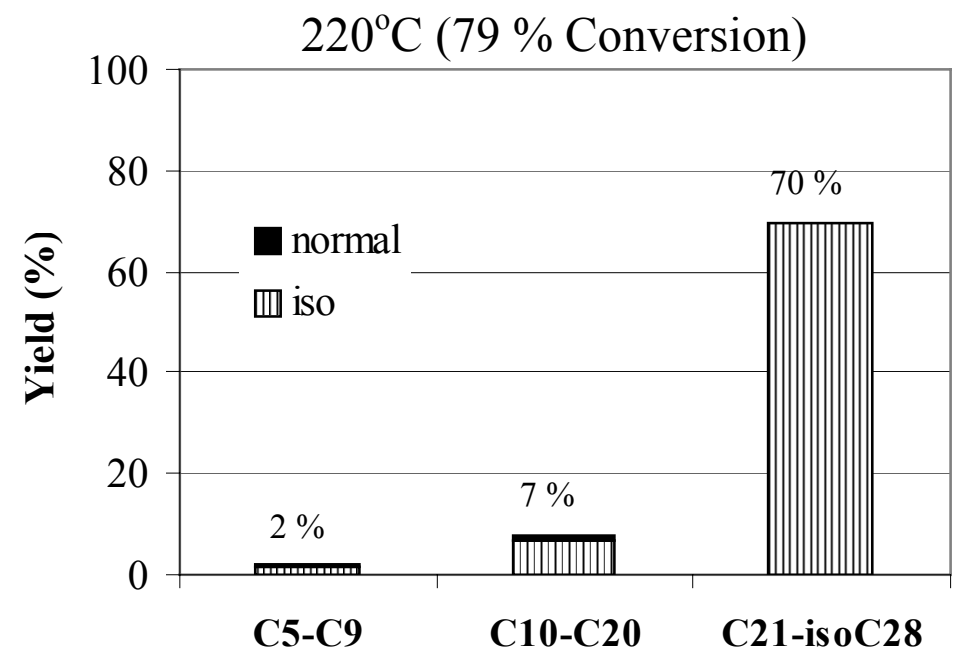

b-)

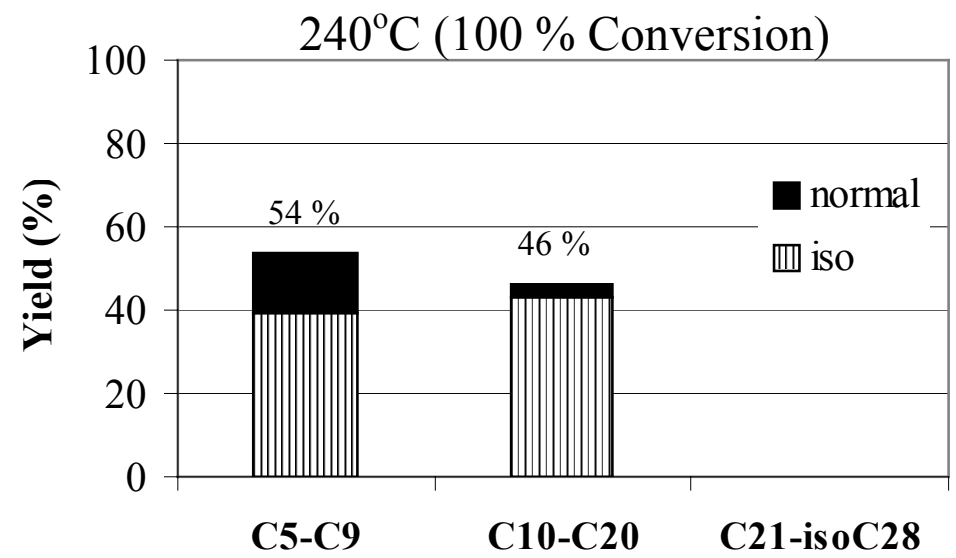

c-)

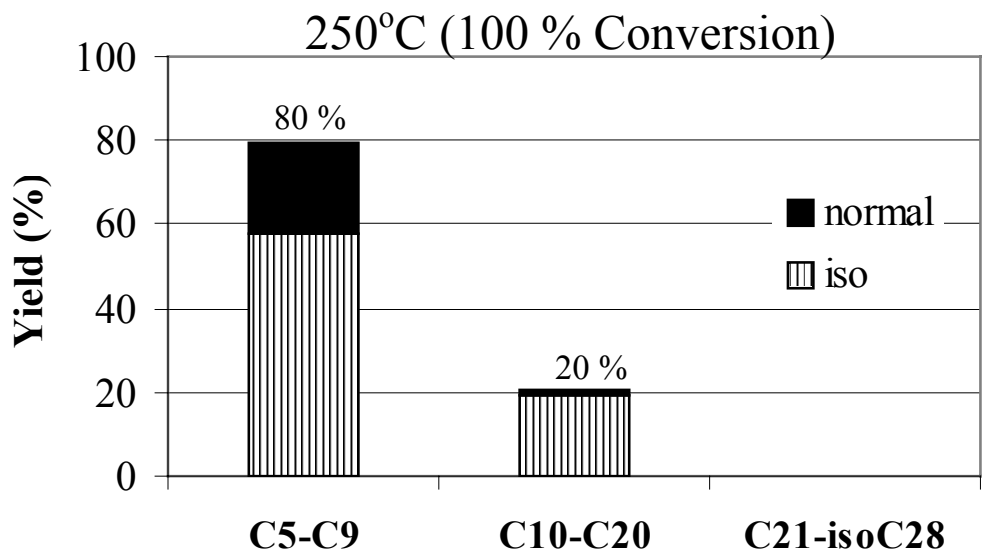

Figure 3 Effect of Temperature on Product Distribution of Reacted $\mathrm{C}_{28}$ at $220^{\circ} \mathrm{C}$ and 500 


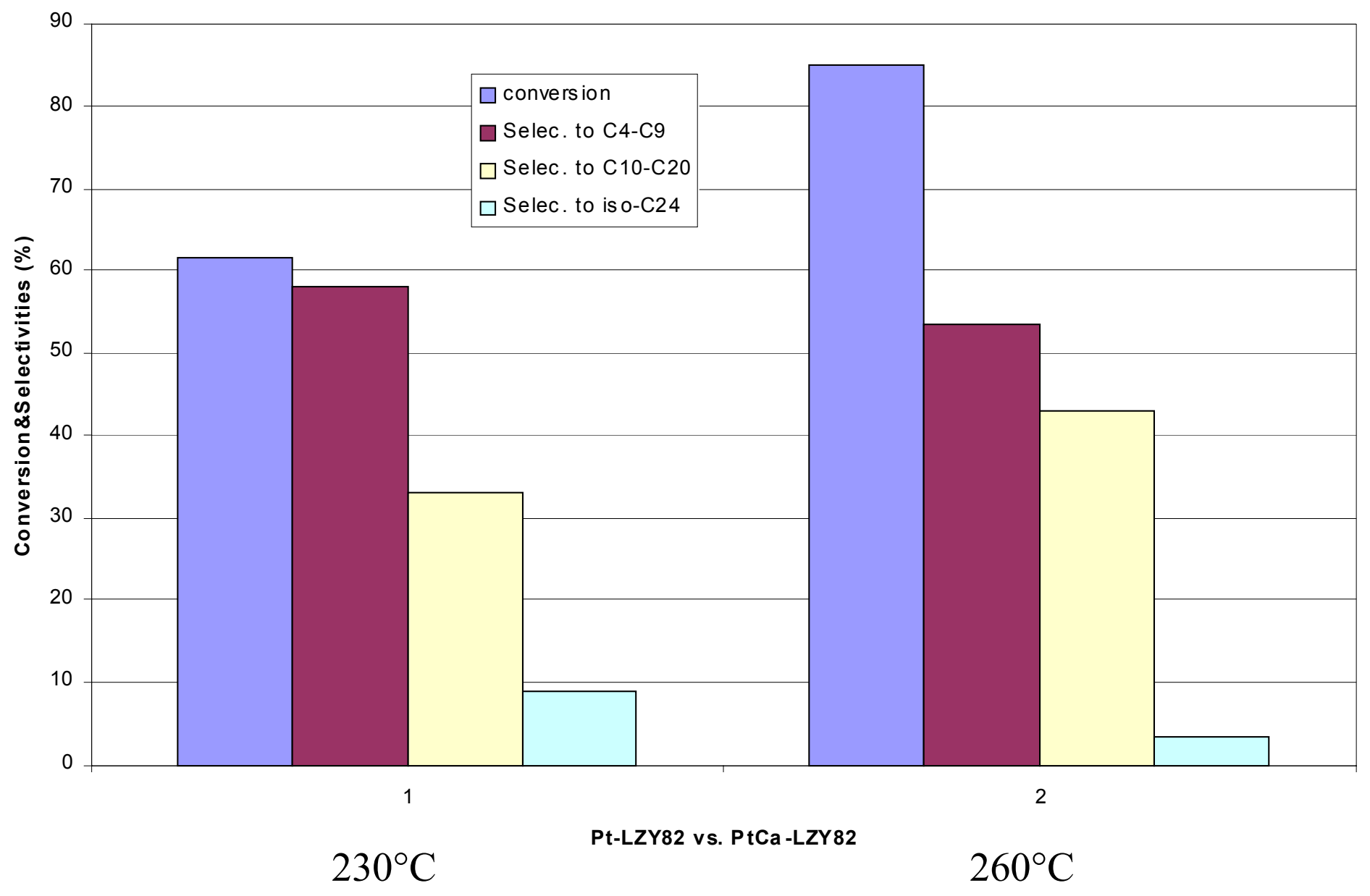

Figure 4. Conversion and selectivity for reaction of $n-\mathrm{C}_{24}$ with Pt-Y(1) and PtCa-Y(2) zeolite catalysts. 


\section{Supercritical Fluids as an Alternative Reaction Medium for Fischer-Tropsch Synthesis}

Xiwen Huang, Yoonkook Park, Christine W. Curtis, Christopher B. Roberts, Auburn University

\section{Introduction}

Supercritical fluids (SCFs) offer several advantages over traditional solvents as reaction media for catalytic reactions including the ability to manipulate the reaction environment through simple changes in pressure to enhance solubility of reactants and products, to eliminate interphase transport limitations, and to integrate reaction and separation unit operations. Supercritical fluid solvents offer attractive physical properties including; low viscosity and high diffusivity resulting in superior mass transfer characteristics; low surface tension enabling easy penetration into the pores of a solid matrix (catalyst) for extraction of nonvolatile materials from within the pores; high compressibility near the critical point inducing large changes in density with very small changes in pressure and/or temperature enabling separation of the dissolved material easily and completely.

The unique properties of SCFs can be exploited in various ways for the design of heterogeneous catalytic reaction systems. As a result, several classic industrial processes are conducted under SCF conditions such as ethylene polymerization, ammonia synthesis and methanol synthesis. As an example of the potential of SCF reaction solvents, Li Fan et al. investigated the effect of supercritical conditions on alkylation reactions on Y-type zeolites. Reactions under SCF conditions exhibited both higher catalyst activity along with longer lifetimes compared to the reaction in the liquid or gas phase. SCF solvents offer many opportunities for heterogeneous catalysis in $\mathrm{C} 1$ chemistry.

The advantages of SCF-phase Fischer-Tropsch synthesis (SCF-FT) include gaslike diffusivities and liquid-like solubilities, which together combine the desirable features of the gasand liquid-phase FT synthesis routes. These advantages can be attributed to the SCF offering high diffusivities and improved heat transfer (relative to a liquid) and high solubility (relative to a gas). The supercritical phase reaction can also (1) reduce production of undesirable products; produce less methane because of better distribution of heat in the reactor; (2) produce more longchain olefins as a result of the enhanced solubility of these higher hydrocarbons in the SCF; (3) mitigate deactivation of the catalyst through better heat and mass transfer; (4) provide in-situ extraction of heavy hydrocarbons from the catalyst surface and their transport out of the pores thereby extending catalyst lifetime; (5) enhance pore-transport of the reactants such as hydrogen to the catalyst surface thereby promoting desired reaction pathways; (6) enhance desorption of the primary products preventing secondary reactions that adversely affect product selectivity.

\section{Objective}

The objective of our project is to establish optimum operating conditions for FT synthesis within the supercritical region itself and to investigate the product selectivity alteration when FT synthesis is operated in a SCF medium vs. a liquid or gas medium. We are also evaluating the feasibility of maintaining catalyst activity by continuous in situ extraction of products with the SCF medium. We plan to establish an optimum method to increase the selectivity to desired products such as diesel and high-octane gasoline to improve the economics of FT synthesis. 


\section{$\underline{\text { Our recent work }}$}

We have finished our design, development and construction of a continuous fixed-bed reactor system for fundamental investigations of SCF-based FT synthesis. We have completed all aspects of the design and construction of the reactor, which is equipped with a safety alarm detector system, computer controlled gas supply and on-line GC analysis systems and methods for evaluation of products up to $\mathrm{C} 20$ hydrocarbons and oxygenates. The high-pressure fixed-bed reactor allows a wide range of temperatures (up to $400^{\circ} \mathrm{C}$ ), pressures (up to $200 \mathrm{bar}$ ), gas and SCF flowrates and catalyst loadings to be studied. We have performed studies of the SCF-FT synthesis reaction under supercritical hexane conditions by employing traditional $\mathrm{Fe}$ and $\mathrm{Co}$ catalysts (some results are discussed below) and comparisons were made to conventional gas phase and liquid phase FT synthesis.

\section{Experimental}

The reaction conditions employed in our previous experiments are shown below.

\begin{tabular}{|l|l|}
\hline Reactor & Fixed bed: $1.27 \mathrm{~cm}(0.5 \mathrm{in}) * 25.4 \mathrm{~cm}(10 \mathrm{in})$ with an effective volume of $32 \mathrm{~cm}^{3}$ \\
\hline Catalyst & $15 \% \mathrm{Co}-0.5 \% \mathrm{Pd}-\mathrm{Al}_{2} \mathrm{O}_{3}$ \\
\hline Solvent & Hexane $\left(\mathrm{Pc}=29.7 \mathrm{bar}, \mathrm{Tc}=233.7^{\circ} \mathrm{C}\right) ;$ Flowrate: $1.0 \mathrm{ml} / \mathrm{min}$ \\
\hline Syngas & Space velocity: $50 \mathrm{sccm} / \mathrm{g}$ cat; Ratio: $\mathrm{H}_{2} / \mathrm{CO}=2.0$ \\
\hline $\begin{array}{l}\text { Reaction } \\
\text { Condition }\end{array}$ & $\begin{array}{l}\text { Teducing gas type: } \mathrm{CO} ; \text { Flowrate: } 50 \mathrm{sccm} \\
\text { Time: } 20 \mathrm{hr} ; \text { Temperature, } \text { Pressure: } 280^{\circ} \mathrm{C}, 1 \mathrm{~atm} .\end{array}$ \\
\hline
\end{tabular}

\section{$\underline{\text { Result and Discussion }}$}

\section{Product Distribution}

The product distributions at $8 \mathrm{~h}$ and $29 \mathrm{~h}$ are shown in Figure 1. From Figure 1, we can see little variation of the product distribution between $8 \mathrm{hrs}$ and $29 \mathrm{hrs}$, which suggests that steady state can be easily approached in the supercritical conditions. In general, the lumped hydrocarbon product distribution diagram under supercritical conditions is similar in shape to that obtained under gas phase and liquid phase conditions. The SCF-FT process has a marked effect on the hydrocarbon product distribution with a shift to higher carbon number products owing to enhanced heat and mass transfer from the catalyst surface. Enhanced heat transfer from the catalyst surface will result in an increase in the median carbon number in the product distribution as is observed in these SCF-FT results. Relatively flat product distributions with similar mass percentages of the $\mathrm{C} 11-\mathrm{C} 17$ products were observed. The increased mass transfer in the SCF phase can result in higher diffusivities and desorption rates of high molecular weight hydrocarbons.

Hence, the heavy product can diffuse easily from the catalyst bed along with light compounds rather than remaining on the catalyst surface or pores shortening the catalyst lifetime or leading to more secondary undesired reactions. 


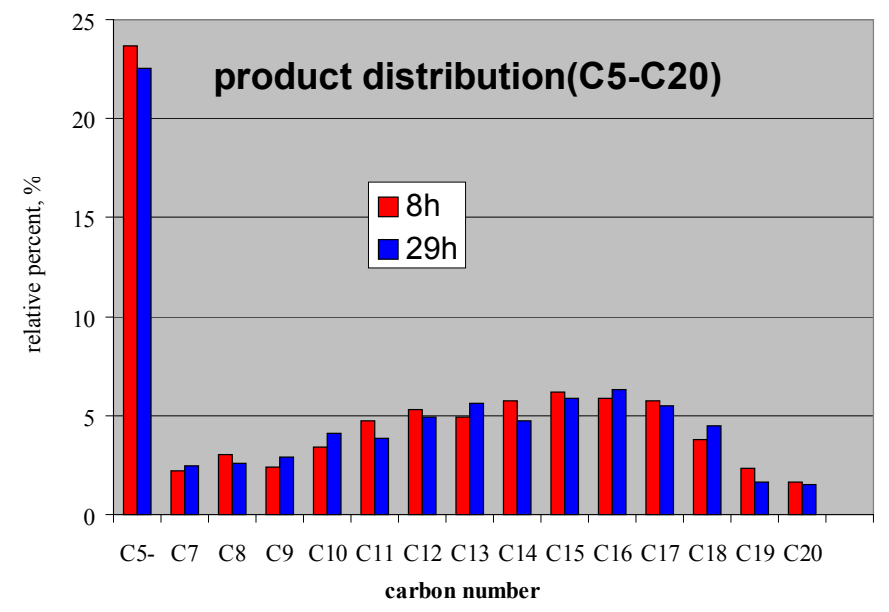

Figure 1. Product distributions at 8 and 29 hours.

\section{1-olefin Content in Hydrocarbon Product}

In the conventional FT reaction, the 1-olefin products are generally produced as the primary products and are successively hydrogenated to paraffins. A decrease in the olefin content with increasing carbon number is due to the relatively lower diffusion and desorption rate of heavy hydrocarbon (high molecular weight) components from the catalyst surface or pores. The larger compounds experience greater Van der Waals forces between the molecule and catalyst surface and thus stay longer on the surface for easy hydrogenation.

In the gas-phase or liquid-phase FT process, the olefin content (the fraction of product of a given carbon number that is the olefin product) dramatically decreases with an increase of carbon number. For example, in gas phase reaction, when the carbon number is increased to 16, very little olefin is contained in the product, whereas it is a larger fraction of the $\mathrm{C} 7$ product.

Under SCF-FT conditions, an obvious difference in the olefin content is observed where the 1olefin content in the SCF phase is higher than in gas- or liquid-phase. From the result in Figure 2 , we can conclude that the olefin product comprises much of the product distribution relative to the paraffin products even at the higher carbon numbers. As example, at a carbon number of 16 the olefin content is as much as one third. We are currently collecting experimental data in the gas phase and liquid phase in our reactor system for direct comparison. Referring to Fujimoto's results, as presented in Figure 3, we can see an obvious difference in the olefin content where the 1-olefin content in supercritical phase is always higher than in gas- or liquid-phase. One possible explanation for this is as follows. 


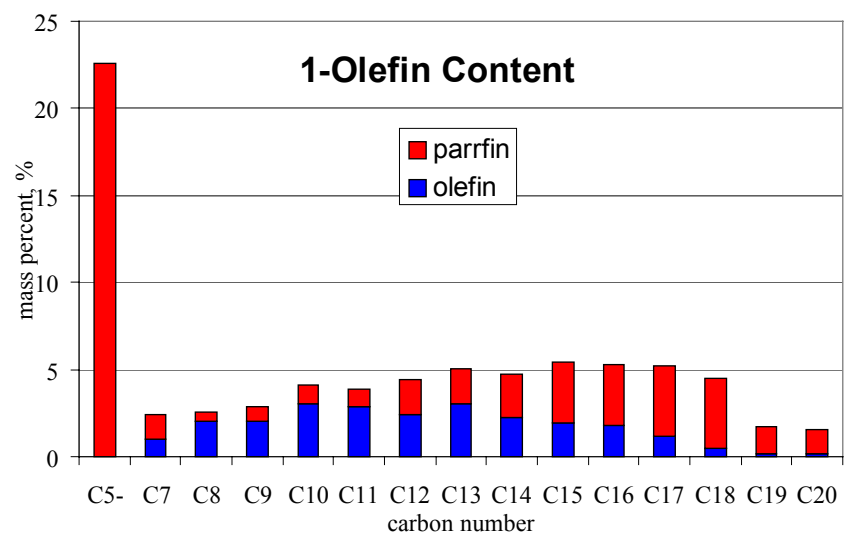

Figure 2: 1-olefin Mass Percentages in Supercritical Phase FT Reaction
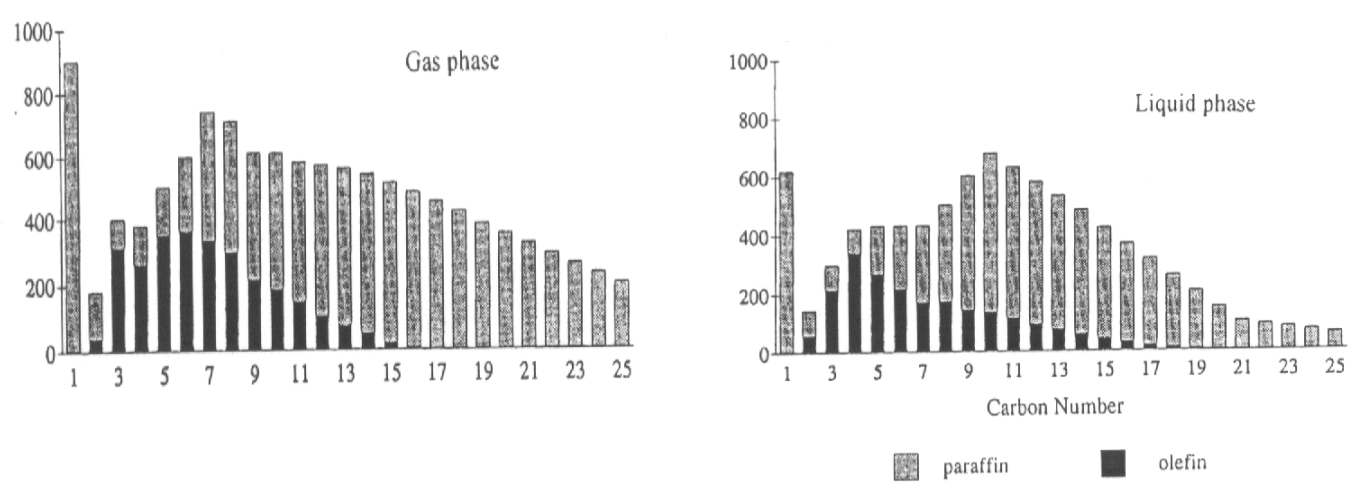

Figure 3: 1-olfin Contents in Gas- and Liquid-Phase FT (From Fujimoto)

The heavier hydrocarbons (e.g. $\mathrm{C16}^{+}$) olefins are more strongly adsorbed on the catalyst surface during the reaction and, in the case of gas-phase FT, hardly de-absorbed into the gas phase. However, in the SCF-FT process, the SCF readily extracts these heavy olefins from the catalysts surface and transports them effectively out of the catalyst bed reducing opportunity for the subsequent hydrogenation. In liquid phase, the olefin product should be extracted quickly by the liquid media. However, the much slower mass transfer prohibits the olefin product from flowing out of the catalyst bed inducing a long residence time and enhanced opportunity for hydrogenation. Therefore, the degree of olefin hydrogenation is higher in both the gas and liquid phases than in the SCF hexane phase. The decrease in the olefin content with the increasing carbon number in each reaction-phase should be attributed to the increase in the hydrogenation 
rate relative to the diffusion rate with the increasing carbon number. This is due to the longer residence time on the catalyst surface derived from the slower diffusion rate of these olefins.

These results suggest the SCF-FT reaction rate is not diffusion controlled, whereas the secondary olefin hydrogenation and isomerization reactions are diffusion limited. The SCF-FT process results in higher diffusivity and more rapid removal of high molecular weight 1-olefins and suppresses secondary hydrogenation and isomerization reactions. The observed increase in olefin content in SCF phase is in agreement with results obtained by Bukur et al.

\section{$\underline{\text { Future Plan }}$}

- Perform detailed SCF-FT reaction studies on traditional Fe and Co catalysts in the SCF solvents: propane, n-pentane, hexane, and mixtures of these solvents at temperatures up to $300 \mathrm{oC}$ and pressures up to $200 \mathrm{bar}$. Analyze reaction products to determine the effect of the reaction parameters and catalysts. A variety of solvent/syngas flow rates and feed compositions will be explored.

- A variety of catalyst materials will be examined including traditional iron and cobalt based catalysts as well as alumina-supported ruthenium catalysts, $\mathrm{Co}-\mathrm{Ni}-\mathrm{ZrO}_{2}$ and $\mathrm{K}-\mathrm{MoO}_{3}$ $\mathrm{Al}_{2} \mathrm{O}_{3}$.

- Perform comparative studies of FT reactions (with the catalysts of interest here) under liquid and gas phase conditions in order to make comparisons of the syngas conversion, product selectivity, reaction rates and catalyst activity in SCF, liquid, and gas phase media.

- Analyze and simulate the experimental data; conduct kinetic mechanism analysis of reaction pathways using labeled molecules during steady-state; determine the apparent activation energies of SCF-FT reaction system; create the modeling of product distribution for the prediction and control of FTS selectivity, specifically chain growth probability and olefin content in products, without requiring separate exploratory and development research programs for their implementation.

\section{$\underline{\text { References }}$}

1. Noritastu Tsubaki, Kaoru Fujimoto; Fuel Processing; 2000, 62, 173-186

2. Yongqing Zhang, Burton H Davis; $219^{\text {th }}$ National Meeting, American Chemical Society; 2000, March, 16-31

3. Li Fan, Kaoru Fujimoto; Applied Catalysis A: General; 1999, 186, 343-354

4. Bala Subramaniam; Energeia; 1999,10(3)1-4

5. Shirun Yan, Li Fan, Kaoru Fujimoto; Applied Catalysis A: General; 1998, 247-254

6. Bala Subramaniam; Industrial Engineering Chemistry Research; 1997, 36(10); 4413-4420

7. Dragomir B. Bukur, Xiaosu Lang, Industrial Engineering Chemistry Research; 1997; 36(7); 2580-2587

8. Burt Davis; Energeia; 1997, 8(3), 1-5 


\title{
New and Improved Catalysts/Processes for Production of Ethylene, Propylene
}

\section{and other Light Olefins via C-1 Chemistry}

\author{
James A. Guin, Shaobin Wang, Delphine R. Dubois, Jing Liu, Yoon Kook Park, Auburn \\ University
}

During this year, based on recommendations of the CFFLS Advisory Council and Industrial Advisory Board (IAB) Meeting from August, 2000, and subsequent meetings with CFFLS members, we redirected our project developing novel catalysts for the production of higher ethers as oxygenated fuel additives. The results of our ether work have been summarized in the previous six-month report and are available in literature publications ${ }^{(1-4)}$. Our redirected project focuses on the development of a non-petroleum source for light olefins, especially ethylene and propylene.

New molecular sieve catalysts are being developed to convert syngas, methanol, and remote natural gas to light olefins by $\mathrm{C}-1$ chemistry. ${ }^{(5)}$. If desired, these light olefins can be further converted to premium liquid transportation fuels as well as a vast array of products including fuels and fuel additives, e. g. ethanol, dimethyl ether (DME), and valuable chemicals which are currently available only via a petroleum route. Remote natural gas or any other hydrocarbon source such as coal could serve as a raw material for such a process based on C-1 chemistry. In recent years, several paths have been examined to increase selectivity of conversion processes for light olefins. These include ideas such as optimization of the operating conditions using HZSM-5 zeolite, modifications in the HZSM-5, and testing of other natural and synthetic zeolites ${ }^{(6)}$. Also, various silicoaluminophosphate (SAPO) catalysts have been developed and tested. Recent research sponsored by DOE and NSF has identified methylbenzenes as key intermediates in methanol-to-olefins (MTO) processes, although these compounds do not leave the pores of the SAPO catalyst ${ }^{(7)}$. The SAPO catalysts exhibit good selectivity; however, they suffer from rapid deactivation by coke formation, possibly due to further condensation reactions of the aforementioned methylbenzene intermediates, which are retained in the pores. It is highly desirable to develop modified SAPO catalysts, or other new catalysts, which will show more stable performance and even better selectivity ${ }^{(8)}$.

Reaction Conditions. During this year, we have built a quartz tube catalyst-testing unit as shown in figure 1. The unit consists of a nitrogen gas feed stream, which can be saturated with methanol followed by a tubular reactor consisting of a packed bed of catalyst in a temperaturecontrolled furnace. Typical reaction conditions are: nitrogen flow rate $=60 \mathrm{ml} / \mathrm{min}$; temperature $=400{ }^{\circ} \mathrm{C}$; pressure $=1 \mathrm{~atm}$, catalyst loading $=0.5 \mathrm{~g}$.

Product Analysis. The reaction products are collected in a gas bulb and analyzed by Gas Chromatograph (GC) using two Varian chromatographs: one equipped with GS-GasPro column and the other equipped with a Plot-Q capillary column. The latter column was found to be necessary for analysis of methanol. The carrier gas used is helium.

Catalyst Preparation. Several catalysts have been prepared and tested for the methanol to hydrocarbons reaction, with special attention given to olefins production. These include HZSM5 (a commercial catalyst), three supported sulfated zirconia catalysts, and two mesoporous 
silicoaluminophosphate (SAPO) catalysts. The sulfated zirconia catalysts are prepared via an impregnation procedure. The MCM (Si-MCM41 and AlSi-MCM41) and SAPO catalysts are prepared from gels, which are subjected to hydrothermal crystallization for an extended time period. An organic templating agent, e. g., tetraethylammonium ion (TEA), is then removed by calcination prior to catalyst testing. Sample preparations are:

Si-MCM41. A solution of $4.1 \mathrm{~g}$ of fumed $\mathrm{SiO}_{2}, 6.2 \mathrm{~g}$ of TEAOH (20 wt.\% solution) and $10 \mathrm{~g}$ of cetyltrimethylammonium bromide in $40.4 \mathrm{~g}$ of $\mathrm{H}_{2} \mathrm{O}$ was stirred at a temperature of $70^{\circ} \mathrm{C}$ for $2 \mathrm{~h}$. The mixture was then aged at room temperature for $24 \mathrm{~h}$. The temperature was increased to $100^{\circ} \mathrm{C}$ for $48 \mathrm{~h}$ under autogenous pressure and then calcined in air at $550^{\circ} \mathrm{C}$ for $9 \mathrm{~h}$. AlSiMCM41 is prepared from Si-MCM41, which is mixed with $0.10 \mathrm{M} \mathrm{Al}\left(\mathrm{NO}_{3}\right)_{3}$ for 24 hours, followed by filtration and calcination at $600^{\circ} \mathrm{C}$ for $2 \mathrm{~h}$.

Supported SZ catalysts. $3 \mathrm{~g}$ of $\mathrm{Zr}\left(\mathrm{SO}_{4}\right)_{2}$ was impregnated on $3 \mathrm{~g}$ of $\mathrm{SiO}_{2}$ and calcined at $600^{\circ} \mathrm{C}$ for $2 \mathrm{~h}$. For SZ/Si-MCM41, $3 \mathrm{~g}$ of $\mathrm{Zr}\left(\mathrm{SO}_{4}\right)_{2}$ was impregnated on $3 \mathrm{~g}$ of Si-MCM41 and calcined at $600^{\circ} \mathrm{C}$ for $2 \mathrm{~h}$. For SZ/AlSi-MCM41, $3 \mathrm{~g}$ of $\mathrm{Zr}\left(\mathrm{SO}_{4}\right)_{2}$ was impregnated on $3 \mathrm{~g}$ of AlSiMCM41 and calcined at $600^{\circ} \mathrm{C}$ for $2 \mathrm{~h}$.

SAPO. A mixture (aluminum isopropoxide- $15.1 \mathrm{~g}, \mathrm{H}_{2} \mathrm{O}-26.7 \mathrm{~g}, 85$ wt. $\% \mathrm{H}_{3} \mathrm{PO}_{4}-8.6 \mathrm{~g}$ and fumed $\mathrm{SiO}_{2}-0.24 \mathrm{~g}$ ) was stirred at room temperature until homogeneous. $27.2 \mathrm{~g}$ TEAOH solution (20 wt.\%) as a templating agent was added and stirred until homogeneous $(2 \mathrm{~h})$. After that it was synthesized at $200^{\circ} \mathrm{C}$ for $84 \mathrm{~h}$ under autogenous pressure in a Teflon lined vessel and then calcined in air at $550^{\circ} \mathrm{C}$ for $10 \mathrm{~h}$. A nitrate solution was used to prepare the Ni-SAPO.

Catalyst Testing Results. Reactions were carried out in the quartz tube reactor at $400^{\circ} \mathrm{C}$ at a nitrogen flow rate of $60 \mathrm{ml} / \mathrm{min}$ with $0.5 \mathrm{~g}$ of catalyst. Figures 2 and 3 show the results of catalyst testing with a commercial catalyst HZSM-5 used as a reference for this study. The hydrocarbon distribution is centered on $\mathrm{C} 3$ with some $\mathrm{C} 5$ and $\mathrm{C} 6+$ compounds formed. Little deactivation is observed up to 6 hours of reaction time. The olefin distribution is also centered on $\mathrm{C} 3$, with some $\mathrm{C} 2$ and $\mathrm{C} 4$ olefins. Total olefins yield was around $65 \%$ with an ethylene yield of about $20 \%$. No DME was formed under these conditions, although some $\mathrm{CH}_{4}$ is formed. Typical results from the sulfated zirconia catalysts are shown in Figures 4 and 5, where the AlSiMCM41 support is used. The major product initially $(10 \mathrm{~min})$ is ethylene; however after 4 hours of time on-stream the major product becomes DME, indicating that the catalyst deactivates fairly rapidly. Indeed, the breakthrough time of DME formation is sometimes used as a benchmark for catalyst lifetime. This rapid deactivation is probably due to the high acidity of the SZ catalysts. As shown in figures 6 and 7, the laboratory prepared SAPO catalyst provides good yields of ethylene and propylene even after 5 hours on-stream. The total olefins yield was about $90 \%$ with the SAPO catalyst and the ethylene yield was about $45 \%$, both of which exceed yields with the commercial HZSM-5. The good ethylene yield with the SAPO catalyst is a due to a combination of molecular sieving pore size effects and mild acidity. Figure 8 shows an extended reaction run using the Ni-SAPO catalyst for 22 hours. The initial conversion of methanol is around $100 \%$ and initial yield of ethylene is around 50\%; however, after about 5 hours on-stream, the catalyst begins to deactivate and after 22 hours the methanol conversion is reduced to less than $60 \%$ with ethylene yield of less than $10 \%$. The balance of the products at this time is DME. 
Catalyst Characterization. Several of the prepared catalysts have been analyzed by XRD and SEM. A typical SEM micrograph of a SAPO catalyst made in our laboratory is shown in figure 9. The crystals are 1 to 5 microns in size with cubic morphology typical of SAPO-34. In some micrographs, hexagonal crystals, suggestive of SAPO-5, were also apparent.

An XRD diffraction pattern for one of the synthesized SAPO catalysts is shown in figure 10. The material appears to be well crystallized. Taken together, the SEM and XRD results in figures 9 and 10 suggest the SAPO catalyst is mixture of SAPO-34 and SAPO-5.

Future work. It is planned to prepare additional SAPO based catalysts and to study the effects of preparation conditions on catalytic activity, with emphasis on maximizing olefin yield and catalyst lifetime. Additional metals will be inserted into the framework during synthesis. Further catalyst characterization will be performed by SEM and XRD, as well as other techniques. 


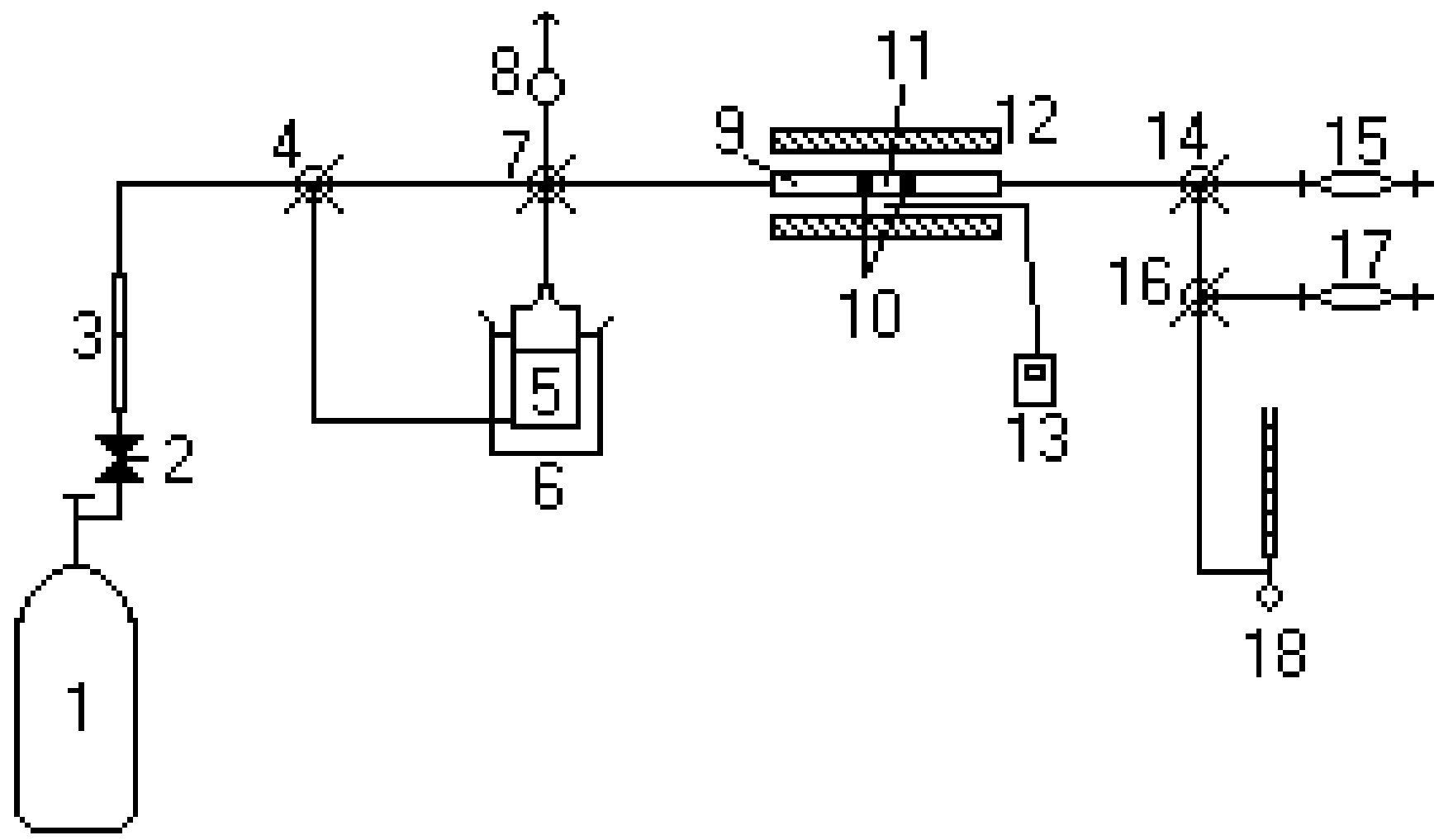

Figure 1. Schematic diagram of quartz flow-type reaction apparatus. (1) Nitrogen gas; (2) needle valve; (3) flow meter; (4) three-way stop-cock; (5) liquid $\mathrm{MeOH}$; (6) water bath; (7) threeway stop-cock; (8) sampling port for inlet methanol; (9) tubular reactor; (10) quartz wool; (11) catalyst; (12) furnace; (13) thermocouple; (14) three-way stop-cock; (15) sampling port for outlet product; (16) three-way stop-cock; (17) sampling port for outlet product; (18) soap-film flow meter.

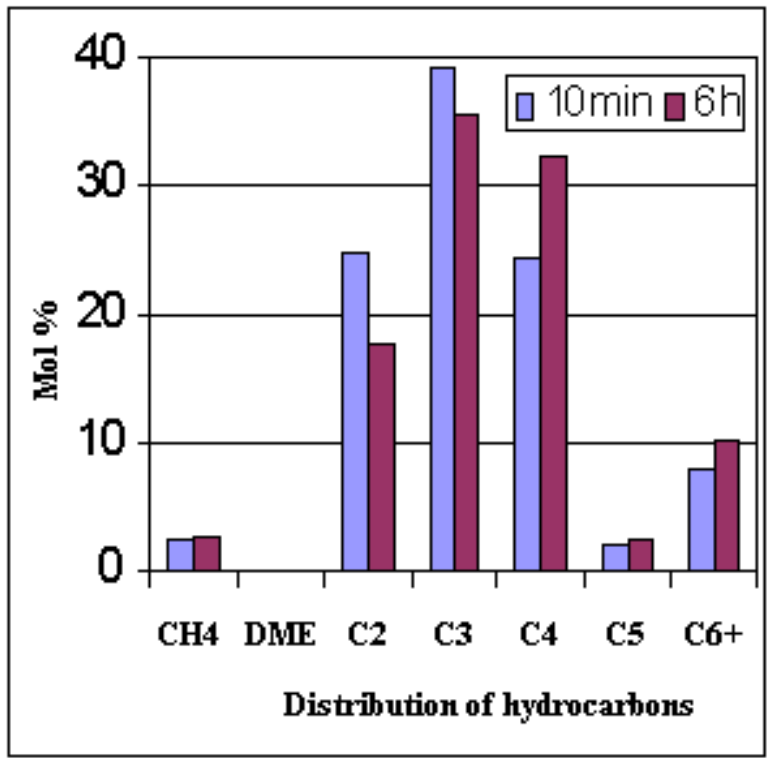

Figure 2. Distribution of hydrocarbons from HZSM-5 catalyst testing.

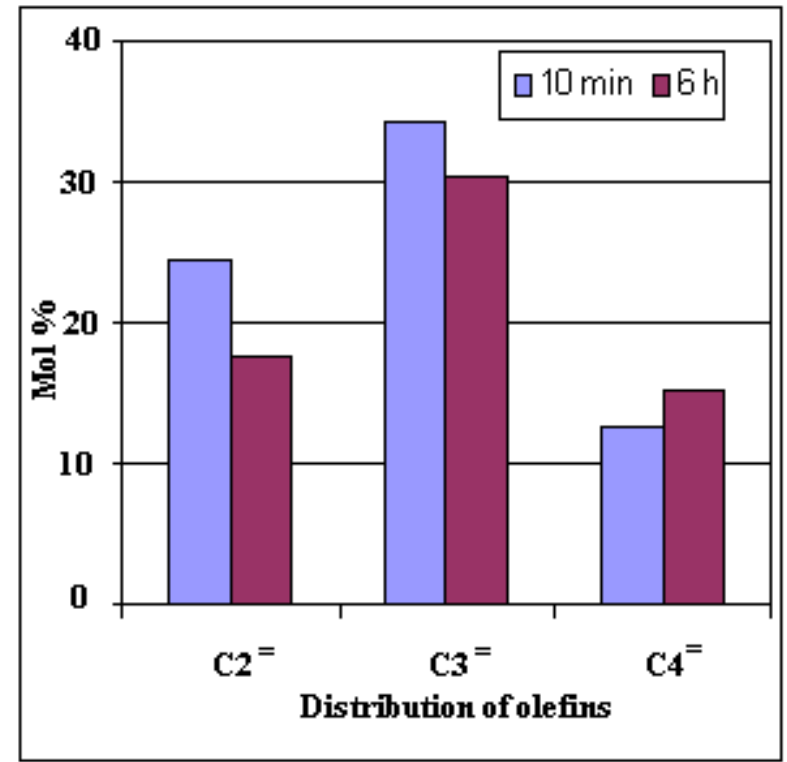

Figure 3. Distribution of olefins from HZSM-5 catalyst testing. 


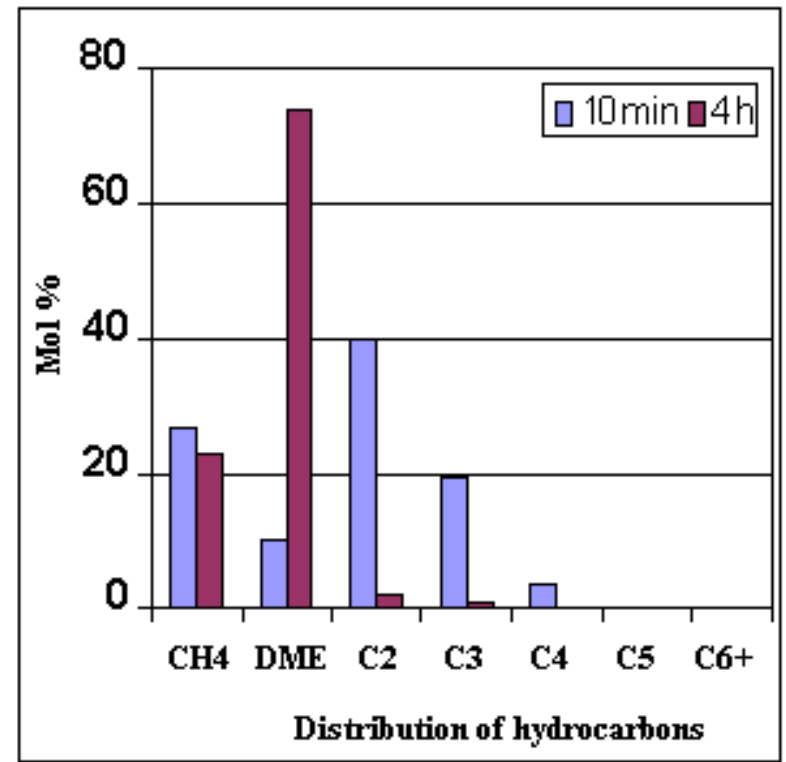

Figure 4. Distribution of hydrocarbons from SZIAISi-MCM41 catalyst testing.

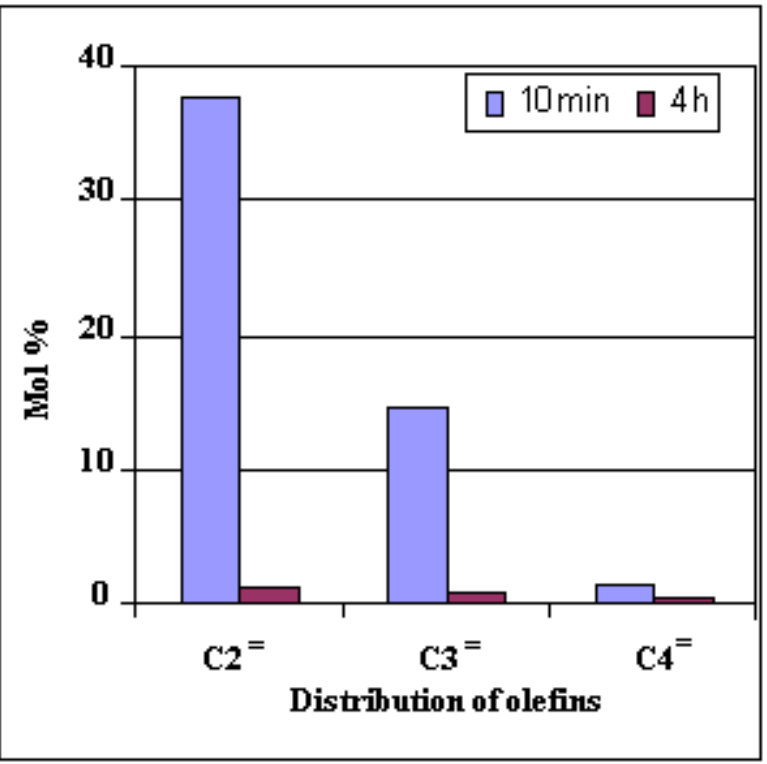

Figure 5. Distribution of olefins from SZIAISi-MCM41 catalyst testing.

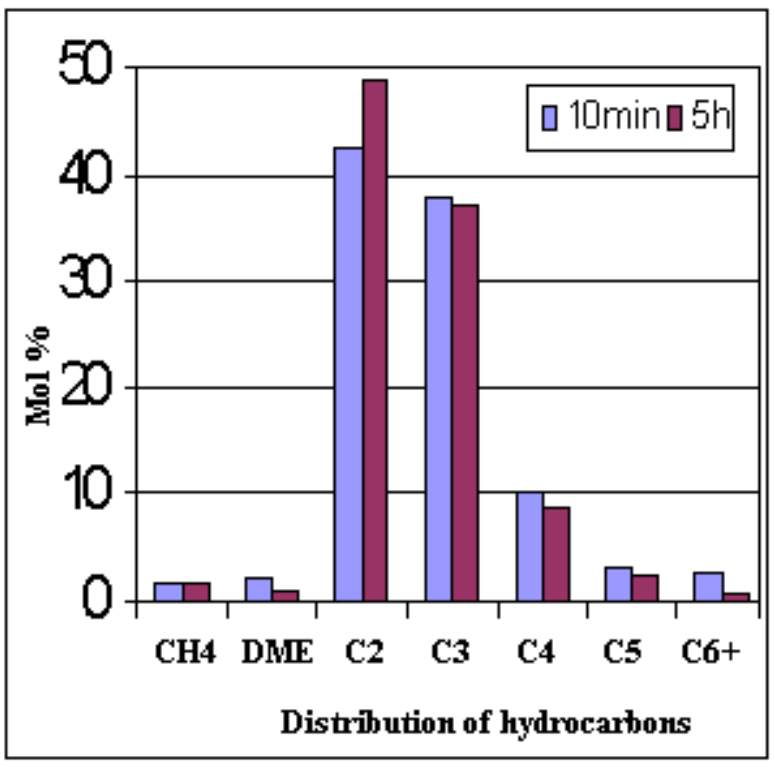

Figure 6. Distribution of hydrocarbons from SAPO catalyst testing.

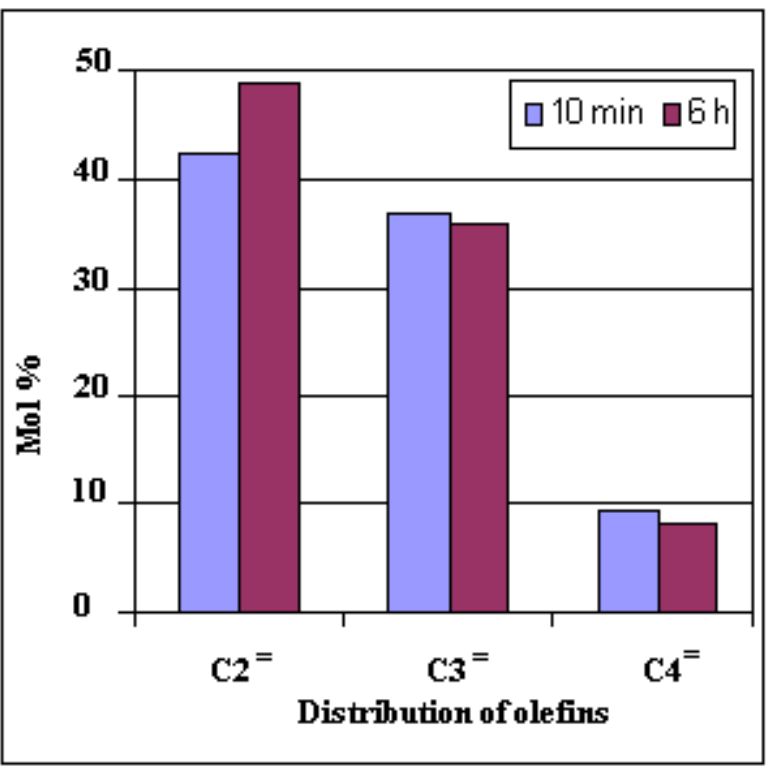

Figure 7. Distribution of olefins from SAPO catalyst testing. 


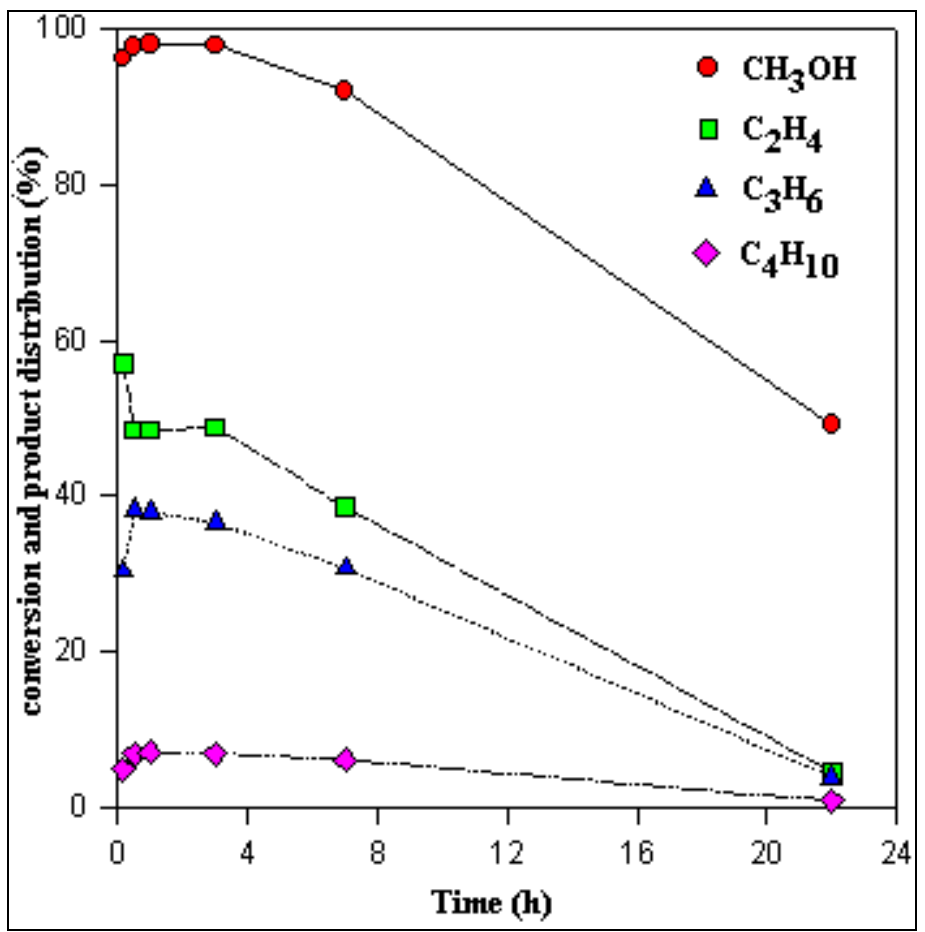

Figure 8. Ni-SAPO catalyst testing for a period of 22 hours.

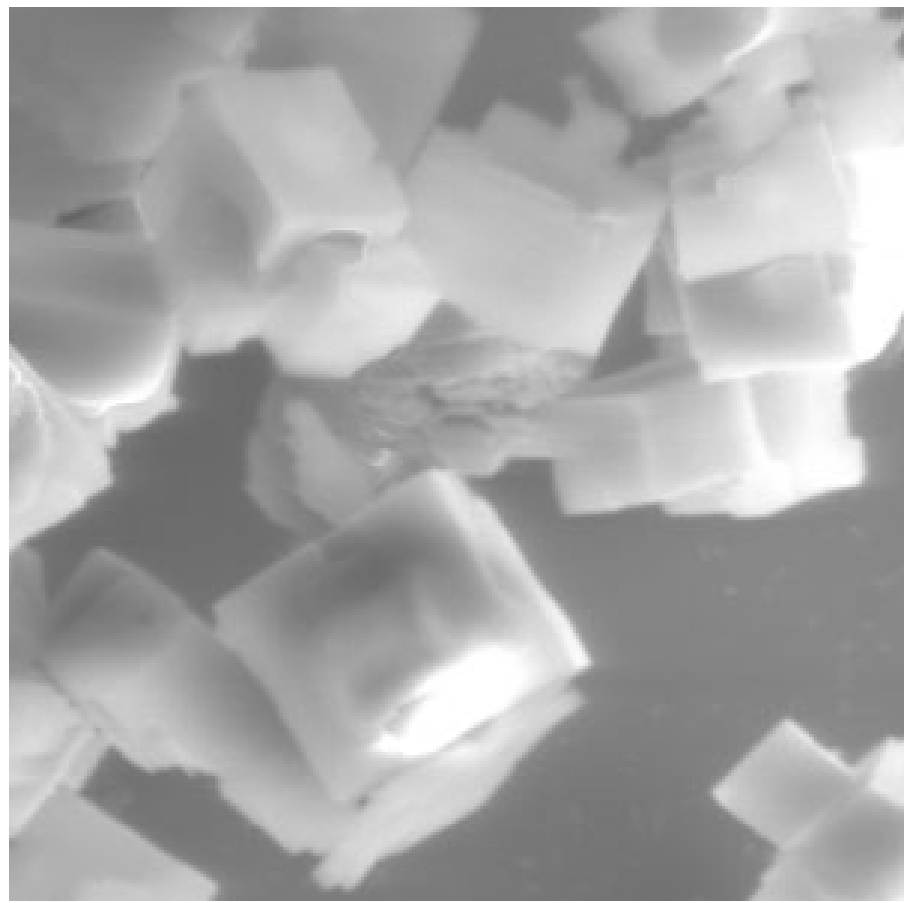

Figure 9. SEM micrograph of SAPO crystals. Magnification 3000X. 


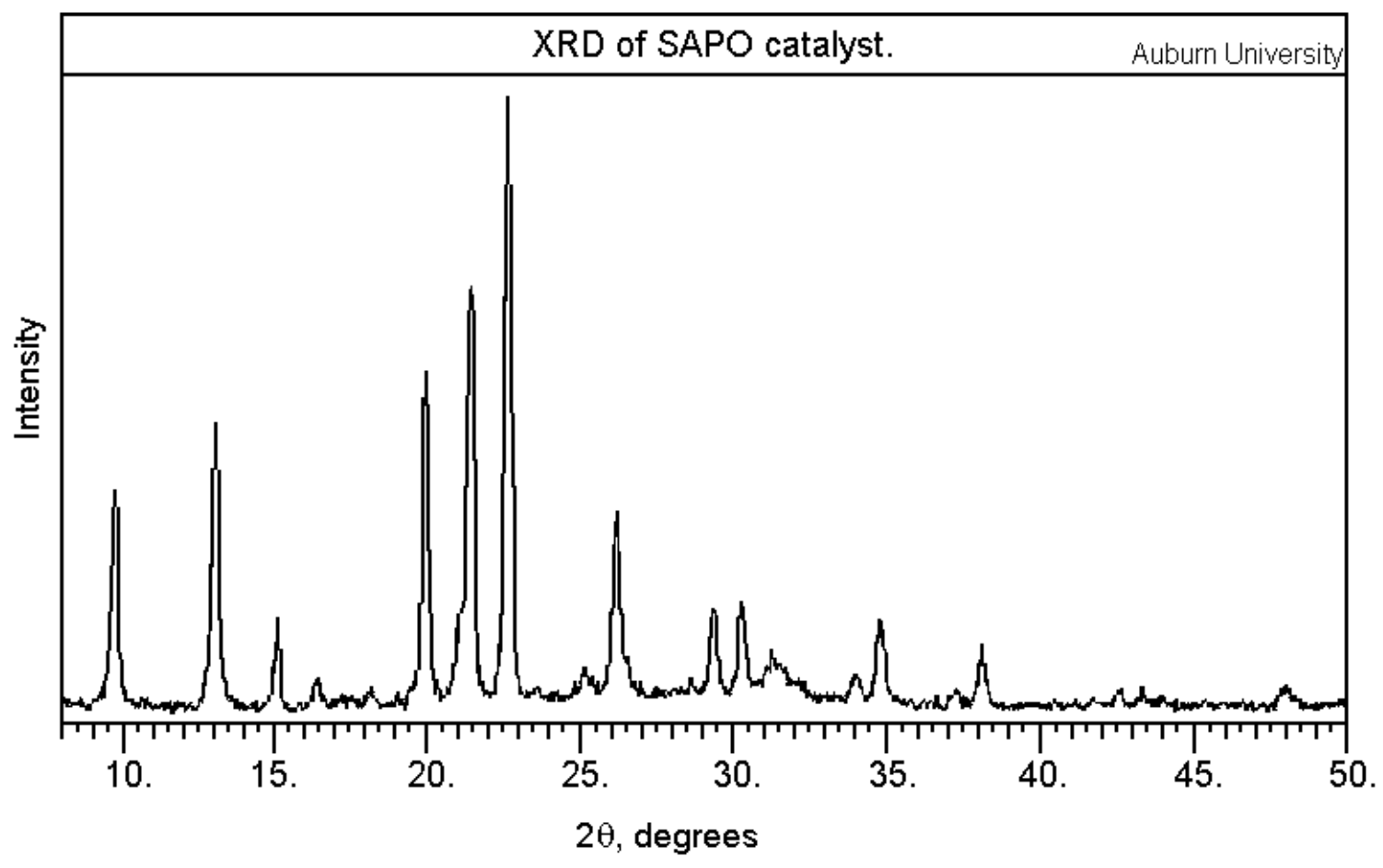

Figure 10. X-ray powder diffraction pattern of SAPO catalyst.

\section{REFERENCES}

1. Wang, Shoabin and Guin, J. A., "Silica-Supported Sulfated Zirconia: A New Effective Acid Solid for Etherification" Chem. Comm., 2000, 24, 2499-2500.

2. Liu, Jing, Wang, Shaobin and Guin, J. A., "Etherification of Dimethylbutenes in Excess Methanol", Fuel Processing Technology, 2001, 69 (3), 205-219.

3. Wang, Shaobin and Guin, J. A., "Si-MCM41 Supported Sulfated Zirconia and Nafion for Ether Production" Energy \& Fuels, 2001, 15, 666-670.

4. Wang, Shaobin and Guin, J. A., "Catalytic Activity of Acid-Treated Solids in Synthesis of Ethers from $\mathrm{C}_{6}$ Olefins and Methanol", manuscript submitted.

5. Microporous and Mesoporous Materials, June, 1999, 29, No. 1-2, 1-218. This entire issue is devoted to methanol conversion to hydrocarbons and olefins. Also see Froment, et al. Catalysis, 1992, 9, 1-64.

6. Gayubo, A. G. et al., Ind. Eng. Chem. Res., 2000, 39, 292.

7. Song, W. et al. J. Am. Chem. Soc., 2000, 122, 10726

8. Djieugoue, M. et al., J. Phys. Chem. B., 2000, 104, 6452. 


\title{
Synthesis and Testing of Diethyl Carbonate as a Possible Diesel Fuel Additive
}

\author{
E. M. Eyring, H. L. C. Meuzelaar and R. J. Pugmire \\ University of Utah
}

Typical automotive diesel engine exhaust contains substantial amounts of particulate matter (smoke). Addition of small amounts of oxygenated organic compounds to diesel fuel can diminish the amount of smoke emitted by the engine. A promising oxygenated compound for addition to diesel fuel is diethyl carbonate (DEC), $\mathrm{O}=\mathrm{C}\left(\mathrm{OCH}_{2} \mathrm{CH}_{3}\right)_{2}$, also called ethyl carbonate, carbonic acid diethyl ester, or Eufin. Its melting point is $-43{ }^{\circ} \mathrm{C}$, its boiling point is $126{ }^{\circ} \mathrm{C}$, and its flash point is $25^{\circ} \mathrm{C}$. DEC is readily miscible with diesel fuel and will not phase separate. Its place in a "C-1 chemistry" program is secured by its synthesis from carbon monoxide and ethanol in the gas phase reaction

$$
2 \mathrm{CH}_{3} \mathrm{CH}_{2} \mathrm{OH}+\mathrm{CO}+\frac{1}{2} \mathrm{O}_{2} \stackrel{\text { cat. }}{\longrightarrow} \mathrm{O}=\mathrm{C}_{2}\left(\mathrm{OCH}_{2} \mathrm{CH}_{3}\right)_{2}+\mathrm{H}_{2} \mathrm{O}
$$

over a heterogeneous catalyst. Carbon monoxide and ethanol are both starting materials for DEC synthesis that can be produced in the huge quantities that would be necessary if DEC became the additive of choice for diesel automotive fuel in the U. S. A further significant advantage of DEC over other oxygenates such as MTBE is that DEC decomposes slowly to $\mathrm{CO}_{2}$ and ethanol and therefore would not damage an aquifer if DEC accidentally entered the environment.

What we knew on May 1, 2001 was that $\mathrm{CuCl}_{2}$ and $\mathrm{PdCl}_{2}$ supported on activated carbon and subsequently impregnated with a methanolic $\mathrm{Ba}(\mathrm{OH})_{2}$ solution yielded an active catalyst for DEC synthesis. Other reaction products included ethyl formate and acetaldehyde. Hydroxide added to the catalyst significantly improved selectivity for DEC production, but the yield of DEC did not exceed $20 \%$.

\section{Results}

Accumulated since May 1, 2000 include the following:

1) Productive catalysts contain at least two forms of copper. This conclusion is drawn from XRD work done at West Virginia University (Seehra) in which both $\mathrm{CuCl}_{2}$ and $\mathrm{Cu}_{2}(\mathrm{OH})_{3} \mathrm{Cl}$ are detected when the $\mathrm{Cu} / \mathrm{Pd}$ catalysts are treated with hydroxide during preparation. This is further supported from our observations that kinetic curves, when non-hydroxide treated $\mathrm{Cu} / \mathrm{Pd}$ catalysts are used, follow an ideal first order process and that when hydroxide treated $\mathrm{Cu} / \mathrm{Pd}$ catalysts are used, the kinetics are more complex as shown in Figures 1 and 2. As the hydroxide is predicted to have no impact on the activated carbon support, its influence must be localized to the metal salts loaded onto the support prior to its use as a catalyst for the gasphase oxidative carbonylation of ethanol. 
2) Residence times in the flow reactor on the order of ten seconds are optimum for DEC production with longer residence times giving rise to more byproducts such as ethyl formate.

3) When the reaction is carried out at constant reactant composition and $150{ }^{\circ} \mathrm{C}$, the yield of $\mathrm{DEC}$ is greater at higher pressures.

4) With a view to getting copper atoms in the catalyst less agglomerated, sol-gel silica has been used in place of activated carbon as the heterogeneous catalyst support. Starting materials include<smiles>CO[Si](CCCN)(OC)OC</smiles>

the idea being that one amine will complex one copper ion. The sol-gel catalyst has been tried in the batch reactor, and $\mathrm{DEC}$ was detected by $\mathrm{GC}$ in the reaction products. The effect of changing counter-ions (to enhance DEC yield) and the incorporation of complexed palladium(II) into the sol-gel are both still under investigation.

5) The diesel engine has been moved to a building in downtown Salt Lake City (a little over two miles from the University) where it is being maintained and operated by employees of Prof. Adel Sarofim. Data on particulate matter in the exhaust from this engine operating under idling and load conditions began accumulating after April 30, 2001. Qualitatively, it is clear that DEC has the expected effect of drastically diminishing smoke in the exhaust under all operating conditions of the diesel engine.

\section{Projections of Further Work}

Questions that merit answers include the following:

1) Does the mixture of products from the $\mathrm{Cu} / \mathrm{Pd}$ catalyzed reaction of $\mathrm{CO}$ and ethanol perform about as well as DEC when added to diesel fuel?

2) Can unreacted $\mathrm{CO}$ and ethanol be recycled efficiently in the DEC synthesis to improve the economics of the DEC synthesis?

3) What is the useful lifetime of the best $\mathrm{Cu} / \mathrm{Pd}$ supported catalyst?

4) What are the species that remain adsorbed on the spent $\mathrm{Cu} / \mathrm{Pd}$ supported catalyst?

5) Will a sol-gel supported cobalt catalyst (prepared in a similar manner as the $\mathrm{Cu} / \mathrm{Pd}$ sol-gel catalyst) work well in a Fischer-Tropsch reaction?

\section{Publications}

1. B. C. Dunn, C. Guenneau, S. Hilton, E. M. Eyring, J. Dworzanski, H. L. C. Meuzelaar, J. Z. $\mathrm{Hu}$, and R. J. Pugmire, "Production of Diethyl Carbonate from Ethanol and Carbon 
Monoxide over a Heterogeneous Catalyst," Fuel Chemistry Division Preprints 2001, 46 (1), 236, 237 [San Diego ACS Mtg.].

2. B. C. Dunn, C. Guenneau, S. Hilton, N. S. Rho, E. M. Eyring, J. Dworzanski, H. L. C. Meuzelaar, J. Z. Hu, and R. J. Pugmire, "Diethyl Carbonate Production from Ethanol and Carbon Monoxide," Fuel Chemistry Division Preprints 2001, in press [Chicago ACS Mtg.].

3. B. C. Dunn, C. Guenneau, S. A. Hilton, J. Pahnke, E. M. Eyring, J. Dworzanski, H. L. C. Meuzelaar, J. Z. Hu, R. J. Pugmire, "Production of Diethyl Carbonate from Ethanol and Carbon Monoxide over a Heterogeneous Catalyst," in preparation.

\section{Personnel}

People participating in this team effort (listed in alphabetical order) are: Brian C. Dunn, Jacek Dworzanski, Edward M. Eyring, Catherine Guenneau, Emily Hieder, Steven Hilton, Kerry Kelly, Henk L. C. Meuzelaar, N. S. Rho, Ronald J. Pugmire, Sidney N. Thornton, David Wagner, and Guojin Wang. 


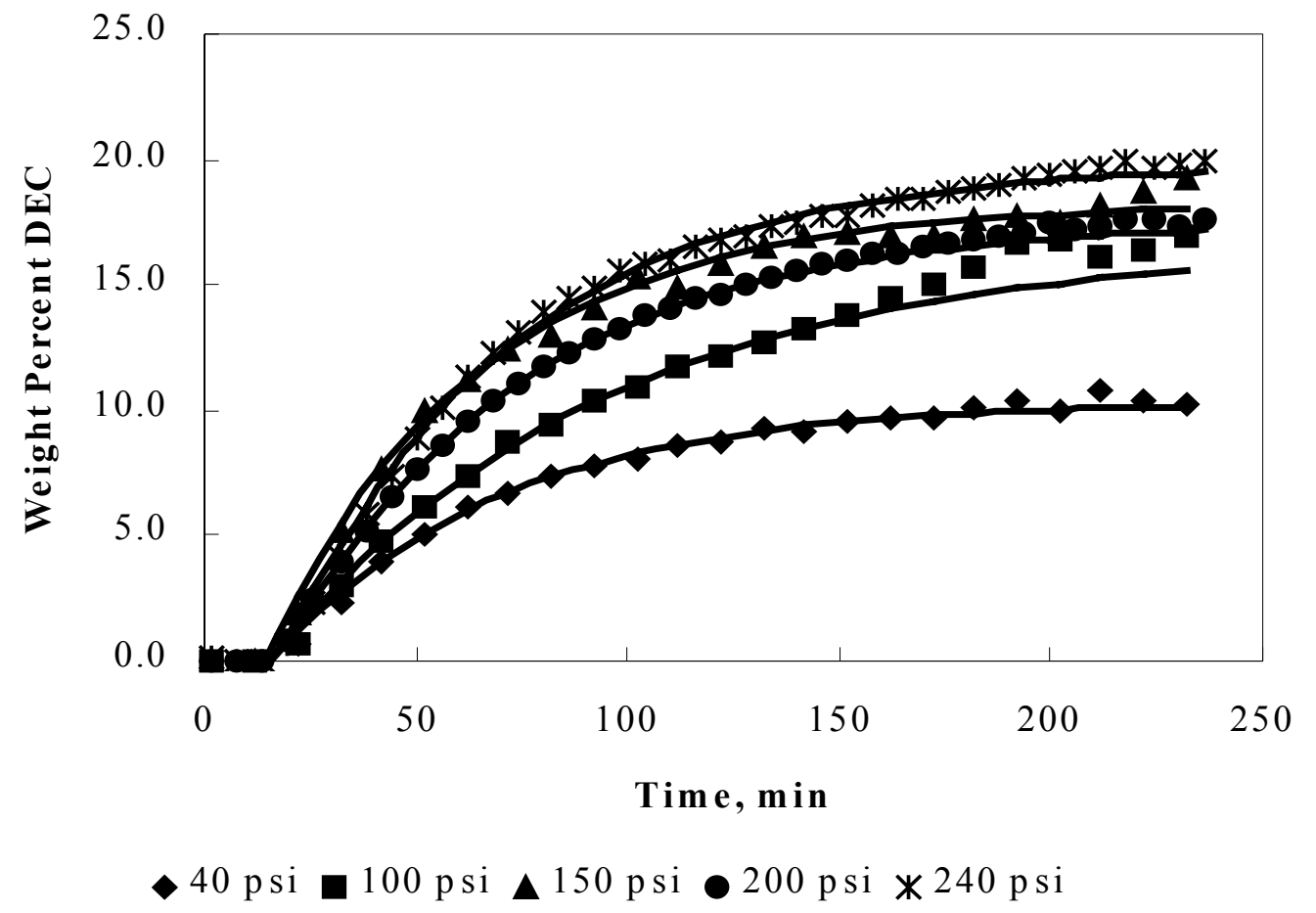

Figure 1. Evolution of DEC with varying amounts of CO. Other conditions: $0.5 \mathrm{~g}$ catalyst, 3.6 g EtOH, 60 psi air, 300 psi total pressure, $170{ }^{\circ} \mathrm{C}, 4$ hrs. Curves are best fit first order kinetic traces. 


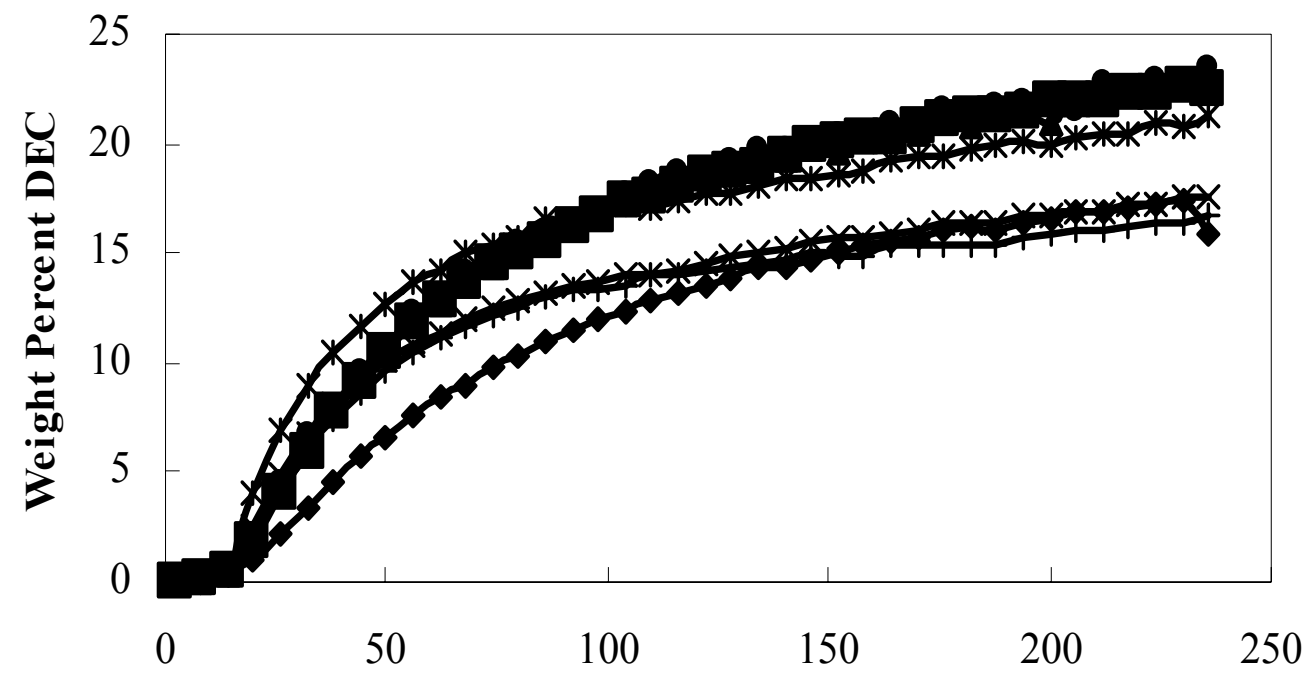

Time, min

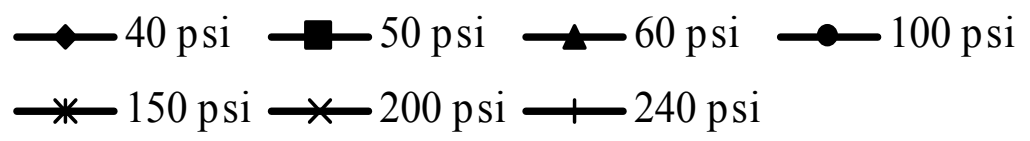

Figure 2. Evolution of DEC with hydroxide treated catalyst with varying amounts of CO. Other conditions: $0.5 \mathrm{~g}$ catalyst, $3.6 \mathrm{~g}$ EtOH, $60 \mathrm{psi}$ air, $300 \mathrm{psi}$ total pressure, $170{ }^{\circ} \mathrm{C}, 4 \mathrm{hrs}$. Traces do not obey first order kinetics. 


\title{
Higher Alcohol Synthesis From Methanol or Syngas
}

\author{
Lawrence Norcio, Edwin L. Kugler, and Dady B. Dadyburjor \\ Department of Chemical Engineering \\ West Virginia University \\ Morgantown, WV 26506-6102
}

\section{Introduction}

Alcohols are good octane enhancers for gasoline. With stringent restrictions on MTBE use in California, mixed alcohols appear to be the environmentally-friendly fuel additive. Ethanol and methanol have been used as gasoline additives in certain regions of the country for nearly twenty years. However, higher alcohol mixtures (ethanol and those of higher molecular weights) now seem preferable to methanol because of their lower volatility, important for gasoline vapor-pressure specifications.

Prior work in our laboratory has shown that good alcohol synthesis performance can be obtained with molybdenum-based catalysts. The addition of $\mathrm{Ni}$ and $\mathrm{K}$ to these catalysts improves their performance considerably for higher alcohol synthesis. These catalysts generally need to be reduced prior to reaction. The effects of impregnation order as well as the effects of calcination were also found to be significant. Results from previous study [1] show that the calcined Mo-Ni-K/C catalyst should be a superior higher-alcohol-synthesis catalyst.

The work described in this report focuses on material balance measurements. The emphasis on good material balance data will validate the prior work. The computer-controlled reactor used before has been modified to maximize liquid product collection to aid in the carbon balance measurements.

\section{Methodology \\ Catalyst Preparation}

Activated carbon (20-40 mesh) was obtained from Aldrich. Ammonium heptamolybdate, potassium nitrate, and nickel nitrate, obtained from Fisher Scientific, were used as sources of $\mathrm{Mo}, \mathrm{K}$, and $\mathrm{Ni}$, respectively. The incipient-wetness method was used to prepare all samples. Mo was impregnated first followed by $\mathrm{Ni}$ and then $\mathrm{K}$. The calcination procedure in flowing nitrogen was carried out after each impregnation step. The calcination temperature varied as follows, $500^{\circ} \mathrm{C}$ for $\mathrm{Mo}, 500^{\circ} \mathrm{C}$ for $\mathrm{Ni}$, and $300^{\circ} \mathrm{C}$ for $\mathrm{K}$. Typically $0.9 \mathrm{~g}$ of catalyst was used for catalyst testing.

\section{Reactivity}

Reactivity studies were carried out in a computer-controlled reactor system. Catalysts were reduced in flowing $\mathrm{H}_{2}$ at atmospheric pressure and $400^{\circ} \mathrm{C}$ for $12-15$ hours prior to use. Higher-alcohol synthesis was studied at 750 psig. The reactor was run isothermally at 250,300 , and $350^{\circ} \mathrm{C}$. Gas products were analyzed on-line every two hours using gas chromatography (GC). Liquid products were collected once a day and manually injected to the GC. The GC columns used were HayeSep $\mathrm{D}_{\mathrm{B}}$ and DB-Wax.

\section{Summary of Results}

A Mo-Ni-K/C catalyst, similar to the one used for previous work [1], was freshly prepared and tested to obtain carbon balance measurements. The catalyst tested contains $18 \mathrm{wt}$. $\% \mathrm{Mo}, \mathrm{K} / \mathrm{Mo}=1.2$ (molar) and $\mathrm{Ni} / \mathrm{Mo}=0.6$ (molar). Small quantities of methane, and traces of 
ethane and propane are detected as the gas-phase hydrocarbon products. The liquid product consists of an aqueous phase containing alcohols. Alcohols up to $\mathrm{C}_{5}$ can be identified with the HayeSep column. No hydrocarbons can be identified in the liquid products.

Figure 1 shows a typical GC chromatograph when a sample of liquid product containing mixed alcohols is injected to the GC. The major components of the mixed alcohols are methanol, ethanol, 1-propanol, and 1-butanol. This result is also observed with the previous work done on a similar catalyst [1].

Table 1 shows the wt.\% distribution of water-free mixed alcohols at 250,300, and $350^{\circ} \mathrm{C}$. The amount of condensates (mixed alcohols and water) increases as the reaction temperature increases. The volumes collected over a 24 -hour period are $0.35,1.8$, and $4.8 \mathrm{cc}$ at 250,300 , and $350^{\circ} \mathrm{C}$, respectively. A similar trend is observed on the $\% \mathrm{CO}$ conversion and the space-time yield (STY) of higher alcohols. The \%CO conversions obtained are 1.97\%, 14.63\%, and $48.56 \%$ while the STY's are 12,65 , and $161 \mathrm{~g} / \mathrm{h} / \mathrm{kg}$-catalyst, respectively. The calculated selectivity to higher alcohols (wt. $\% \mathrm{CO}_{2}$-free) at $\mathrm{T}=350^{\circ} \mathrm{C}$ is $60 \%$ which is the same as the published data [1] for the same catalyst and reaction conditions.

Table 2 shows the summary of the carbon balance calculations at 250,300 , and $350^{\circ} \mathrm{C}$. The $\%$ accounted carbon at 250,300 , and $350^{\circ} \mathrm{C}$ are $99.78,99.38$, and $98.71 \%$, respectively.

The liquid product was also injected to another GC with a different column. The column used was SIMDIS-2887, used to analyze high-boiling liquids. Figure 2 shows the GC chromatograph of the alcohol product mixture. Peaks were identified by comparing their retention times with those of alcohol standards. From Figure 2, it was found that there are small quantities of alcohols greater than $\mathrm{C}_{5}$ in the product mixture. It appears that there is a successive addition of a carbon atom forming a homologous series of linear alcohols up to $\mathrm{C}_{24}$. This suggests that methanol also acts as a reactant to form higher alcohols. The implication of this result may become clear as we obtain more data on these higher alcohol products.

\section{Reference}

[1] E. L. Kugler, D. B. Dadyburjor, L. Feng, and X. Li., Studies in Surface Science and Catalysis, 130 (2000), 299. 
Table 1. The percentage weight distribution of mixed alcohols obtained at various reaction temperatures.

\begin{tabular}{|c|c|c|c|}
\hline & $\mathbf{2 5 0}{ }^{\circ} \mathbf{C}$ & $\mathbf{3 0 0}^{\circ} \mathbf{C}$ & $\mathbf{3 5 0}^{\circ} \mathbf{C}$ \\
\hline Alcohol & $\mathbf{W t} . \%$ & $\mathbf{W t .} \%$ & $\mathbf{W t .} \%$ \\
\hline $\mathrm{MeOH}$ & 24.82 & 23.10 & 18.67 \\
\hline EtOH & 42.95 & 42.66 & 44.58 \\
\hline $2-\mathrm{PrOH}$ & 0.89 & 1.04 & 1.33 \\
\hline $1-\mathrm{PrOH}$ & 20.73 & 20.41 & 21.37 \\
\hline $2-\mathrm{BuOH}$ & 0.67 & 2.15 & 3.38 \\
\hline $2-\mathrm{Me}-1-\mathrm{PrOH}$ & 1.96 & 2.03 & 2.33 \\
\hline $1-\mathrm{BuOH}$ & 5.39 & 5.45 & 5.71 \\
\hline $3-\mathrm{Me}-1-\mathrm{BuOH}$ & 0.81 & 1.46 & 0.99 \\
\hline $1-\mathrm{PenOH}$ & 1.78 & 1.70 & 1.66 \\
\hline
\end{tabular}

Table 2. Summary of carbon mass balance for Mo-Ni-K/C catalyst run at various reaction temperatures over a 24-hour period.

\begin{tabular}{|c|c|c|c|}
\hline & $\mathbf{2 5 0 ^ { \circ } \mathbf { C }}$ & $\mathbf{3 0 0}^{\circ} \mathbf{C}$ & $\mathbf{3 5 0 ^ { \circ } \mathbf { C }}$ \\
\hline g CO entering & 43.35 & 43.35 & 43.35 \\
\hline g C from CO entering & 18.58 & 18.58 & 18.58 \\
\hline g C from CO left & 18.21 & 15.91 & 10.06 \\
\hline Total g C from hydrocarbons & 0.032 & 0.69 & 2.31 \\
\hline g C from CO 2 & 0.16 & 1.13 & 4.20 \\
\hline g C from alcohol & 0.14 & 0.73 & 1.77 \\
\hline g C accounted & 18.54 & 18.46 & 18.34 \\
\hline \% C accounted & 99.78 & 99.35 & 98.71 \\
\hline
\end{tabular}




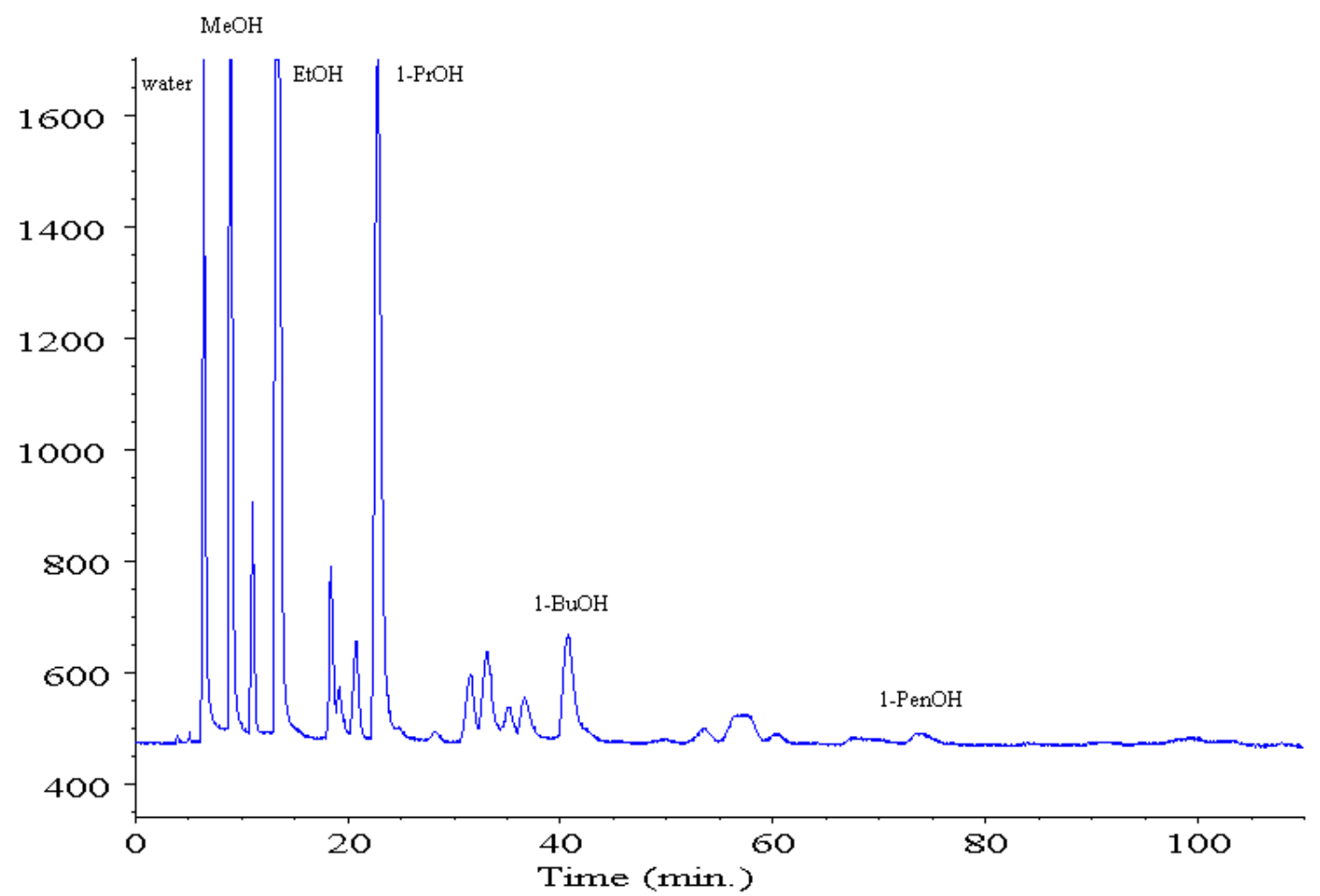

Figure 1. A typical GC chromatograph (TC detector) of mixed alcohols from Mo-Ni$\mathrm{K} / \mathrm{C}$ catalyst. 


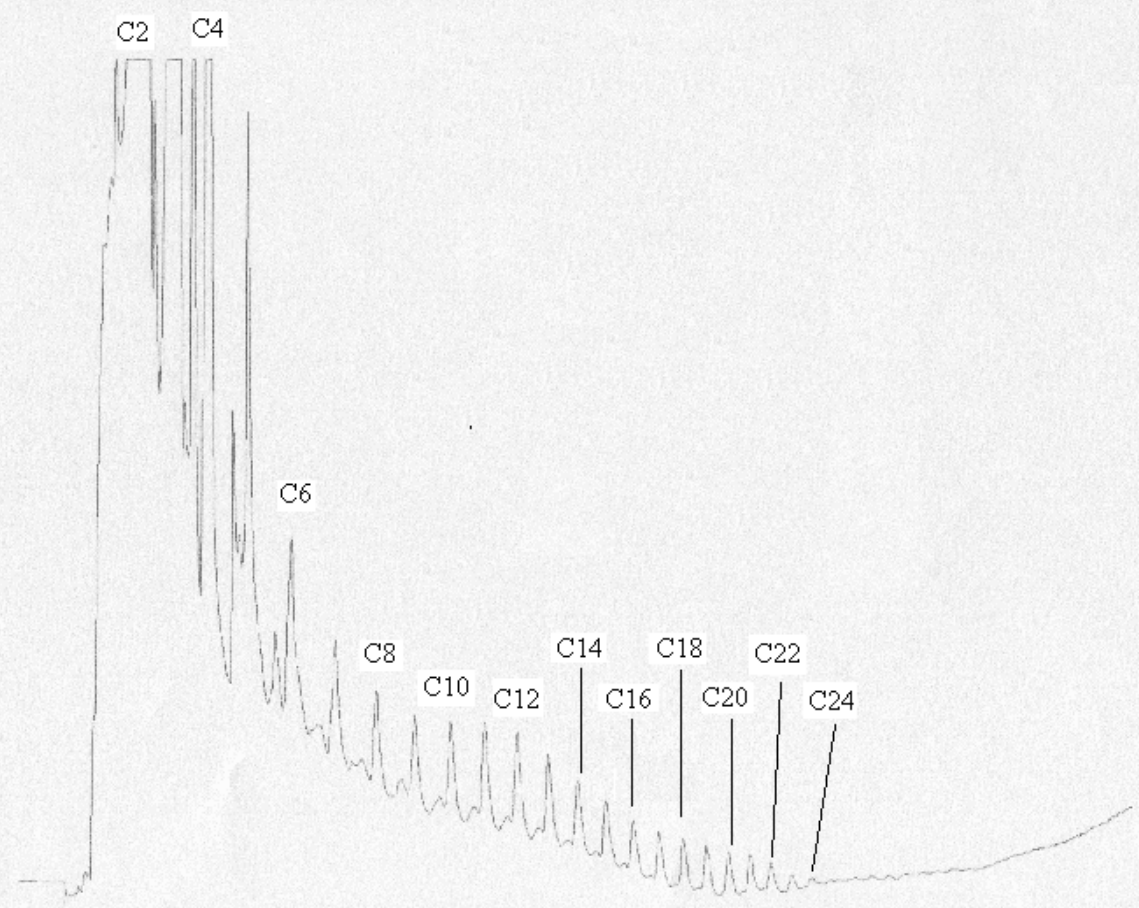

Figure 2. The GC chromatograph of the alcohol product using SIMDIS-2887 column and FI detector. 


\title{
Production of Hydrogen and Carbon Nanotubes by Catalytic Decomposition of Methane
}

\author{
Devadas Panjala, Naresh Shah, and Gerald Huffman, University of Kentucky
}

Production of pure hydrogen from hydrocarbons, particularly methane, the major component of natural gas, has great practical importance. Traditionally, dry (with $\mathrm{CO}_{2}$ ) reforming, wet (with $\mathrm{H}_{2} \mathrm{O}$ ) reforming, and partial oxidation of methane are employed to produce synthesis gas. Converting $\mathrm{CO}$ in synthesis gas using the water-gas shift reaction then produces a relatively pure hydrogen stream. However, this hydrogen still contains enough $\mathrm{CO}$ to poison the catalysts used in PEM electrochemical fuel cells. A reverse methanation reaction has to be carried out to reduce the $\mathrm{CO}$ concentration to sub-ppm levels. Non-oxidative catalytic decomposition of hydrocarbons to produce pure hydrogen is an alternative route to avoid the presence of $\mathrm{CO}$. In the current investigation, nano-scale ferrihydrite and binary ferrihydrites supported on alumina were subjected to various pre-treatments, and were found to be effective catalysts for methane decomposition.

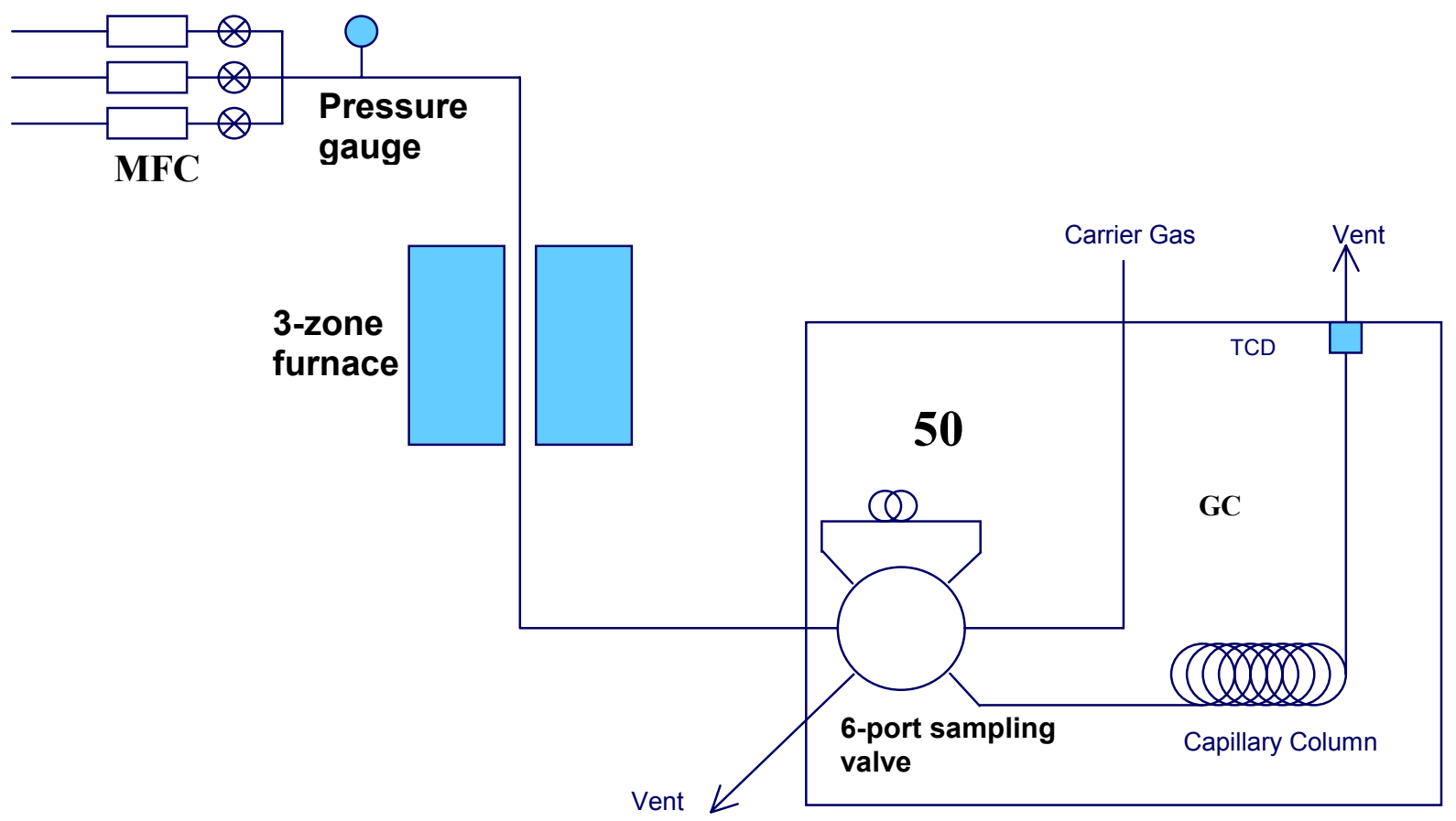

Figure 1: Schematic of experimental set-up for studying catalyst performance for decomposition of methane.

Figure 1 is a schematic of experimental set-up used for studying the catalyst performance. A calibrated volume of undiluted reactant (methane) stream is passed through a catalyst bed. The product gas stream did not contain any appreciable amounts of $\mathrm{C}_{2}$ and higher hydrocarbons. Except in the case of non-catalytic (thermal) cracking, there was complete absence of any liquid products in all experiments. 


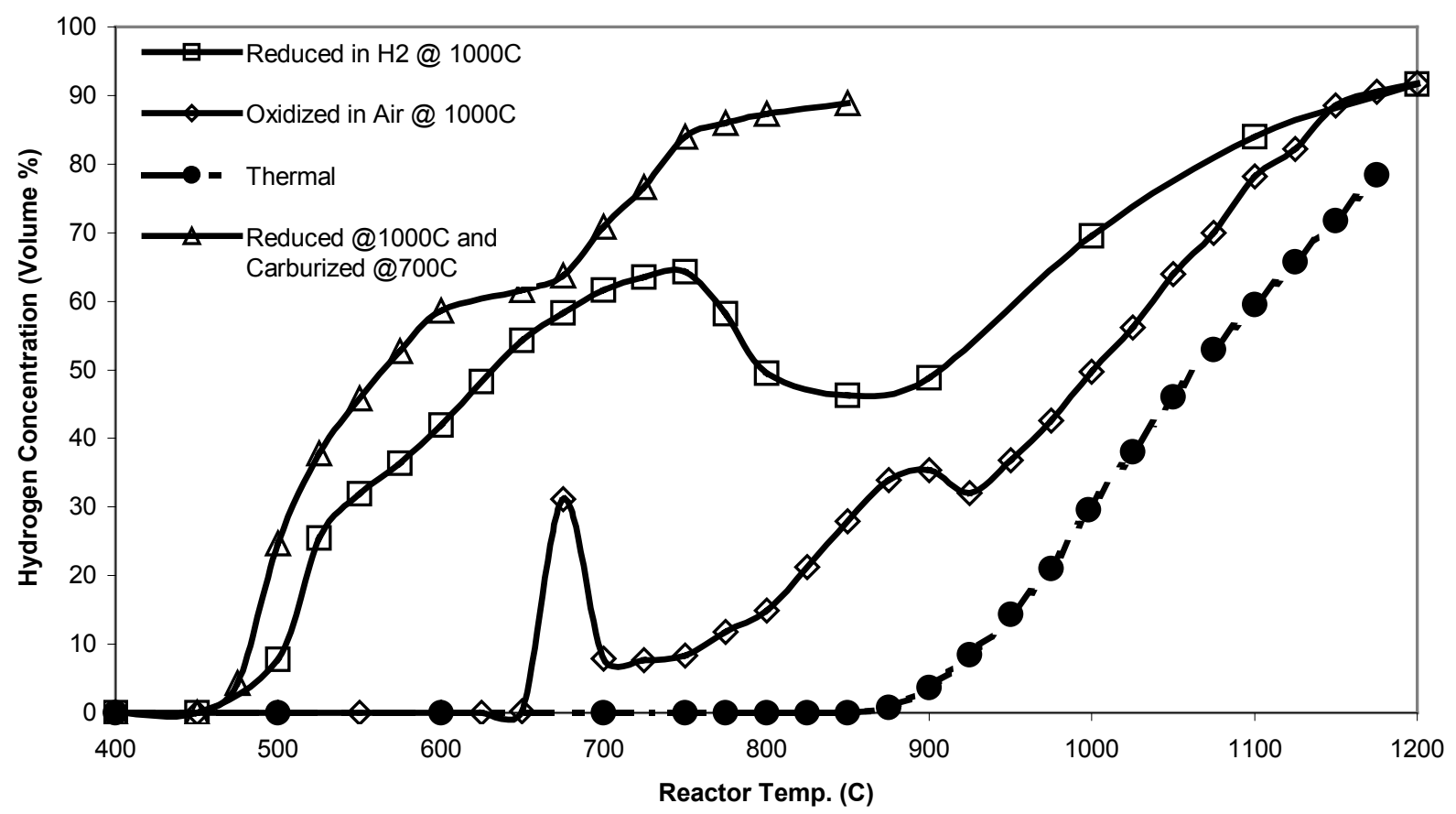

Figure 2: Effect of different pretreatments on catalytic methane decomposition using $5 \% \mathrm{Fe} /$ alumina catalysts.

Figure 2 shows the effect of different pretreatments on $5 \% \mathrm{Fe} /$ alumina catalysts for the methane cracking reaction. For clarity, no methane concentrations are plotted; they are complimentary to the hydrogen concentrations $\left(\% \mathrm{CH}_{4}=100-\% \mathrm{H}_{2}\right)$. Oxidized $\mathrm{Fe}$ is not an active catalyst. However, under reaction conditions, it shows some activity, which may be due to partial conversion to metallic/carbide state. There is not much difference in activity between the prereduced catalyst and the pre-reduced and pre-carburized catalyst. This may be because the metallic phase converts to the carbide phase under reaction conditions. That is, the catalyst state may be essentially the same in both reaction experiments, even though they were pre-treated to produce different states. Only the reduction pre-treatment was carried out for most of the subsequent experiments.

Figure 3 compares the observed $\mathrm{H}_{2}$ concentrations as a function of increasing temperature for all of the different catalysts tested after a reduction pre-treatment at $700{ }^{\circ} \mathrm{C}$. All of the binary catalysts cause substantial reductions in the methane, decomposition temperature. The largest decrease, $500{ }^{\circ} \mathrm{C}$, is produced by the $0.5 \% \mathrm{Pd}-4.5 \% \mathrm{Fe} / \mathrm{Al}_{2} \mathrm{O}_{3}$ catalyst. It is apparent that the bimetallic supported catalysts are significantly more active than the monometallic supported catalysts. 


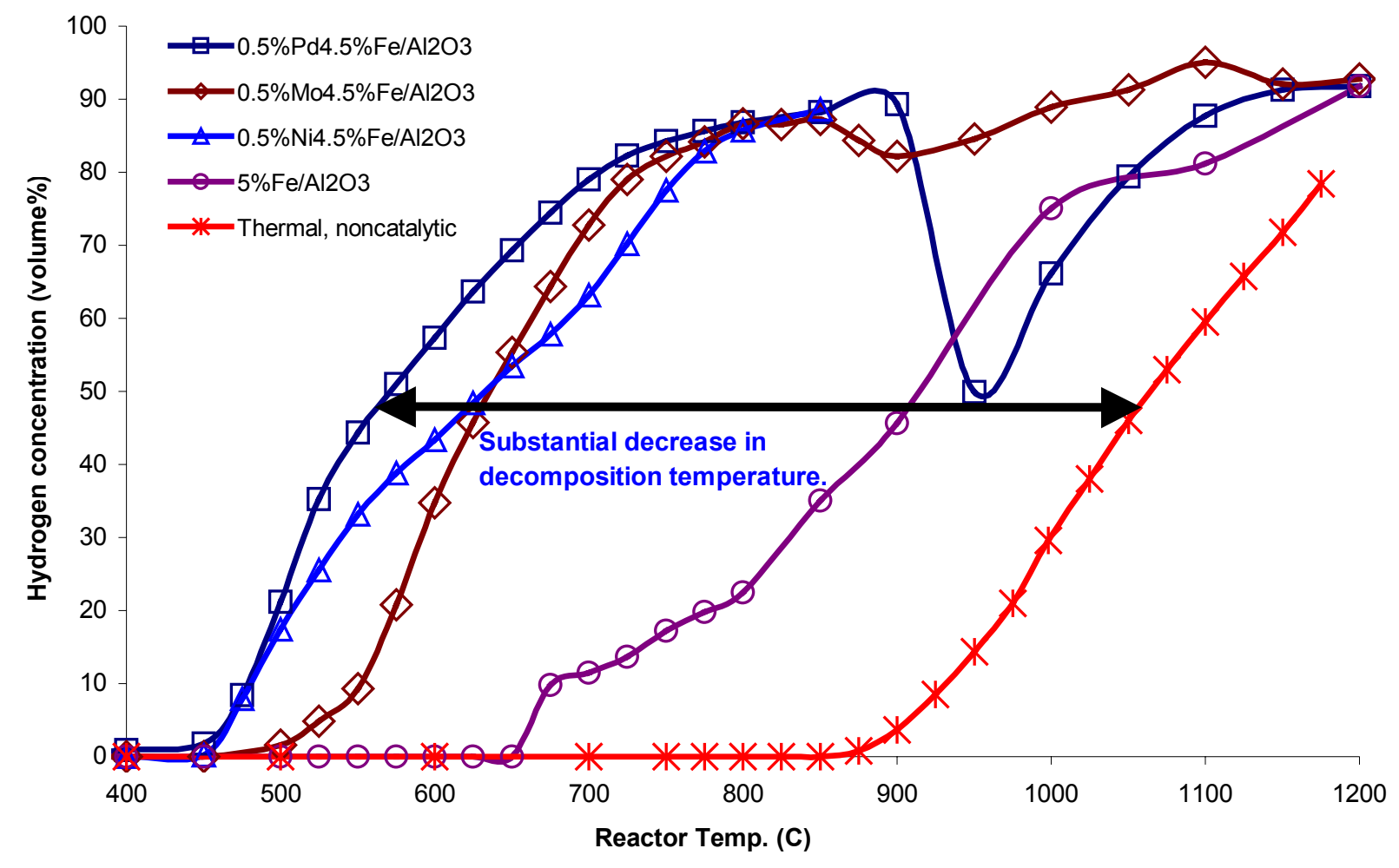

Figure 3. Comparison of alumina supported binary Pd-Fe, Mo-Fe and Ni-Fe catalysts prereduced at $700{ }^{\circ} \mathrm{C}$ for hydrogen production.

Decomposition of methane converts a gaseous methane inlet stream to a gaseous hydrogen outlet stream and a solid carbon. It is believed that methyl radicals polymerize to form cyclic and aromatic precursors to graphitic soot particles. During non-catalytic, thermal decomposition experiments, we found that smooth and shiny graphitic film covers the entire heated section of the reactor as well as the catalyst support and quartz wool. It is very difficult to remove this film. Exposure to a strong oxidizer (air, rather than $\mathrm{CO}_{2}$ or steam) at relatively high temperature $\left(>700{ }^{\circ} \mathrm{C}\right)$ is required to oxidize this tenacious film. Exposure to this strongly oxidizing atmosphere also oxidizes the metallic catalyst and it has to be re-reduced to recover its activity for methane decomposition.

The form of carbon produced is quite different for catalytic decomposition of methane at lower $\left(\sim 700{ }^{\circ} \mathrm{C}\right)$ temperatures. Figure 4 is an SEM image showing that the most $(>90 \%)$ of the carbon formed under these conditions is in the form of carbon nanotubes. Carbon fibers (Figure 5) were observed in very small amounts $(<5 \%)$ and only at higher reactor temperatures, where the catalysts are not so active.

High-resolution transmission electron microscopy (HRTEM) showed that the nanotubes were multi-walled and that most of the nanotube ends did not contain catalyst particles (figure 6). This indicates that the binary metallic catalyst particles are anchored at the support surface and the nanotubes continue to grow upwards from the catalysts particles. However, quite a few 
nanotubes were observed that contained metallic Fe particles within the tube (figure 7). EDX spectra showed that such particles did not contain the secondary element, indicating poorer metal-support anchoring for catalyst particles containing only iron and suggesting that the secondary element may play a critical role in the anchoring mechanism. This topic is under further investigation. 


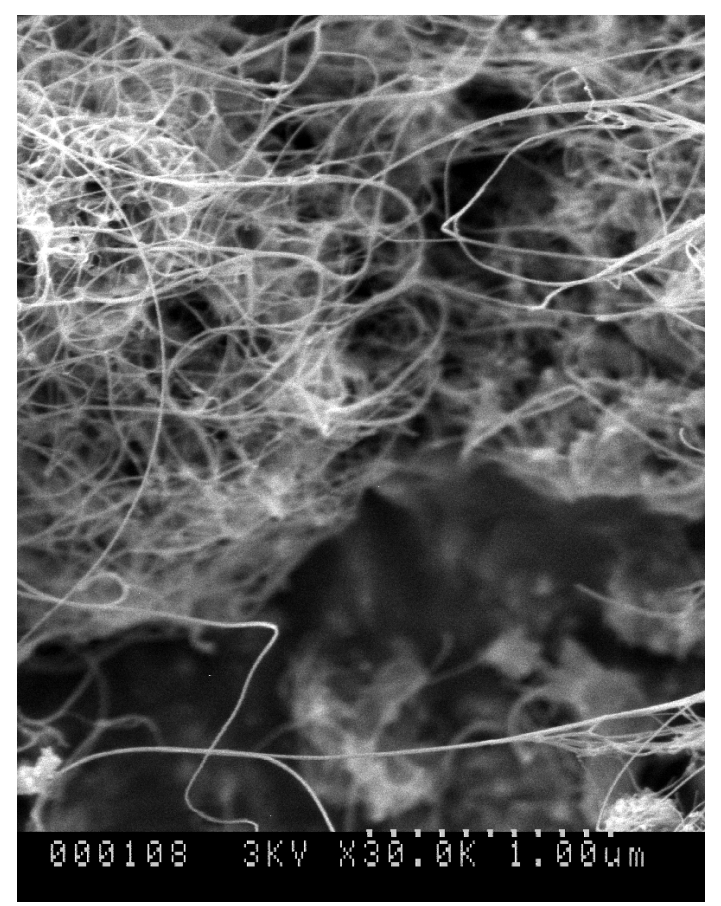

Figure 4. SEM image of multi-walled

carbon nanotubes grown by decomposing undiluted methane over pre-reduced (at 1000C) $0.5 \% \mathrm{Mo} 4.5 \% \mathrm{Fe} / \mathrm{Al}_{2} \mathrm{O}_{3}$ catalyst at $900{ }^{\circ} \mathrm{C}$ reactor temperature.

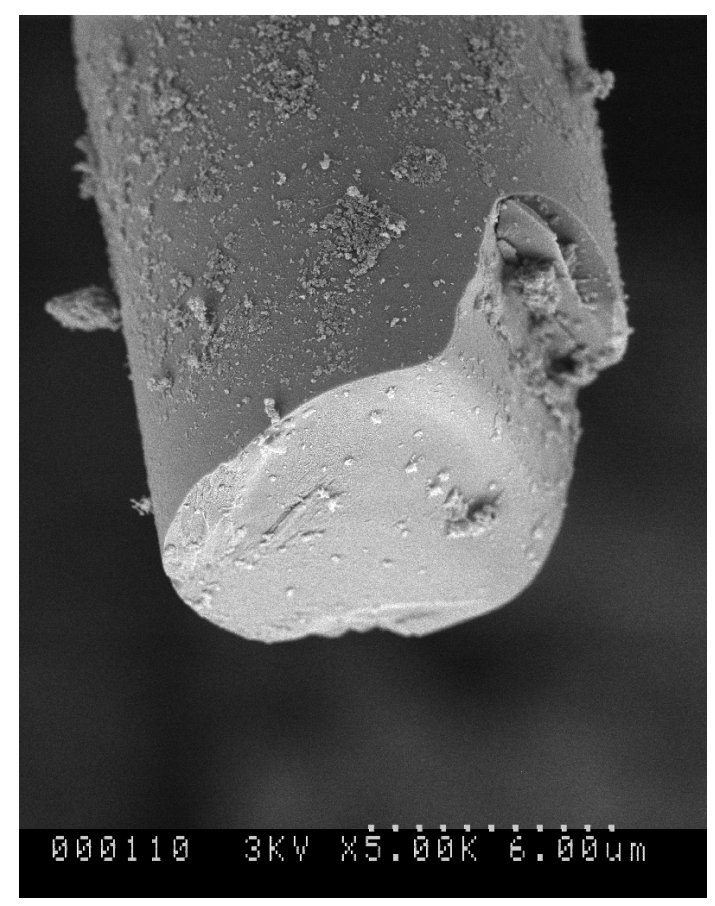

Figure 5. SEM image of carbon nano-fiber (whisker) grown by decomposing undiluted methane over as-prepared $0.5 \% \mathrm{Pd}$ $4.5 \% \mathrm{Fe} / \mathrm{Al}_{2} \mathrm{O}_{3}$ catalyst at $850{ }^{\circ} \mathrm{C}$ reactor temperature. 
In conclusion, it has been demonstrated that alumina supported binary Fe-Pd, Fe-Mo, and Fe-Ni catalysts are quite active for catalytic decomposition of methane, yielding a pure hydrogen stream and a potentially valuable carbon nanotube byproduct. Reduced activity of these catalysts due to carbon deposition can be recovered by an oxidative regeneration step. If this regeneration is carried out with $\mathrm{CO}_{2}$, it yields a rather pure $\mathrm{CO}$ stream, which is valuable for many $\mathrm{C} 1$ reactions.

A more detailed summary of this work has been prepared and submitted to Energy \& Fuels. Presentations on the work have recently been made at the American Chemical Society meeting in San Diego and at the North American Catalysis Meeting in Toronto. A patent disclosure has also been filed.

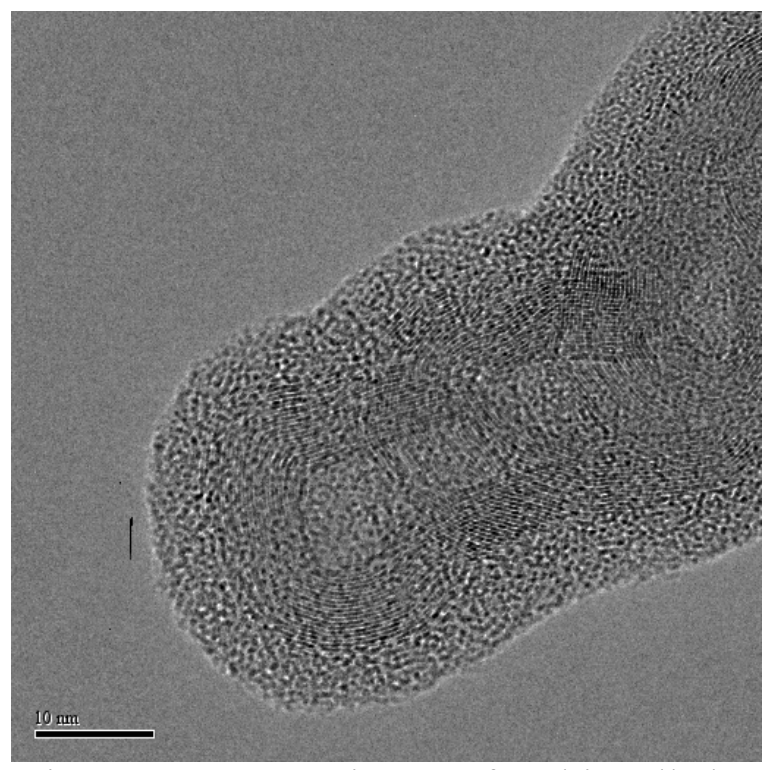

Figure 6. HRTEM image of multi-walled carbon nanotubes grown by decomposing undiluted methane over as-prepared $0.5 \% \mathrm{Pd}-4.5 \% \mathrm{Fe} / \mathrm{Al}_{2} \mathrm{O}_{3}$ catalyst at $600{ }^{\circ} \mathrm{C}$ reactor temperature. Note the absence of any metallic particle at the nanotube ends.

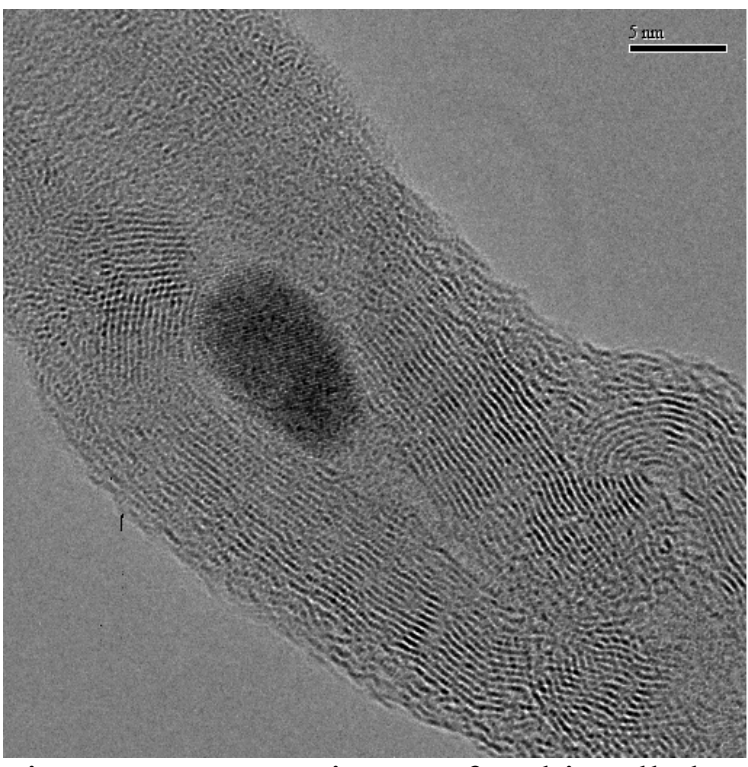

Figure 7. HRTEM image of multi-walled carbon nanotube grown by decomposing undiluted methane over pre-reduced (at 1000C) $0.5 \% \mathrm{Mo}-4.5 \% \mathrm{Fe} / \mathrm{Al}_{2} \mathrm{O}_{3}$ catalyst at $600{ }^{\circ} \mathrm{C}$ reactor temperature. An EDX spectrum showed the particle to be pure Fe. 


\section{Investigation of the Molecular Structure of Nanoscale, Binary $\mathrm{Fe} / \mathrm{M} / \mathrm{Al}_{2} \mathrm{O}_{3}$ catalysts by XAFS and Mössbauer Spectroscopy}

N. Shah, D. Panjala, S. Pattanaik, F.E. Huggins, and G.P. Huffman, University of Kentucky

\section{In situ XAFS Spectroscopy}

A major problem in determining catalytic reaction mechanisms is assessing the state of the catalyst during the reaction and relating that to the product distribution. While measurements of catalyst structure before and after reaction often provide significant insight, active metal-based catalysts often have an extremely fine particle size distribution and undergo spontaneous oxidation when they are removed from the reactor and exposed to air prior to examination.

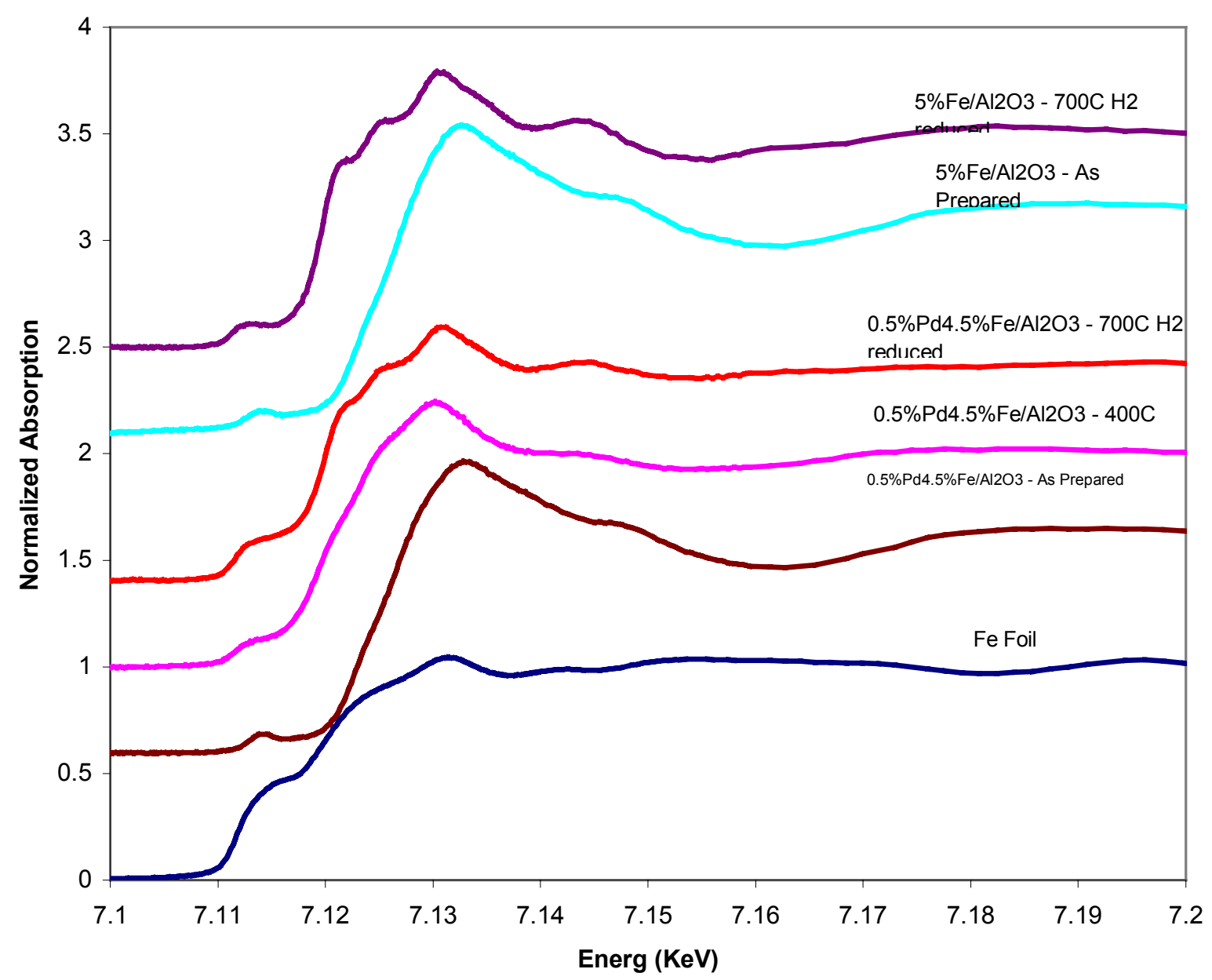

Figure 1. Fe K-edge in situ XAFS of as prepared and reduced under flowing hydrogen spectra of $5 \% \mathrm{Fe} / \mathrm{Al}_{2} \mathrm{O}_{3}$ and $0.5 \% \mathrm{Pd} 4.5 \% \mathrm{Fe} / \mathrm{Al}_{2} \mathrm{O}_{3}$ catalysts. 
A novel in situ XAFS cell optimized for investigation of $\mathrm{C} 1$ chemistry processes has been built and tested. Figure 1 shows Fe K-edge XAFS spectra of a $5 \% \mathrm{Fe}_{\mathrm{Al}} \mathrm{O}_{3}$ catalyst and a $0.5 \% \mathrm{Pd}$ $4.5 \% \mathrm{Fe} / \mathrm{Al}_{2} \mathrm{O}_{3}$ catalyst in their as-prepared state and during reduction in flowing hydrogen at 700 ${ }^{\circ} \mathrm{C}$. Both catalysts show partial conversion of the ferrihydrite phase to a metallic phase under reducing conditions.

\section{Mossbauer Spectroscopy}

To better understand the effect of pre-reduction treatment on the behavior of catalysts, $5 \% \mathrm{Fe} / \mathrm{Al}_{2} \mathrm{O}_{3}, 0.5 \% \mathrm{Mo}-4.5 \% \mathrm{Fe} / \mathrm{Al}_{2} \mathrm{O}_{3}, 0.5 \% \mathrm{Ni}-4.5 \% \mathrm{Fe} / \mathrm{Al}_{2} \mathrm{O}_{3}$ and $0.5 \% \mathrm{Pd}-4.5 \% \mathrm{Fe} / \mathrm{Al}_{2} \mathrm{O}_{3}$ catalysts were treated under flowing hydrogen at $700{ }^{\circ} \mathrm{C}$ and $1000{ }^{\circ} \mathrm{C}$ and examined using Mossbauer spectroscopy. Figures 2-5 are for the catalysts reduced at $700{ }^{\circ} \mathrm{C}$ and figures $6-9$ are for the catalysts reduced at $1000{ }^{\circ} \mathrm{C}$. The following tables show the distribution of iron phases in these various catalysts. All catalysts in as-prepared state show the iron to present as ferrihydrite.

Catalysts reduced at 700

\begin{tabular}{|l|l|c|c|c|c|}
\hline MK & Catalyst & $\mathrm{Fe}^{++}$ & $\mathrm{Fe}^{++}$ & Fe Alloy & Fe Metal \\
\hline 2675 & $5 \% \mathrm{Fe} / \mathrm{Al}_{2} \mathrm{O}_{3}$ & 72 & 17 & & 11 \\
\hline 2602 & $0.5 \% \mathrm{Mo} 4.5 \% \mathrm{Fe} / \mathrm{Al}_{2} \mathrm{O}_{3}$ & 66 & 15 & $16(\bullet)$ & 3 \\
\hline 2678 & $0.5 \% \mathrm{Ni} 4.5 \% \mathrm{Fe} / \mathrm{Al}_{2} \mathrm{O}_{3}$ & 68 & 24 & & 8 \\
\hline 2673 & $0.5 \% \mathrm{Pd} 4.5 \% \mathrm{Fe} / \mathrm{Al}_{2} \mathrm{O}_{3}$ & 54 & 23 & & 22 \\
\hline
\end{tabular}

Catalysts reduced at 1000

\begin{tabular}{|l|l|c|c|c|c|}
\hline MK & Catalyst & $\mathrm{Fe}^{++}$ & $\mathrm{Fe}^{+++}$ & Fe Alloy & Fe Metal \\
\hline 2625 & $5 \% \mathrm{Fe} / \mathrm{Al}_{2} \mathrm{O}_{3}$ & & 4 & & 96 \\
\hline 2600 & $0.5 \% \mathrm{Mo} 4.5 \% \mathrm{Fe} / \mathrm{Al}_{2} \mathrm{O}_{3}$ & & 29 & $48.5(\bullet)$ & 22.5 \\
\hline 2679 & $0.5 \% \mathrm{Ni} 4.5 \% \mathrm{Fe} / \mathrm{Al}_{2} \mathrm{O}_{3}$ & & & $46(\bullet)$ & $54(\bullet)$ \\
\hline 2666 & $0.5 \% \mathrm{Pd} 4.5 \% \mathrm{Fe} / \mathrm{Al}_{2} \mathrm{O}_{3}$ & & & 1 & 99 \\
\hline
\end{tabular}

(*) Fe exists as $\mathrm{Mo}_{2} \mathrm{Fe}$

( $) \mathrm{Ni}$ is substituted for $\mathrm{Fe}$ in austenite phase

(•) evidence of Ni substitution for Fe in Fe metal 

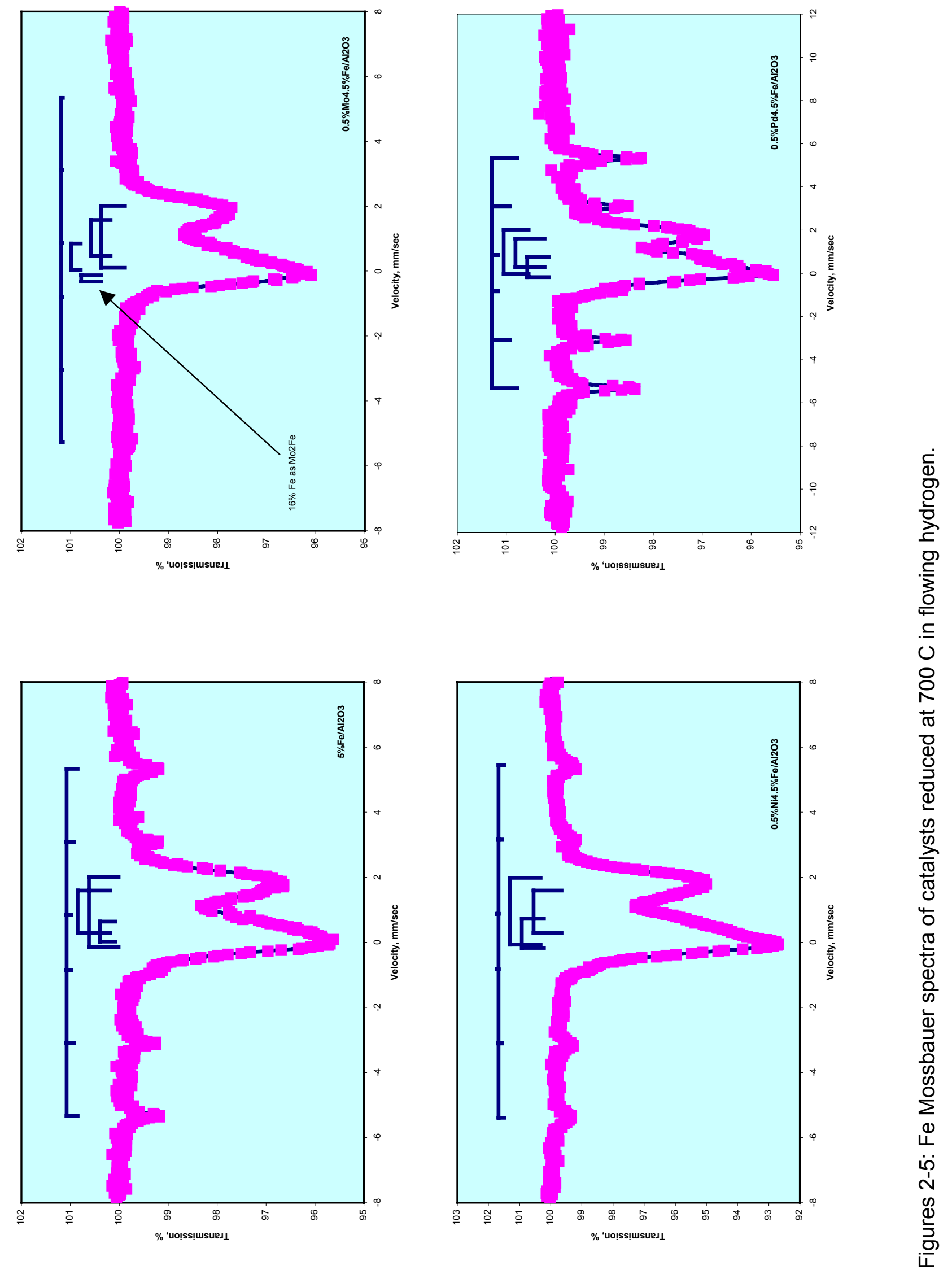

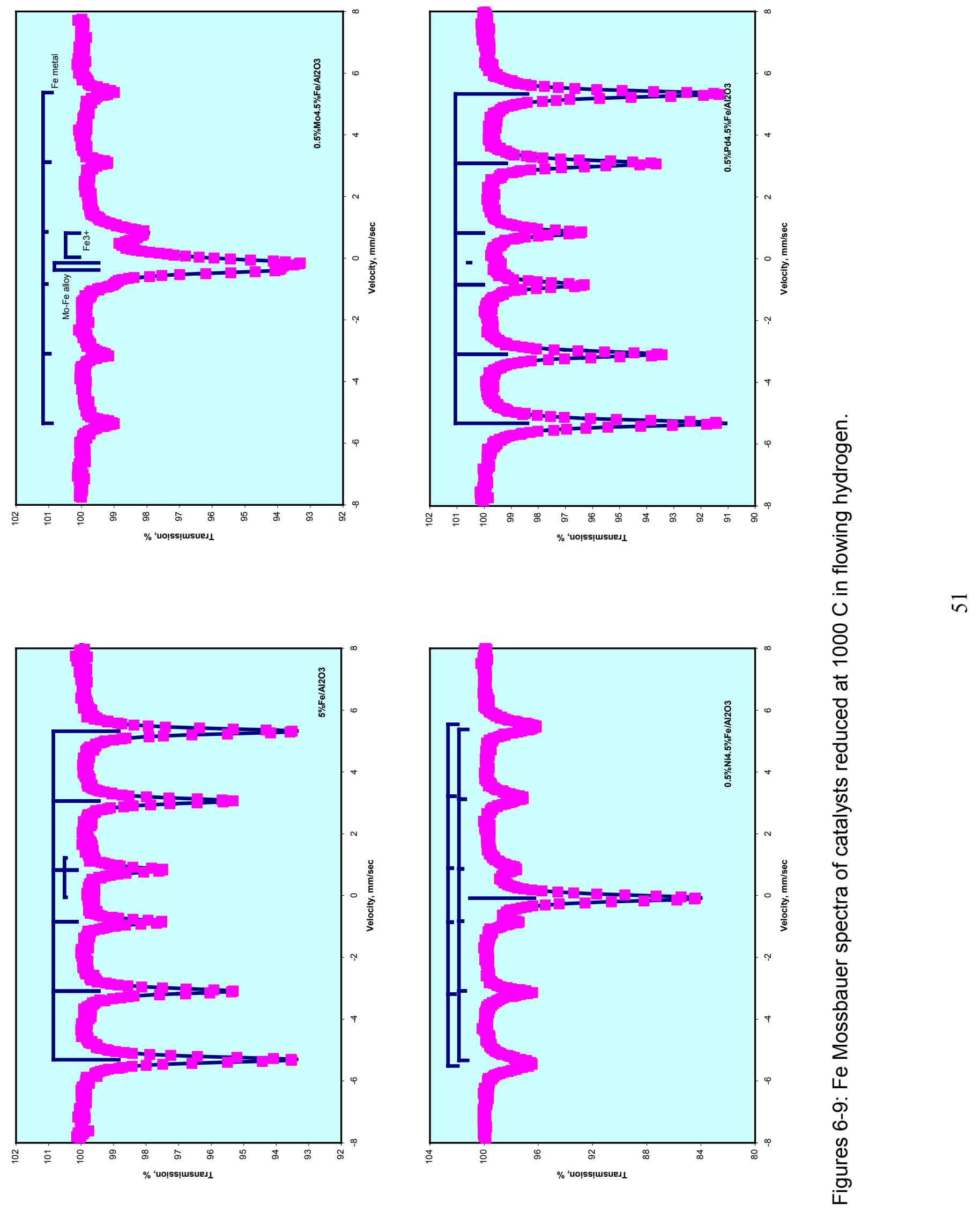


\title{
Dry Reforming of Methane with Tungsten Carbide Catalyst
}

\author{
Mahesh V. Iyer, Lawrence Norcio, Edwin L. Kugler and Dady B. Dadyburjor \\ Department of Chemical Engineering \\ West Virginia University, P.O. Box 6102 \\ Morgantown, WV 26506-6102
}

\section{INTRODUCTION}

In recent years, the dry reforming of methane for the production of synthesis gas using carbon dioxide has received considerable attention as compared to conventional steam reforming (1-5). Methane reforming with carbon dioxide is appealing because it produces synthesis gas with higher purity and lower $\mathrm{H}_{2} / \mathrm{CO}$ ratio than either partial oxidation or steam reforming. This lower $\mathrm{H}_{2} / \mathrm{CO}$ ratio is a preferable feedstock for the Fischer-Tropsch synthesis with iron catalysts $(2,3)$. From the environmental perspective, methane reforming is enticing due to the reduction of carbon dioxide and methane emissions as both are viewed as harmful greenhouse gases. Besides, $\mathrm{CO}_{2}$ is frequently a significant component of natural gas. Consequently, reforming with $\mathrm{CO}_{2}$ eliminates extra processing steps for synthesis gas production.

Commercially, nickel is used for methane reforming reactions due to its lower cost compared to noble metals. However, nickel also catalyses carbon formation via methane decomposition and $\mathrm{CO}$ disproportionation (Boudouard reaction) (4). Thus, notable efforts have been concentrated on developing new catalysts, which are resistant to carbon formation. Sulfur passivated nickel catalysts and noble metals have been shown to exhibit resistance to carbon formation. But the low activity of sulfur passivated nickel and the high cost of noble metals promotes continued research for more active or less expensive catalysts.

Recently, there has been considerable interest in the catalytic properties of metal carbides $(5,6)$. The production of metal carbides is abundant and their price is cheap compared to noble metals. Boudart suggested that they could replace the rare and expensive noble metals in catalysis (7). Identifying better catalysts would reduce process costs for methanol, ammonia, and Fischer-Tropsch plants. There have been reports of tungsten and molybdenum carbide catalysts being active for the methane dry reforming reaction without any significant deactivation at high pressures and temperatures (5). The purpose of this study is to investigate the performance of the cobalt tungsten carbide catalyst $\left[\mathrm{Co}_{6} \mathrm{~W}_{6} \mathrm{C}\right]$ for the dry reforming of methane to produce synthesis gas and to understand the behavior of the reaction rates with varying partial pressures of methane and carbon dioxide. 


\section{EXPERIMENTAL}

The unsupported cobalt tungsten carbide $\left[\mathrm{Co}_{6} \mathrm{~W}_{6} \mathrm{C}\right]$ catalyst was obtained from Nanodyne Inc. The details of the preparation procedure can be obtained from U.S. Patent 5,138,111 (8). The catalyst-testing unit is as shown in Figure 1 and is similar to that used by Liu et al. (9). The entire system is computer controlled from which most of the operating conditions can be set. The computer logs in data automatically at operator-determined intervals. The unit has four lines for gas feed, each being independently controlled by a mass-flow controller. The differential reactor consists of a silica-lined stainless-steel tube placed in a single-zone furnace. The silica lining on the stainless tubes was applied at Restek Corp. The catalyst is placed in the center of the reactor, with the quartz chips placed upstream and downstream of the catalyst. The product stream is sampled immediately downstream using a gas-sampling valve. There is a cooling system between the reactor outlet and the sampling valve. The products are analyzed on-line by a gas chromatograph (GC), which provides quantitative analysis for $\mathrm{He}, \mathrm{H}_{2}, \mathrm{CO}, \mathrm{CH}_{4}, \mathrm{CO}_{2}$ and $\mathrm{H}_{2} \mathrm{O}$. Helium is used as the internal standard while argon serves as the carrier gas. The GC feed line from the sample loop is maintained at a temperature of $150{ }^{\circ} \mathrm{C}$ by wrapping the line with heating tapes. This prevents the water in the product stream from condensing before reaching the GC inlet. The reactor effluent (vapor phase) that is not passed through the GC is vented after passing through a scrubber. The entire unit is located in a walk-in hood. The computer continuously monitors alarms for $\mathrm{CO}$ and for flows of reactive gases, hood velocity, ambient hood temperature, reactor temperature, reactor pressure and electric power. The unit automatically shuts down in the event of hood failure, fire, power and air supply failure, or CO leak detection or if the gas flows or reactor temperature exceed any of the preset operating ranges.

\section{RESULTS AND DISCUSSION}

The silica-lined stainless steel reactor tube was first packed with quartz chips without any catalyst (blank run) to determine the reactivity of the reactor at different temperatures and feed ratios. Results show that the $\mathrm{CH}_{4}$ and $\mathrm{CO}_{2}$ conversions for the blank runs are small. The conversions from the catalytic runs were obtained by subtracting the molar rates of formation of any species as obtained by the blank runs from those of the catalytic runs.

The unsupported cobalt tungsten carbide catalyst was tested for activity at various temperatures and feed ratios. The particle size of the catalyst used was less than 38 microns. The catalyst was found to be very stable at $850{ }^{\circ} \mathrm{C}$ for a period of over 90 hours with a feed ratio of $\mathrm{CH}_{4} / \mathrm{CO}_{2}=1$ (Figure 2). The $\mathrm{CH}_{4}$ and $\mathrm{CO}_{2}$ conversions increased steadily with time at $850{ }^{\circ} \mathrm{C}$ and then stabilized at $82 \%$ and $78 \%$ respectively, with a $\mathrm{H}_{2} / \mathrm{CO}$ ratio close to 1 . When the reaction temperatures were subsequently decreased, the conversions were found to decrease, but were also stable. A similar trend was observed for the $\mathrm{H}_{2} / \mathrm{CO}$ ratio, which decreases as reaction temperature decreases. These trends lead to a working hypothesis that the catalyst is undergoing certain phase transformations. Evidence to these transformations will become apparent when the $\mathrm{X}$-ray diffraction patterns of the catalyst are obtained. The carbon balances obtained for the continuous experiments were better than $98 \%$. 
The catalyst was tested for activity at different partial pressures of $\mathrm{CH}_{4}$ and $\mathrm{CO}_{2}$ at 600 , 550 and $500{ }^{\circ} \mathrm{C}$. Figures 3 and 4 show the effects of varying the partial pressures of $\mathrm{CH}_{4}$ and $\mathrm{CO}_{2}$ on the reaction rates of methane reforming $\left(\mathrm{r}_{\mathrm{MR}}\right)$, reverse water gas shift $\left(\mathrm{r}_{\mathrm{RW}}\right)$, and carbon deposition $\left(r_{C D}\right)$ at $600{ }^{\circ} \mathrm{C}$. Similar trends were observed at lower temperatures. The reaction rates increase initially with increasing partial pressure, but later on approach a constant value as the partial pressures reach a higher value. These observations suggest a Langmuir-Hinshelwood model for rate kinetics.

\section{FUTURE WORK}

The future work includes testing the catalyst over a wider range of temperatures for different partial pressures of $\mathrm{CH}_{4}$ and $\mathrm{CO}_{2}$. The short-term goal includes modeling the rate expressions to fit the Langmuir-Hinshelwood model for rate kinetics. The long-term objectives include (1) carrying out mixed reforming studies by introducing steam into the feed mixture and (2) X-ray diffraction studies of the fresh and used catalysts, in collaboration with Prof. M. Seehra at West Virginia University.

\section{LITERATURE CITED}

(1) Ross J. R. H., Keulen van A. N. J., Hegarty M. E. S. and Seshan K., Catal. Today, $\underline{30}$, 193-199 (1996).

(2) Wang S., Lu. G.Q. and Millar G. J., Energy Fuels, 10, 896-904 (1996).

(3) Bradford M. C. J. and Vannice M. A., Catal. Rev.- Sci. Eng., 41 (1), 1-42 (1999).

(4) Seshan K., Barge T. H. W., Hally W., Keulen van A. N. J. and Ross J. R. H., Natural Gas Conversion II (Curry-Hyde H. E. and Howe R. F., eds.), Elsevier, Amsterdam pp. 285290 (1994).

(5) Claridge J. B., York A. P. E., Brungs A.J., Marquez-Alvarez C., Sloan J., Tsang S. C. and Green M. L. H., J. Catal., 180, 85-100 (1998).

(6) York A. P. E., Chem. Brit., 25-27 (1999).

(7) Levy R. B. and Boudart M., "Platinum-Like Behavior of Tungsten Carbide in Surface Catalysis", Science, 181, 547-549 (1973).

(8) Kugler E. L., McCandlish L. E., Jacobson A. J. and Chianelli R. R., US Patent 5,138,111 (1992).

(9) Liu Z., Li X., Close M. R., Kugler E. L., Peterson J. L. and Dadyburjor D.B., Ind. Eng. Chem. Res., 36, 3085-3093 (1997). 


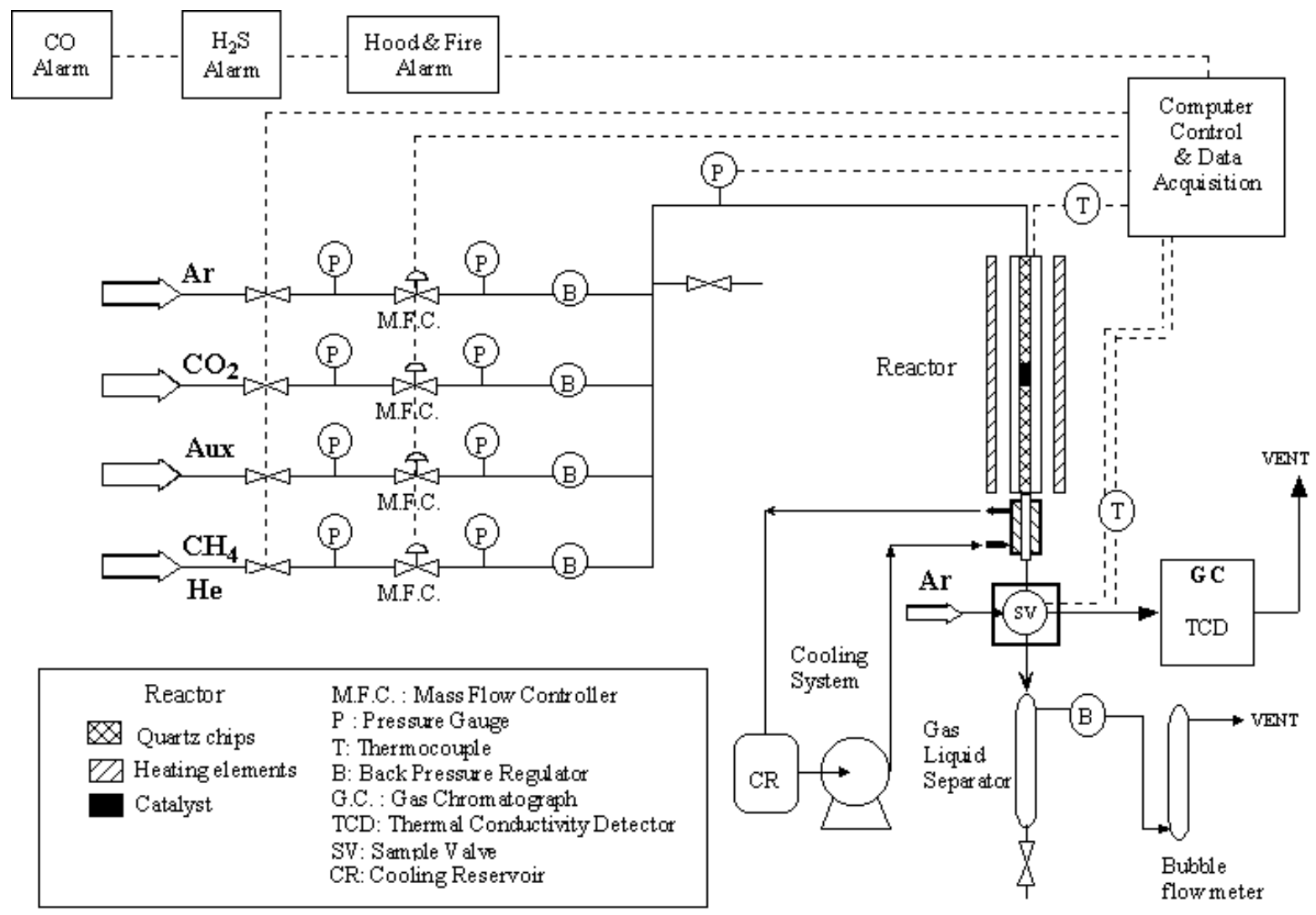

Figure 1. Flow sheet of the catalyst-testing unit 


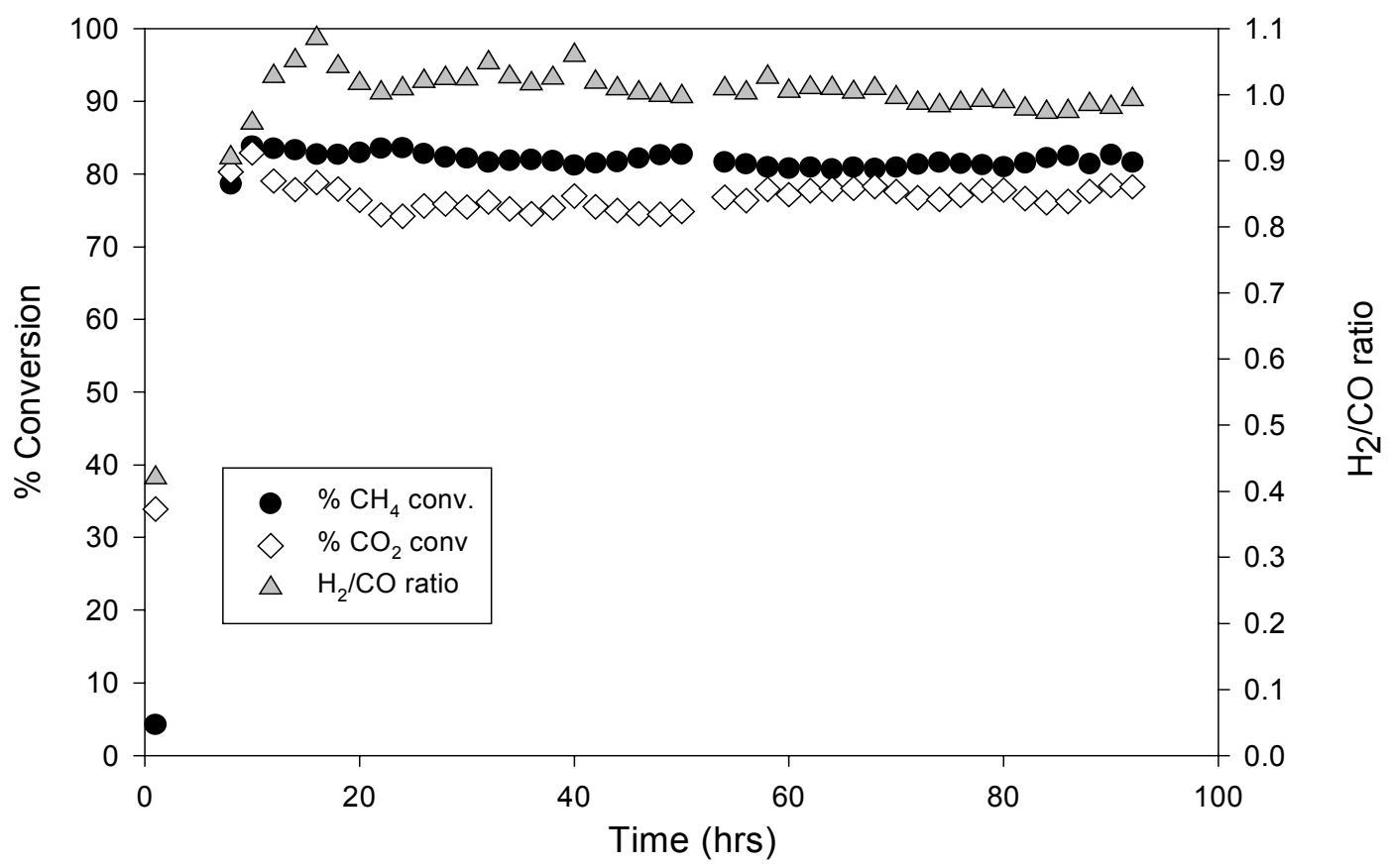

Figure 2. Lifetime study of the $\mathrm{Co}_{6} \mathrm{~W}_{6} \mathrm{C}$ catalyst for the dry reforming reaction $\left(850{ }^{\circ} \mathrm{C}\right.$, particle size $<38$ microns, $\mathrm{P}_{\mathrm{CH} 4}=1$ bar, $\mathrm{P}_{\mathrm{CO} 2}=1$ bar) 


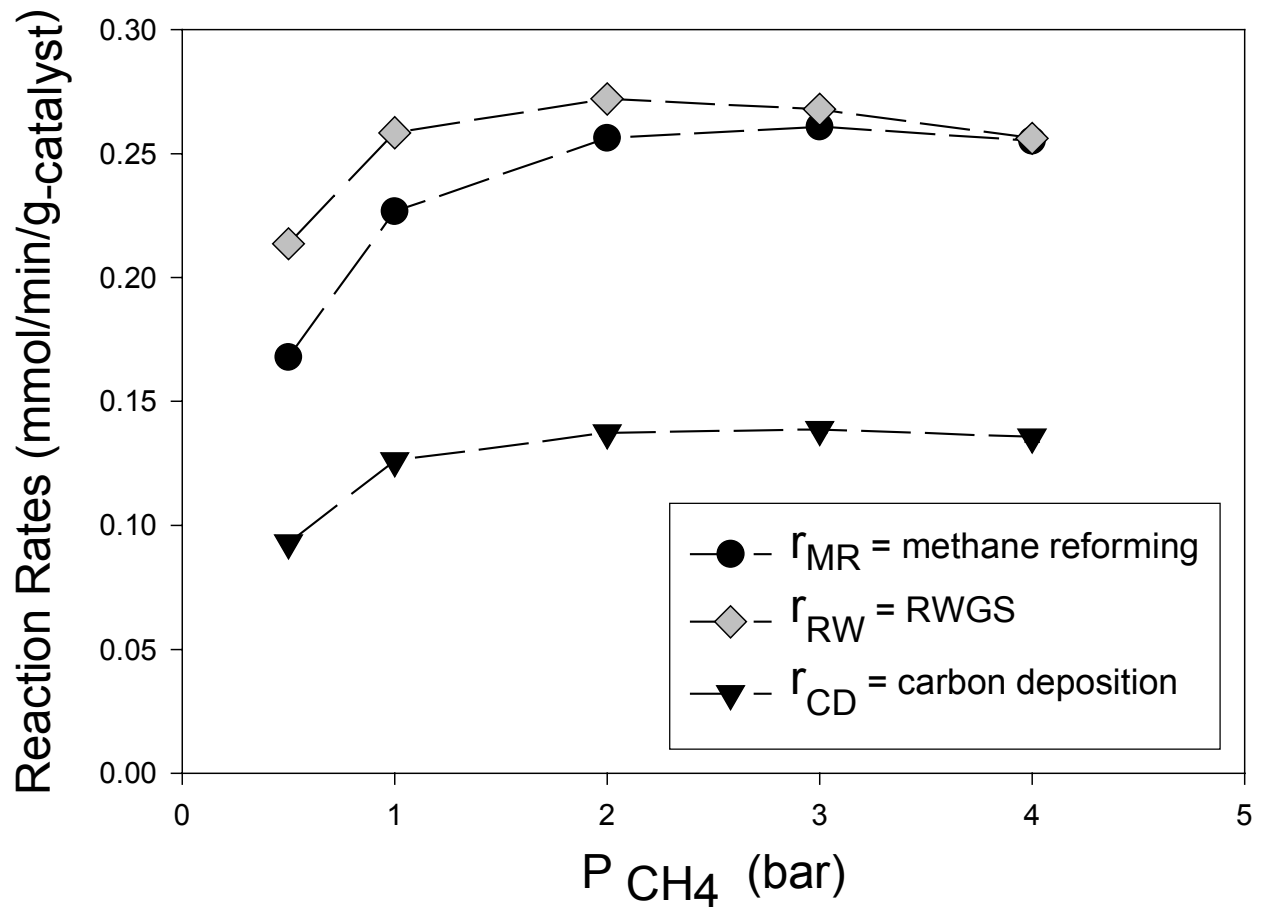

Figure 3. Effect of varying $\mathrm{P}_{\mathrm{CH} 4}$ on the reaction rates $\left(600{ }^{\circ} \mathrm{C}\right.$, particle size $<38$ microns, $\mathrm{P}_{\mathrm{CO} 2}=$ 1 bar) 


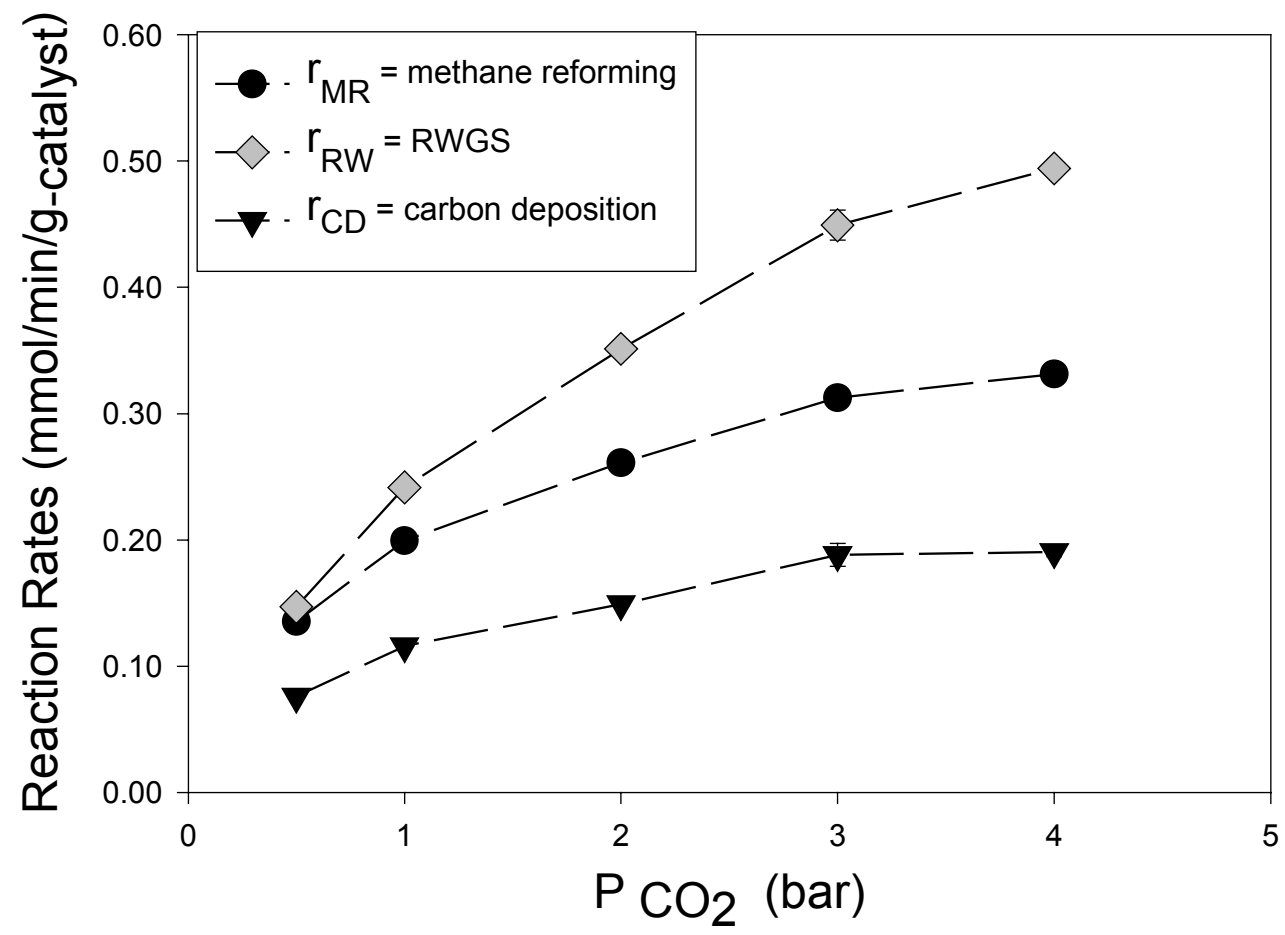

Figure 4. Effect of varying $\mathrm{P}_{\mathrm{CO} 2}$ on the reaction rates $\left(600{ }^{\circ} \mathrm{C}\right.$, particle size $<38$ microns, $\mathrm{P}_{\mathrm{CH} 4}=$ 1 bar) 


\title{
Analytical Characterization of Catalyst Structure and Product Distribution
}

\author{
M. S. Seehra and A. Punnoose, West Virginia University
}

\section{Objectives}

Determination of reaction mechanisms in a catalytic reaction requires an understanding of the electronic and structural properties of the catalyst and catalyst support under reaction conditions and their relationship to product distribution. This information is essential in improving existing catalysts and designing new catalysts. To that end, our work under this task involves in-situ and ex-situ investigations of a number of catalysts using the techniques of x-ray diffraction (XRD), electron spin resonance (ESR) spectroscopy, SQUID magnetometry, and photoacoustic/FTIR spectroscopy. We are working with three research groups in CFFLS (Eyring et al at Utah, Wender et al at Pittsburgh, and Huffman et al at Kentucky) to obtain the relevant samples of catalysts and to coordinate our findings with their results of catalytic activity and product distributions. A brief summary of these results is given below, with details available in the cited publications.

\section{Summary of the results}

Catalysts for the production of diethyl carbonate:

Eyring et al at Utah are investigating the use of $\mathrm{CuCl}_{2} / \mathrm{PdCl}_{2} / \mathrm{AC}$ (activated carbon) catalysts for the production of diethyl carbonate (DEC), an alternative to MTBE as a fuel additive. We have

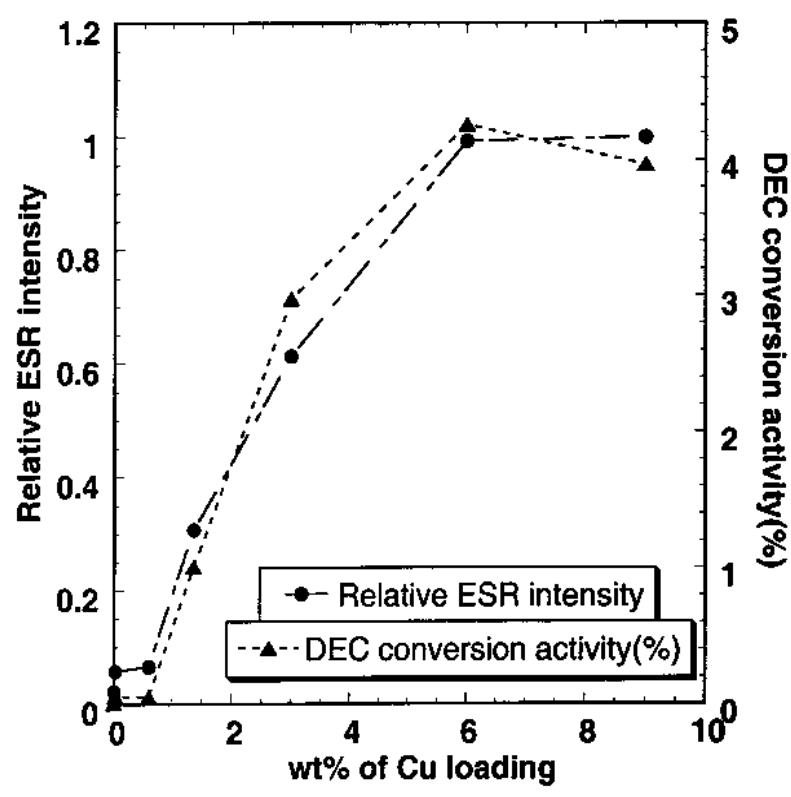

Fig. 1. Plot showing the variation of the ESR intensity of the $\mathrm{Cu}^{2+}$ surface species and the $\%$ DEC yield as a function of $\mathrm{Cu}$ loading.

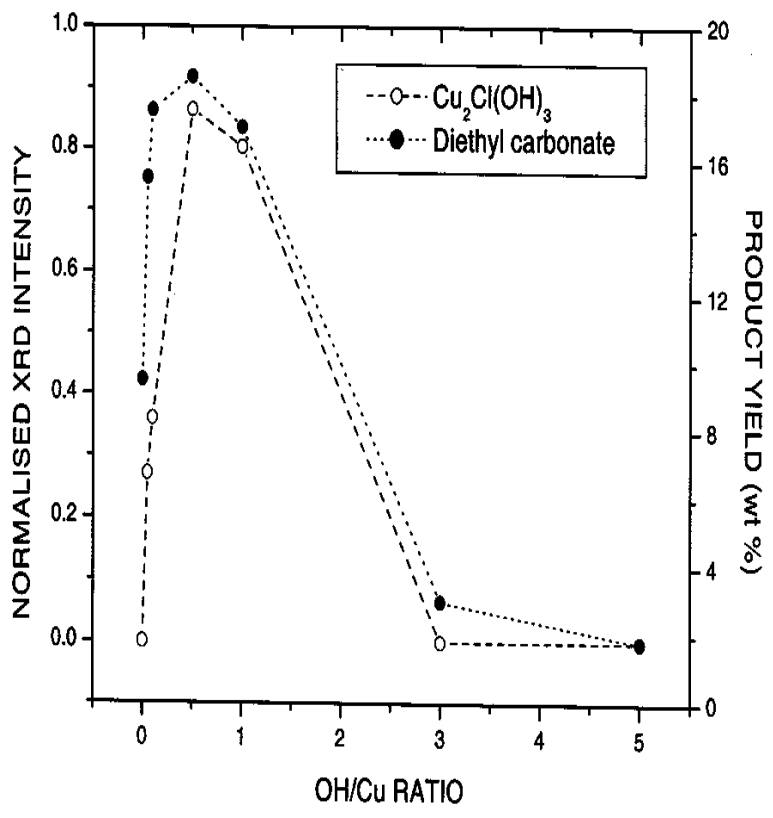

Fig. 2. Variations of the normalized XRD intensity of the paratacamite peak and the \%DEC yield as a function of 
investigated about 20 samples of these catalysts with different loadings of $\mathrm{CuCl}_{2}$ and $\mathrm{PdCl}_{2}$ and the catalysts pretreated with $\mathrm{KOH}$, which have shown higher selectivity and yields for DEC. We have carried out room temperature XRD investigations and ESR spectroscopy at different temperatures ( 5 to $300 \mathrm{~K}$ ) on all these samples and coordinated our results with the \% yield of DEC obtained by Eyring et al. Details of these results are planned to be published as two consecutive papers in the same journal [1,2]. The major conclusions from our studies [1] are summarized below.

For $\mathrm{CuCl}_{2} / \mathrm{AC}$ samples, we have identified two types of $\mathrm{Cu}^{2+} \mathrm{ESR}$ signals: $\mathrm{Cu}^{2+}$ attached to $\mathrm{AC}$ support and clusters of $\mathrm{CuCl}_{2}$ nanoparticles. A close correlation between the $\%$ yield of DEC and the intensity of the $\mathrm{Cu}^{2+}$ species is observed (Fig. 1), although the \% yield of DEC is only about $4 \%$ with 6 to $9 \mathrm{wt} \% \mathrm{Cu}$ loading. The addition of $\mathrm{PdCl}_{2}$ increases this yield to about $10 \%$. The pretreatment of $\mathrm{PdCl}_{2} / \mathrm{CuCl}_{2} / \mathrm{AC}$ catalysts with $\mathrm{KOH}$ increases the yield to about $18 \%$ for $\mathrm{x}=\mathrm{OH} / \mathrm{Cu}=1$. In our XRD experiments, we see the presence of paratacamite, $\mathrm{Cu} 2 \mathrm{Cl}(\mathrm{OH})_{3}$, whose XRD intensity correlates well with the \% yield of DEC(Fig. 2). For $x>1$, the activity drops dramatically (Fig. 2), with the simultaneous conversion of paratacamite to calumetite, $\mathrm{Cu}(\mathrm{OH}, \mathrm{Cl})_{2} .2 \mathrm{H}_{2} \mathrm{O}$. Thus paratacamite appears to be more efficient than $\mathrm{CuCl}_{2}$ and certainly calumetite for regeneration of $\mathrm{Pd}(0)$ to $\mathrm{PdCl}_{2}$ to continue the reaction. Details of our finding are given in Ref. 1 whereas the details of the preparation of the catalysts and production of DEC are given in the paper by Dunn/Eyring et al[2]

\section{$\mathrm{Pt}_{0.5} / \mathrm{WO}_{x} / \mathrm{ZrO}_{2}(\mathrm{PWZ})$ catalysts for the hydroisomerization of long-chain linear alkanes:}

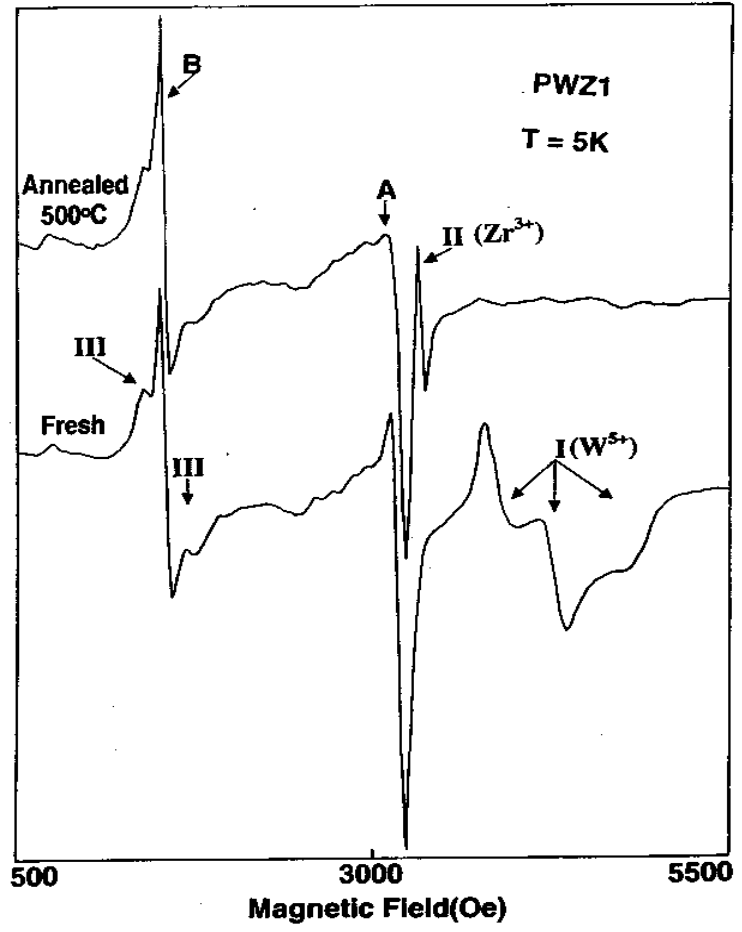

Fig. 3. ESR spectra of fresh and annealed PWZ catalyst showing the $\mathrm{W}^{5+}$ and $\mathrm{Zr}^{3+}$ signals.
Wender et al[3] at Pittsburgh have used these catalysts for the hydroisomerization of long chain linear alkanes since the PWZ catalysts provide good stability and selectivity. We have investigated the structural and electronic properties of the three constituents of the PWZ catalysts, viz $\mathrm{Pt}, \mathrm{WO}_{\mathrm{x}}$ and $\mathrm{ZrO}_{2}$ using XRD, low temperature ESR spectroscopy, temperature variation of the magnetic susceptibility $\chi$ and thermogravimetric analysis (TGA). We have investigated the effects of preparation procedures, heat treatments to $1000 \mathrm{C}$, tungsten loading and chemical reactions on the properties of the three constituents. Our results, a summary of which is given below, are detailed in two publications $[4,5]$

$\mathrm{ZrO}_{2}$ has two phases, monoclinic (m) and tetragonal (t). Our results show that with increasing $\mathrm{WO}_{\mathrm{x}}$ loading, $\mathrm{t}-\mathrm{ZrO}_{2}$ phase is stabilized and under heat treatments, the gradual transformation of $\mathrm{t}-\mathrm{ZrO}_{2}$ to $\mathrm{m}-\mathrm{ZrO}_{2}$ 
above $700 \mathrm{C}$ is accompanied by crystallization of $\mathrm{m}-\mathrm{WO}_{3}$, which is not observable at lower annealing temperatures presumably due to its high dispersion and non-crystallinity. This leads us to propose that the dispersed $\mathrm{WO}_{\mathrm{x}}$ species are associated with $\mathrm{t}-\mathrm{ZrO}_{2}$ only. From the magnitudes and the temperature variation of $\chi$, we have inferred that Pt in fresh PWZ catalysts exists in oxidized form, $\alpha-\mathrm{PtO}_{2}, \mathrm{Pt}_{3} \mathrm{O}_{4}$ or their combination, depending upon their thermal history. These oxides are reduced to metallic $\mathrm{Pt}$ in the hydroisomerization reactions [4].

Additional important information on the PWZ catalysts has come from the recently reported ESR observation of the $\mathrm{W}^{5+}$ and $\mathrm{Zr}^{3+}$ states at low temperatures [5]. These signals are absent in samples without $\mathrm{Pt}$ suggesting that $\mathrm{Pt}$ has a role in changing the oxygen stoichiometry of $\mathrm{WO}_{3}$ and $\mathrm{ZrO}_{2}$ to generate the observed $\mathrm{W}^{5+}$ and $\mathrm{Zr}^{3+}$ states. In stoichiometric $\mathrm{WO}_{3}$ and $\mathrm{ZrO}_{2}$, the states $\mathrm{W}^{6+}$ and $\mathrm{Zr}^{2+}$ are diamagnetic and ESR silent. Also, studies on samples annealed at 500C showed possible electron transfer between the $\mathrm{W}^{5+}$ and $\mathrm{Zr}^{3+}$ states in which the concentration of one state increases at the expense of the other [5]. These studies have thus established electron transfer processes that are crucial in the catalytic activity of these catalysts.

\section{Doped ferrihydrites and other nanoparticle systems:}

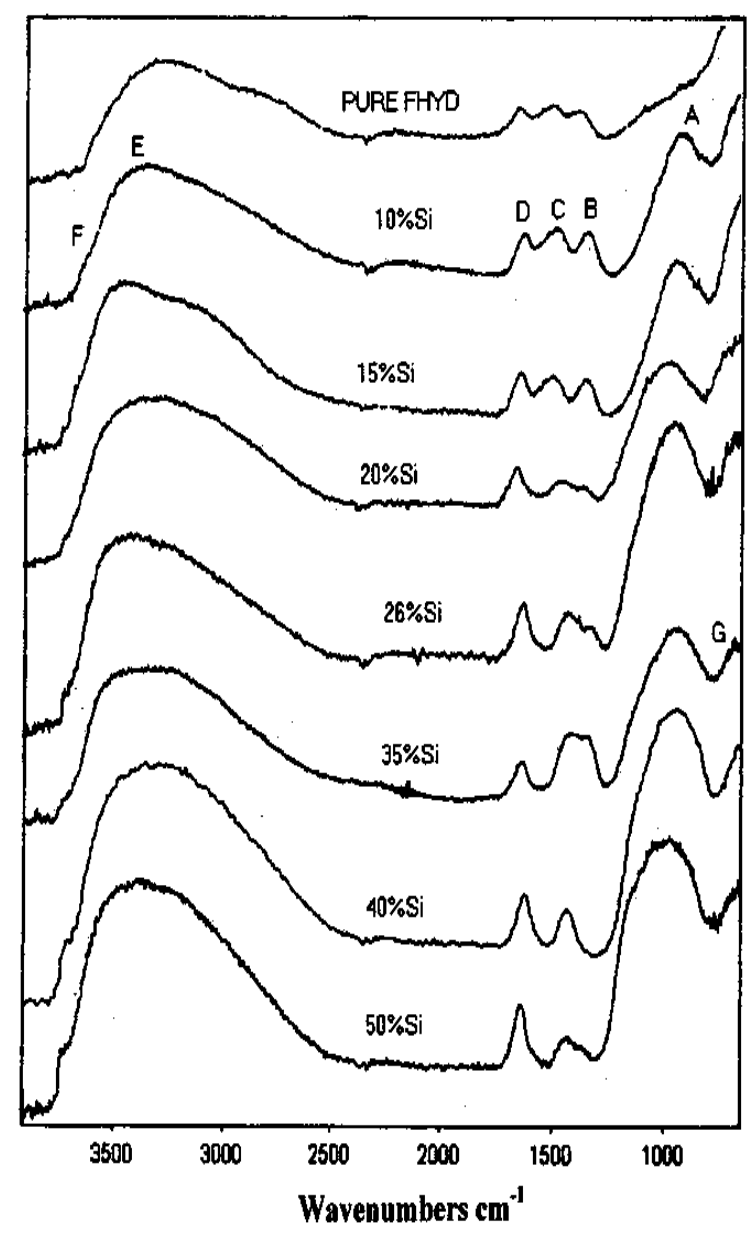

Fig. 4. PAS spectra of FHYD illustrating the effect of Si doping.
Nanoparticles of ferrihydrites, $\mathrm{FeOOH} . \mathrm{nH}_{2} \mathrm{O}$, doped with $\mathrm{Si}, \mathrm{Al}, \mathrm{Ni}, \mathrm{Mo}$, Ir and transition metals supported on alumina are being tested by Huffman et al as catalysts for reforming reactions. We have made considerable progress in understanding the structural and electronic properties of these ferrihydrites (FHYD), as detailed in several publications [6 - 11]. A

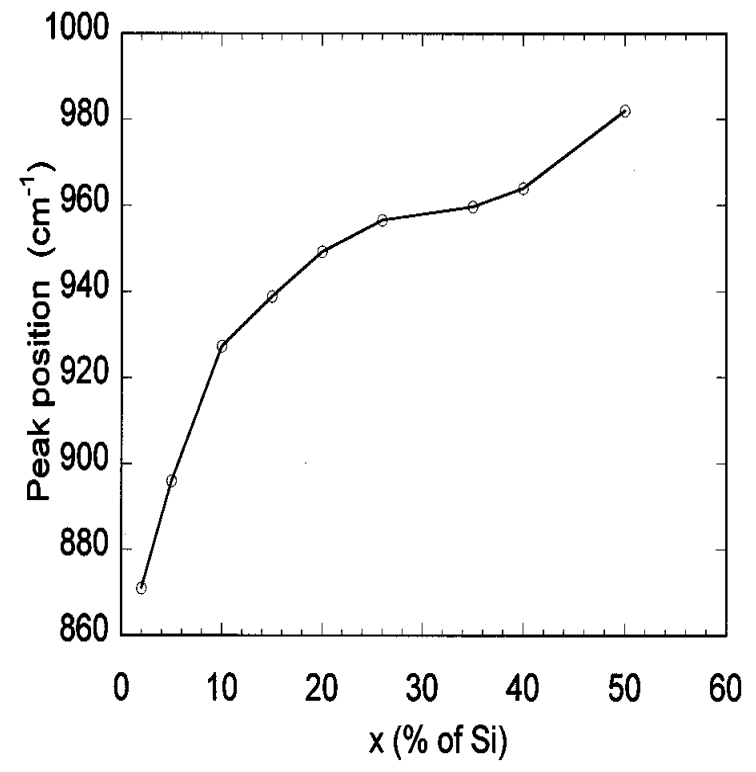

Fig. 5. Plot showing the shift of the peak A in Fig. 4 with Si doping. 
major result is that $\mathrm{Fe}^{3+}$ spins on the surface of FHYD are nearly free and available for participation in catalytic reactions. Doping with $\mathrm{Si}, \mathrm{Al}, \mathrm{Ni}, \mathrm{Mo}$, and Ir affects both magnetic and structural properties (Fig. 4 and Fig. 5), but by different levels [8, 9, 11]. In the PAS/FTIR studies of the doped FHYD, the appearance of a new band A near $900 \mathrm{~cm}^{-1}$ (Fig. 4) and its shift with \% of Si (Fig. 5) is assigned to Fe-O-Si species. Other changes observed with Si doping viz. the decrease in magnetization and increase in the ESR linewidth can also be explained if Si replaces $\mathrm{Fe}$ [9]. It is known that doping with $\mathrm{Si}$ also increases the useful stability range of FHYD from $200^{\circ} \mathrm{C}$ to $400^{\circ} \mathrm{C}$, without seriously affecting its catalytic properties.

We have synthesized other nanoparticle systems such as $\mathrm{CuO}$ [12], $\mathrm{Mn}_{5} \mathrm{O}_{8}$ [13], $\mathrm{CoFe}_{2} \mathrm{O}_{4}$ and $\mathrm{NiO}$ by sol-gel and electrochemical methods for potential applications. The nanoparticles of $\mathrm{CuO}$ were found to have some catalytic activity by the Utah group [2]. In 6.6nm CuO particles, we have observed anomalous hysteresis loops at room temperature, a detailed paper on which is now ready for submission. Besides their catalytic potential, nanoparticles of $\mathrm{CuO}$ and $\mathrm{NiO}$ may have applications in the emerging field of spintronics.

\section{$\underline{\text { Students }}$}

During 2000, two graduate students completed their M. S. theses: Paromita Roy on "Magnetic properties of Si-doped ferrihydrite nanoparticles" and Heidi Magnone on "Synthesis and characterization of metal oxide nanoparticles". Another student, Monica Constantinescu, is expected to complete her M. S. thesis in the next few months.

\section{Future Plans}

The implications of our recent ESR results in the PWZ catalysts [5] will be investigated for developing a suitable reaction mechanism in consultation with Dr. Wender. For the $\mathrm{PdCl}_{2} / \mathrm{CuCl}_{2} / \mathrm{AC}$ catalysts, the results are being organized in a manuscript and this paper will be submitted for publication in the near future. At the CFFLS meeting in August 2001, we will consult with the Utah group to plan followup experiments to improve the yield for DEC. For ferrihydrites, our recent breakthrough for the analysis of the magnetic data [10] will now allow us to complete our analysis of the magnetic data on doped ferrihydrites [13]. This work will be written up for publication in the next few months, in collaboration with Huffman et al [11]. Analysis of the structural data from FTIR and XRD on doped ferrihydrites (Fig. 4 and 5) is also near completion [14].

\section{Cited publications}

1. A. Punnoose, M. S. Seehra, B. C. Dunn and E. M. Eyring, "X-ray diffraction and ESR investigations of $\mathrm{PdCl}_{2} / \mathrm{CuCl}_{2} /$ activated carbon catalysts used in the synthesis of diethyl carbonate" (to be submitted)

2. B. C. Dunn, E. M. Eyring et al " Production of diethyl carbonate from ethanol and CO over a heterogeneous catalyst" (to be submitted). 
3. S. Zhang, Y. Zhang, J. W. Tierney, and I. Wender, "Hydroisomerization of normal hexadecane with platinum-promoted tungstate-modified zirconia catalysts". Appl. Catal. A, 4930, 1-17 (1999).

4. A. Punnoose, M. S. Seehra and I. Wender, "Structure, properties and roles of the different constituents in $\mathrm{Pt} / \mathrm{WO}_{\mathrm{x}} / \mathrm{ZrO}_{2}$ catalysts" to be published in Fuel Processing Technology.

5. A. Punnoose and M. S. Seehra, "ESR observation of $\mathrm{W}^{5+}$ and $\mathrm{Zr}^{3+}$ states in $\mathrm{Pt} / \mathrm{WO}_{\mathrm{x}} / \mathrm{ZrO}_{2}$ catalysts" submitted for publication to Catalysis Letters.

6. M. S. Seehra, V. S. Babu, A. Manivannan and J. W. Lynn, "Neutron scattering and magnetic studies in ferrihydrite nanoparticles" Phys. Rev. B $\underline{61}$, 3513-3518 (2000).

7. M. S. Seehra, P. Roy and A. Manivannan, "Hysteresis loop shifts in magnetic field cooled FeOOH nanoparticles”, Mater. Res. Soc. Symp. Proc., 58, 511-516 (2000).

8. M. S. Seehra, V. S. Babu, P. Roy and A. Manivannan, in Cluster and Nanocluster $\underline{\text { Interfaces }}$ edited by Jena, Khanna and Rao (World Scientific Publishing Co., 2000) pp. $229-234$.

9. M. S. Seehra, A. Punnoose, P. Roy, and A. Manivannan, "Effect of Si doping on the ESR properties of ferrihydrite nanoparticles", IEEE Transaction on Magnetics (in press).

10. M. S. Seehra and A. Punnoose, "Deviations from the Curie law variation of magnetic susceptibility in antiferromagnetic nanoparticles", Phys. Rev. B (in press).

11. A. Punnoose, M. S. Seehra, N. Shah and G. P. Huffman, "Magnetic properties of ferrihydrite nanoparticles doped with $\mathrm{Ni}$, Mo and $\mathrm{Ir}^{\prime}$, presented at the Eleventh Conference on Computational Research on Materials, Morgantown, 2001(to be submitted for publication).

12. A. Punnoose, H. Magnone, M. S. Seehra and J. Bonevich, "From bulk to nanoscale magnetism and exchange bias in CuO nanoparticles", Phys. Rev. B (to be submitted).

13. A. Punnoose, H. Magnone and M. S. Seehra, "Synthesis and antiferromagnetism of $\mathrm{Mn}_{5} \mathrm{O}_{\mathrm{s}}$ ", IEEE Transaction on Magnetics (in press).

14. M. S. Seehra, A. Manivannan, A. Raman, A. Punnoose and P. Roy, "Structural properties of ferrihydrite nanoparticles determined by x-ray diffraction and FTIR spectroscopy", presented at the Eleventh Conference on Computational Research on Materials, Morgantown, 2001(to be submitted for publication). 


\title{
Capabilities at the Diesel Engine Test Facility for Measuring Gas-Phase and Particulate Emissions
}

\author{
Kerry Kelly, Guojin Wang, A. F. Sarofim and H. L. C. Meuzelaar \\ Combustion Research Laboratory, Department of Chemical and Fuel Engineering \\ Center for Micro Analysis and Reaction Chemistry \\ Department of Chemistry \\ University of Utah \\ Salt Lake City, UT 84112
}

\section{Description of the test facility}

The combustion research laboratory has a variety of capabilities for measuring and characterizing emissions produced from the test diesel engine. For particulate matter, the combustion laboratory has a TSI Scanning Mobility Particle Sizer (SMPS) that measures particle size distributions from $7 \mathrm{~nm}$ to $300 \mathrm{~nm}$, and a Lasair 310 optical particle counter (OPC) that measures particle counts in seven size ranges from $0.3 \mu \mathrm{m}$ to $10 \mu \mathrm{m}$. In addition, the laboratory can measure real-time PAH (polycyclic aromatic hydrocarbon)-laden particles and elemental carbon on particles (with a PAS 2000 and photoacoustic instrument developed by Desert Research Institute). The photoacoustic analyzer and the PAS 2000 are relatively new instruments, and details of these two instruments can be found below. The laboratory also has a high volume particulate matter sampler (developed by Graseby Andersen, Inc.) for collecting large quantities of particulate matter with a diameter less than $10 \mu \mathrm{m}$. For gas-phase emissions, the laboratory has the capabilities to measure $\mathrm{CO}, \mathrm{CO}_{2}, \mathrm{NO}_{\mathrm{x}}, \mathrm{CO}_{2}$ and total hydrocarbons. $\mathrm{CO}_{2}$ and $\mathrm{CO}$ can be analyzed with a California Analytical infrared analyzer model ZRH (CO) and model $200\left(\mathrm{CO}_{2}\right)$, respectively. The infrared gas analyzer measures gas concentration using the unique absorption spectra of the gas in the infrared region. A Thermo Environmental Instruments NO$\mathrm{NO}_{2}-\mathrm{NOx}$ analyzer model $42 \mathrm{C}$ is used to measure $\mathrm{NOx}$ concentration, and the instrument operates based on the principle that nitric oxide $(\mathrm{NO})$ and ozone $\left(\mathrm{O}_{3}\right)$ react to produce a characteristic luminescence with an intensity linearly proportional to the NO concentration and infrared light emission results when electronically excited $\mathrm{NO}_{2}$ molecules decay to lower energy state. For $\mathrm{CO}_{2}$ concentration, a ZA8 (Yokogawa Electric Corporation) zirconia oxygen analyzer averaging converter system is employed, which can perform multipoint oxygen concentration measurements. For gas-phase hydrocarbons, a AVS-GC/MS (HP5971) can be used, and the AVS (direct Atmospheric Vapor Sampling unit) was developed by the center for Micro Analysis and Reaction Chemistry, University of Utah, for real-time, continuous, online analytical measurements.

\section{Photoelectric aerosol sensor}

Figure 1 shows a schematic of the PAS. Details about the PAS can be found in EPA (1997) and Burtscher (1992). Briefly, an aerosol sample passes through the PAS instrument at a constant flow of $21 / \mathrm{min}$. As the sample passes through the examiner lamp ionization region, the particlebound PAH molecules are ionized, and the electron that is stripped from the PAH molecule has a 
probability of escaping the particle that is dependent on the particle size and composition. The photon energy of the lamp is chosen so that no gas-phase molecules are ionized. The photoelectric ionization and subsequent electron loss leaves the particle with a net positive charge that is detected by measuring the charge that collects on an isolated filter element. Because this charge is exceedingly small, an electrometer is used to detect the change in potential from the filter element to ground. The change in potential can be attributed to a charge and is integrated over time to give the photoelectric current (in femto or pico amps). This current should be proportional to a specific loading of PAH on a particle and related to a specific $\mathrm{PAH}$ mass/volume of surrounding gas.

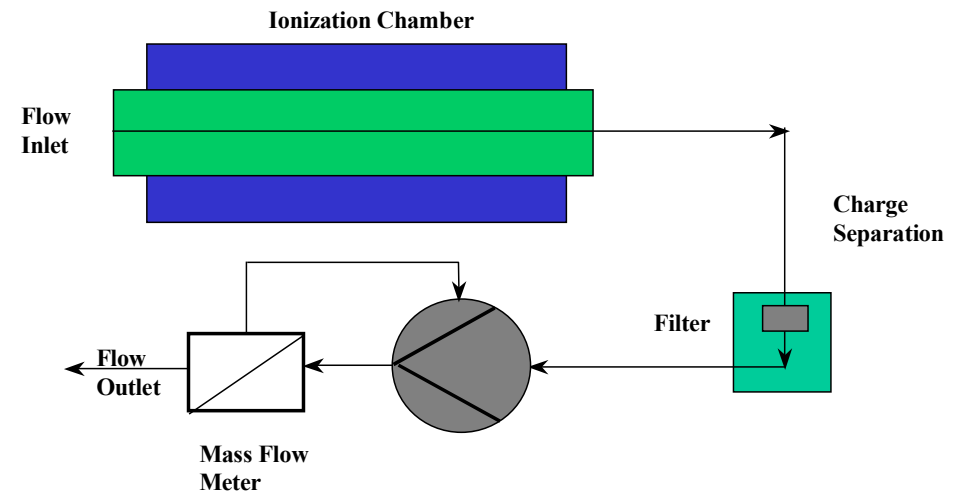

Figure 1. Schematic of the PAS.

\section{Photoacoustic analyzer}

The Desert Research Institute (DRI) PA detects and quantifies black carbon (soot) particles in real time. Detailed instrument description is in Arnott et al. (1999), and calibration is in Arnott et al. (2000). Briefly, the instrument measures light absorption at a laser wavelength of $1047 \mathrm{~nm}$. Black carbon absorbs very strongly at this wavelength, in contrast to other aerosols and gases. Sample air is pulled continuously through an acoustical waveguide, and the laser also passes through the waveguide. The laser power is modulated at the resonance frequency of the waveguide. Now when soot absorbs light, it is heated. This heat transfers very rapidly to the surrounding air, in a time that is much shorter than the period of the laser beam modulation, so all of the heat from light absorption comes out of the particles during each acoustic cycle. Upon receiving heat, the surrounding air expands, generating a pressure disturbance (i.e. an acoustical signal) that is measured with a microphone attached to the waveguide. Since black carbon aerosols absorb light throughout the entire particle volume, the light absorption measurement is also a measure of black carbon mass concentration. This is the reason that light absorption can be used as a measure of black carbon mass concentration. The PA measures particles in a flowing air stream without the need to collect the particles on a filter, and the PA has a very large dynamic range $(130 \mathrm{~dB})$, making it suitable for use on a wide range of exhausts. 


\section{Specifications for the Diesel Engine}

The diesel engine is a two-cylinder Kubota model Z482B, with $482 \mathrm{cc}$ displacement. Its torque curve is consistent from 1800 to $3400 \mathrm{rpm}$, and it consumes between $0.8-2.2 \mathrm{l} / \mathrm{hr}$ of fuel. The dynamometer is a Land and Sea water-break dynamometer with torque load control. The dynamometer absorbs load through entire torque range. In addition, the engine system has speed control and automated computer data acquisition.

\section{$\underline{\text { References }}$}

Arnott, W.P.; Moosmüller, H.; Rogers, C.F.; Jin, T.; and Bruch, R. Atmos. Environ. 1999, 33, 2845.

Arnott, W.P.; Moosmüller, H.; and Walker, J.W. Rev. Sci. Inst. 2000, 71 (7) 4545.

Burtscher, H. (1992). Measurement and Characteristics of Combustion Aerosols with Special

Consideration of Photoelectric Charging and Charging by Flame Ions. J. Aerosol Sci., 23:6, 549 - 595.

EPA (1997). Field and Laboratory Evaluations of a Real-Time PAH Analyzer. US EPA Office of Research and Development. EPA/600/R-97/034. 